\title{
Consumer Price Inflation across the Income Distribution in South Africa
}

\author{
Morné Oosthuizen \\ Development Policy Research Unit \\ University of Cape Town \\ Morne.Oosthuizen@uct.ac.za
}

Development Policy Research Unit

DPRU Working Paper 07/129

November 2007

ISBN Number: 978-1-920055-56-1 


\section{Executive Summary}

Poverty and inequality are two important characteristics of the post-apartheid South African socio-economic context. Rooted in widespread unemployment amongst the less educated and less skilled and apartheid-imposed inequalities in access to quality education, South Africa's level of income inequality is amongst the highest in the world, while millions continue to live in abject poverty more than a decade after the country's democratic transition.

The prices that households face are critical in translating nominal income into specific utility or welfare levels and, therefore, price changes over time, given a specific income level, will positively or negatively impact on welfare. Prices, therefore, are critical to our understanding of poor households' welfare. By monitoring the price changes experienced by some representative household, consumer price indices provide an important measure of changing purchasing power within a given economy. However, irrespective of how the 'representative' household is determined, it is clear that real households may differ sometimes considerably in terms of expenditure patterns, weakening the ability of the price index to proxy the experiences of all households. This is, to some extent, borne out by the claims of individuals across the income distribution that the rates of inflation that they experience are significantly different to (and, as is invariably claimed, higher than) the official consumer inflation statistics.

While demographic and locational factors impact on the spending patterns of households, so too does income. The representivity of the consumer price index, therefore, varies systematically according to these variables. Group price indices offer one method of more accurately reflecting the inflation experiences of specific types of households, such as poor households, elderly households or households with children, for example. Another way of improving the representivity of a price index is by removing, or at least moderating, the bias towards high expenditure households inherent in the calculations of official price indices around the world, ensuring that households of different income levels contribute more equally to the calculation of relative expenditure weights.

This study uses expenditure data from the 2000 Income and Expenditure Survey and price indices from Statistics South Africa to calculate inflation rates for expenditure deciles for the period 1998 to 2006. The results show that the conventionally calculated, plutocratic weight structure does not reflect the 'average' household as is commonly believed. Being related to the level of inequality within a given society, the plutocratic weights calculated above most closely reflect the spending patterns of households in the $95^{\text {th }}$ percentile of the expenditure

Development Policy Research Unit Tel: +27216505705

Fax: +27 216505711
Information about our Working Papers and other published titles are available on our website at: http://www.commerce.uct.ac.za/dpru/ 
distribution. As a result, price indices and inflation rates calculated on the basis of these weights can not accurately reflect the rates of inflation experienced by what would be viewed as the 'average' household.

This study concurs with the majority of the literature surveyed in that neither rich nor poor households are found to have experienced rates of inflation consistently higher or lower than average, with the plutocratic gap shifting from positive values to negative values (or vice versa) seven times between January 1998 and December 2006. The inflation rate calculated using conventional plutocratic weights does not differ substantially over longer periods of time from the democratically weighted inflation rate. However, over shorter time periods, the difference between the two inflation rates can be significant, indicating a marked divergence in the rates of inflation experienced by households at different points of the income distribution. The official $\mathrm{CPI}$ in South Africa is, like those in other countries, unable to accurately reflect the rates of inflation experienced by households of different income levels at all points in time, a fact that should be considered carefully in analysis of household incomes over time, and particularly in the case of poor households. Official price indices play an important role in macroeconomic policymaking, with the official CPI providing an accurate reflection of economy-wide inflation. Plutocratic inflation rates are biased towards the expenditures of wealthier households, but this bias is in line with the overall structure of consumer spending. As such, it would be irresponsible to abandon conventional CPIs in favour of democratic alternatives.

What is clear, however, is that the purpose for which a price index or inflation rate is used should determine the type of weighting structure employed. In the case of monitoring economywide consumer price inflation, the price index should reflect the structure of economy-wide consumer spending. In contrast, where the price index is to be used for adjusting state welfare benefits, or merely for the monitoring of the rate of inflation experienced by the poor, the price index should reflect price changes that are relevant to poorer households. Further, it is acknowledged that democratic weights are just one of numerous possible weighting structures that would result in a price index that more accurately reflects the experience of poorer households.

Inflation amongst poor households over the period was concentrated in three main expenditure categories, namely food, housing and household fuel and power. Within these, the major culprits are easily identifiable: respectively mealie meal and brown and wholewheat bread, poultry and beef and veal, water and house rent, and paraffin and electricity. These eight items accounted for 34.5 percent of decile one inflation and 26.9 percent of decile four inflation and were responsible in large part for the acceleration of inflation during the four inflation peaks over the period. This demonstrates the vulnerability of poor households to inflation deriving from necessities, but also highlights the fact that a targeted response to accelerating inflation may have a significant impact. Thus, during the high inflation episode of 2002/3, Government's policy of subsidising mealie meal would have helped dampen the impact on poor households. 


\section{Acknowledgement}

The DPRU would like to acknowledge the financial support received for this project from the Nations Development Programme. 


\section{Table of Contents}

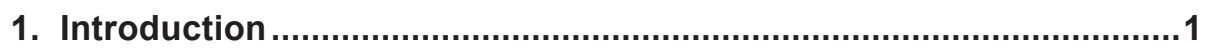

2. Group Price Indices and Price Index Representivity........................ 3

2.1 International Studies ....................................................... 4

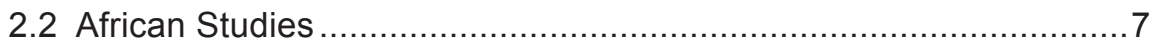

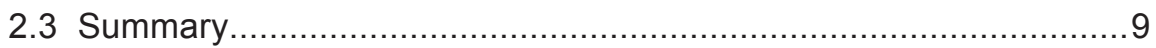

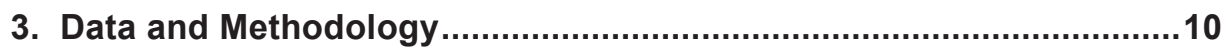

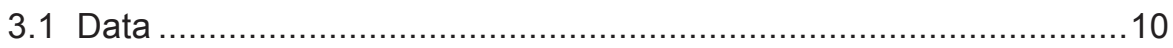

3.1.1 Expenditure Data .............................................................. 10

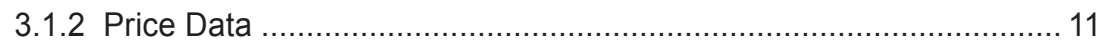

3.1.3 Matching Expenditure and Price Data ....................................... 12

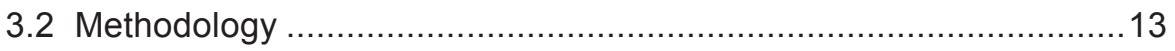

3.2.1 Weight Construction .................................................................. 13

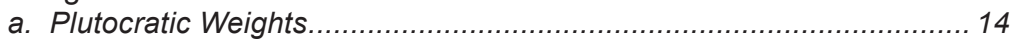

b. Democratic Weights ................................................................ 15

3.2.2 Calculation of Inflation Rates ................................................... 16

3.3 Comparability with Official CPI Statistics ............................... 17

4. Results ...................................................................................... 18

4.1 Overall Expenditure Weights ............................................. 18

4.2 Decile-Specific Expenditure Weights.....................................22

4.3 Official and Calculated CPIX Inflation Rates ..............................23

4.4 The Plutocratic Gap .............................................................. 25

4.5 Inflation Rates Across the Distribution..................................27

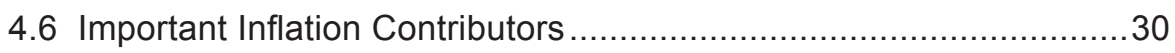

4.6.1 Identifying Key Products Responsible for Inflation amongst Poor

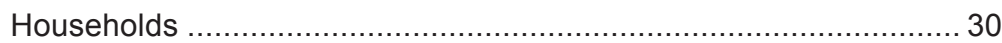

4.6.2 The Changing Drivers of Inflation Across the Distribution between

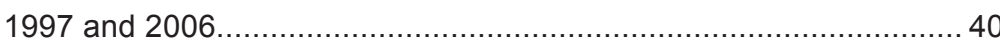

4.6.3 Identifying Key Products Responsible for the Difference in Inflation for Poor Households Compared to Other Groups ............................ 52

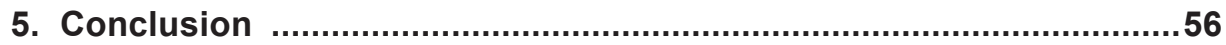

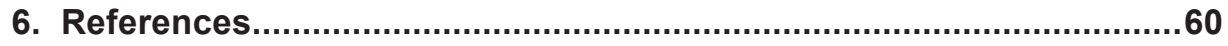

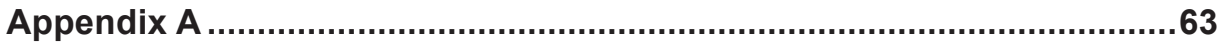

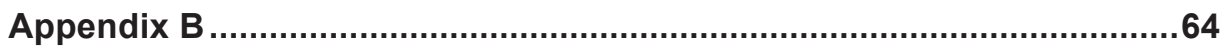

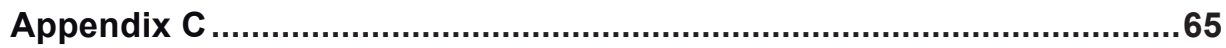




\section{Introduction}

Poverty and inequality are two important characteristics of the post-apartheid South African socio-economic context. Rooted in widespread unemployment amongst the less educated and less skilled and apartheid-imposed inequalities in access to quality education, South Africa's level of income inequality is amongst the highest in the world, while millions continue to live in abject poverty more than a decade after the country's democratic transition.

Many factors, though, combine to determine the income level and consequent poverty status of an individual or household. Perhaps the most important factor is whether or not there is a resident income-earner in a given household. Households also have varying rates of access to remittances from migrant or other non-resident workers, as well as to income from social grants, particularly the old-age pension and the child support grants. Wages and salaries have also been found, internationally and in South Africa, to vary according to demographic factors such as race, gender, age, level of education and work experience, as well as other factors such as geographical location and employment sector.

In determining households' welfare, income is an important variable. However, the prices that households face are critical in translating nominal income into specific utility or welfare levels and, therefore, price changes over time, given a specific income level, will positively or negatively impact on welfare. Prices, therefore, are critical to our understanding of poor households' welfare. By monitoring the price changes experienced by some representative household, consumer price indices provide an important measure of changing purchasing power within a given economy. However, irrespective of how the 'representative' household is determined, it is clear that real households may differ sometimes considerably in terms of expenditure patterns, weakening the ability of the price index to proxy the experiences of all households. This is, to some extent, borne out by the claims of individuals across the income distribution that the rates of inflation that they experience are significantly different to (and, as is invariably claimed, higher than) the official consumer inflation statistics.

While demographic and locational factors impact on the spending patterns of households, so too does income. The representivity of the consumer price index, therefore, varies systematically according to these variables. Group price indices offer one method of more accurately reflecting the inflation experiences of specific types of households, such as poor households, elderly households or households with children, for example. Another way of improving the representivity of a price index is by removing, or at least moderating, the bias towards high expenditure households inherent in the calculations of official price indices around the world, ensuring that households of different income levels contribute more equally to the calculation of relative expenditure weights. 
This study aims to describe and contrast the varying rates of inflation experienced by households at different points across the income distribution in South Africa for the decade between January 1997 and December 2006. In particular, however, the focus is on poor urban households, since poor households are arguably less able to reduce their exposure to or mitigate the negative effects of inflation and South African price surveys are limited to urban areas only. The following section reviews the literature on group price indices and issues around the construction of expenditure weights and the implications for the representivity of the resulting price indices. Section 3 details the data used for this study, as well as presenting the methodology followed in deriving expenditure weights and calculating price indices and inflation rates. In Section 4, the focus turns to the results. The calculated expenditure weights for the ten expenditure deciles and for the urban population as a whole are presented. This is followed by a comparison of the official published inflation rate and the inflation rate calculated here and an investigation of the inflation rates across the distribution. Section 4.6 turns to the identification of the expenditure items that have contributed most to inflation over the decade and those that have contributed to widening or narrowing the gap in the inflation rates of poor households and other households respectively. Finally, Section 5 discusses policy implications and concludes. 


\section{Group Price Indices and Price Index Representivity}

Around the world, households are mindful of and concerned by rising prices and, consequently, the rate of consumer inflation is one of the macroeconomic indicators most closely watched by society. Many households, however, will claim that the published rate of inflation is not an accurate reflection of their own inflation rate and, most often, the claim is that their own rate of inflation is the higher of the two. These claims stem partly from an inability on the part of households to accurately calculate their own rates of inflation, impacting on the accuracy of their comparisons. However, at some level, based on individuals' reactions and media reports, households are often aware that the difference between the official and own inflation rates is linked to the various goods and services they actually purchase, whether or not there is overt reference to the official basket.

This paper addresses two issues raised in the literature, namely the empirical evidence that different households in society experience different rates of inflation, linked directly to their differing consumption patterns, and that the conventional form of consumer price indices provides a biased estimate of average inflation.

There is a long history of group-specific price indices. Interest in the calculation of price indices for specific sub-populations began in the 1950s when Kenneth Arrow noted that individuals and households in different income categories would be likely to have differing patterns of consumption (Garner et al., 1996: 32). It is now "well established that demographic factors exert an influence on consumption patterns net of price and income effects" (Idson \& Miller, 1999: 219). Differing consumption patterns imply different shares of the various goods and services in total expenditure, affecting these items' weights within consumer price indices and, therefore, impacting on the actual inflation rates experienced by each household.

Considerable work has been done internationally on so-called 'group-specific price indices', which take into account the differing expenditure patterns of households and individuals but which recognise that groups of similar households or individuals may have similar expenditure patterns. Work in this area tends to define groups in two key ways. Firstly, groups are defined according to income, with numerous studies focussing on the poor or contrasting the inflation fortunes of the poor with the non-poor (see, for example, Hollister \& Palmer, 1972; Hagemann, 1982; Garner et al., 1996; Murphy \& Garvey, 2004; McGranahan \& Paulson, 2006). Alternatively, groups are defined according to some demographic or household characteristic, such as age or family structure (see Amble \& Stewart, 1994; Idson \& Miller, 1999; McGranahan \& Paulson, 2006). 
The second issue revolves around the bias inherent in the standard calculation of the weights used by statistical agencies to calculate price indices. Standard practice sees expenditures on a given item totalled across households and then divided by total household expenditure across all items and households. These weights are termed plutocratic weights. However, one of various alternative methods first calculates expenditure weights for all households individually, with the overall weight calculated as the mean across all households. According to Prais (1959: 126), the latter method, known as the democratic method, "attaches equal weight to each household in calculating the Weight of the commodity in the index ... [while] ... the conventional [or plutocratic] method gives a result equivalent to taking an unequally weighted average of the proportions for each household, the weights being the total expenditure on all commodities by that household". Differences in calculation of the weights impact on the representivity of the resulting price indices, with the plutocratic index biased towards the upper end of the income/expenditure distribution.

\subsection{International Studies}

Much of the international (non-African) work investigating group-specific price indices has established some consensus on a number of issues. The main conclusion is that there is generally little difference in the rates of inflation between groups and, where differences are found, no single group experiences consistently higher or lower rates of inflation relative to other groups over the longer run. However, evidence does seem to show that there is a greater dispersion in inflation rates during periods of above average inflation.

These findings are consistent across various methods of grouping households. For example, Garner et al. (1996) investigate possible differences in experimental price indices of US poor and non-poor households, covering the period between 1984 and 1994, and find that the price indices of poor households do not differ much from those of the urban population as a whole (Garner et al., 1996: 40). A Canadian study by Taktek (1998) analyses movements in price indices for low-income households, senior citizen households and low-income senior citizen households, over a relatively short period from 1993 (index equals 100) to 1996. The author finds little dispersion between the three indices and the overall index, with the gap between the highest and lowest indices never exceeding two percentage points. Other studies grouping households by income with similar findings include Murphy and Garvey (2004) on Irish data between 1989 and 2001 and Michael (1979) on US data for the period 1967 to mid-1974.

Idson and Miller (1999) investigate how their different expenditure patterns result in differing inflation rates for US families with and without children, with a view to provide improved estimates of child poverty trends. For the two decades between 1968 and 1987, the authors find that families with children experienced lower rates of inflation than those without children. This they link to the fact that families with children tend to be younger than those without and younger families tend to have lower rates of inflation. 
The presence of children in a family does not shift family expenditure to low inflation items as the authors find that, controlling for the family head's age, children actually result in greater consumption of higher inflation goods and services. However, these findings did not materially affect the estimates of child poverty and the authors concluded that a separate price index for families with children was, at the time, unnecessary.

Hobijn and Lagakos (2005), for the period 1987-2001, find that the elderly faced above average rates of inflation in the US, while the converse was true for households with children under the age of 18 years. The authors ascribe the considerable variation of householdspecific inflation rates to three expenditure categories in particular, namely education, health care and gasoline, the former two exhibiting relatively rapid increases in prices over the period, while the price of the latter was extremely volatile. As in other studies, rapid healthcare price inflation was linked to the elderly population's relatively high inflation rate. A further finding of interest is that households that experienced above average rates of inflation in one year were not very likely to experience above average rates of inflation in the following year.

McGranahan and Paulson (2006) analyse the inflation experiences of 31 demographic groups and contrast them with each other and the experience of the urban population as a whole in the US between 1983 and 2005. They find that, overall, the inflation experiences of vulnerable groups have not been very different on average to that of the total urban population, although vulnerable groups have been prone to greater variability in the rate of inflation experienced: inflation was " $3.0 \%$ more volatile for the bottom equivalent income quartile than for the population generally" (McGranahan \& Paulson, 2006: 34).

Only one study was found that contradicts the finding that different groups do not experience long term differences in inflation rates. The study by Lieu et al. (2004), using data from Taiwan, finds that there is "statistically significant evidence to support the claim that different household groups face differential price changes, and that these variations are persistent" (Lieu et al., 2004: 119). Specifically, households in the second quintile, those with heads younger than 20 years, those with children and those in urban areas were found to experience higher rates of inflation between 1991 and 1996. However, this study covers a fairly short period of only five years, which is arguably insufficient time to claim persistent variations between groups.

Several studies find that periods characterised by above average inflation rates are also characterised by greater dispersion in inflation rates amongst groups. The 1961 study by Snyder, one of the earliest investigations of group-specific price indices, on US data for the period 1936 to 1955, calculates experimental price indices for low and high income groups (as summarised by Garner et al., 1996: 33). ${ }^{1}$ During recessions, it was found that the prices

$1 \quad$ Unfortunately, due to the age of the study by Snyder, it has not been possible to locate a freely available electronic version or a locally available hard copy. This means that only second-hand information about this study is available for inclusion here. 
of items consumed in relatively greater amounts by the poor declined more slowly than those of items consumed more often by middle-income households. However, "[during] periods of full employment and rising prices, the prices of 'low-income' items rose, but at a more rapid rate than did the prices of commodities most likely purchased by higher income households" (Garner et al., 1996: 33). However, this finding did not extend to indices calculated from food expenditure data from 1955.

Crawford and Smith (2002) use data from the United Kingdom's Family Expenditure Survey for the quarter century between 1975 and 1999 to investigate the distribution of inflation rates and the differences between various group price indices. They find substantial variation in inflation rates across different households for a given period, with the dispersion being positively related to the mean level of inflation. In terms of the group indices calculated in the study, households with children experienced very similar rates of inflation to their childless counterparts, while pensioners experienced relatively low rates of inflation.

Finally, Artsev et al. (2006) investigate the differences in the rates of inflation experienced by different households and, specifically, the degree of dispersion in inflation rates across households, in Israel between January 1999 and December 2005. They find that, although there are relatively small differences across households in the rates of inflation experienced, dispersion (as measured by the inter-quartile range) increases as the median inflation rate increases (Artsev et al., 2006: 6). The authors conclude that the overall consumer price index is generally good reflection of the inflation experiences of most households.

Studies that have investigated different ways of constructing the expenditure weights underlying consumer price indices, calculating plutocratic and democratic inflation rates, have generally found there to be little difference between the two types of indices. Crawford and Smith (2002: 31) find that, although their calculated plutocratic and democratic indices are often statistically different from each other, "[there] is no persistent 'bias' in either direction in the plutocratic index compared to the democratic index over the period studied". Similarly, Artsev et al. (2006) find little difference in the plutocratic and democratic indices over the period, indicating that neither upper- nor lower-income groups experienced consistently higher rates of inflation.

Kokoski (2000) analyses the differences between plutocratic and democratic consumer price index aggregations for the United States between 1987 and 1997. Using data at the most disaggregated level possible, the author finds little difference between the two indices, with the democratic index generally higher. The biggest difference between the two indices is just over one index point, occurring in 1990/1 during a relatively high inflation episode. An examination of the two index types across expenditure quintiles, however, reveals very little difference between the two indices. In an attempt to glean better evidence of differences between plutocratic and democratic indices, price changes of luxuries and necessities are simulated, but "[only] in extreme scenarios, in which price changes were measured for expenditures on 
inelastic goods, did the democratic and plutocratic index values show a difference ... of about 1 index point for every 10-percent increase in the relative prices of these goods" (Kokoski, 2000: 38).

\subsection{African Studies}

Very little work on this topic has been undertaken in Africa generally, and South Africa in particular. McKay and Sowa (2004) investigate inflation rates across households in different locations and by income groups using the Ghana Living Standards Survey conducted in 1998-1999. The analysis is conducted at a very high level of aggregation - using only nine main commodity groups - and does not find significant differences in the rates of inflation faced by poor households compared to the population as a whole. This is due to the "remarkable consistency in patterns of purchases across household groups" at this level of aggregation (McKay \& Sowa, 2004: 16). However, in further analysis of some of the major food categories, the authors do find important differences in the types of food purchased by households of different income levels.

The only published South African study that was located was that of Kahn (1985), which calculates consumer price indices for various groups defined by location, income and race. Over the seven year period between 1975 and 1982, Kahn calculated that the poorest three groups in both Cape Town and Johannesburg experienced average inflation rates that were above the national average (Table 1). From a base of 100 in 1975, the CPI for Blacks with incomes of between R250 and R499 per annum in Cape Town rose to 246.0 by 1982, while that of their Johannesburg counterparts increased to 242.7. In contrast, the overall CPI increased to 233.7 over the same period, while that of the highest income Whites, those earning in excess of R15 000 per annum, rose to only 229.4. However, Kahn's figures also reveal that for the first two years of the period, these same three poorest groups had lower CPIs than high-income Whites in both cities. While Kahn (1985: 11) notes that the differing expenditure patterns of the various groups gave rise to the differing CPIs, but concludes that "in general the lower income groups are faced with a higher CPI than the higher income groups".

Table 1: Consumer Price Indices by Race, Income and Location, South Africa, 1982

\begin{tabular}{|l|r|r|r|r|r|r|}
\hline \multirow{2}{*}{ CPI Base: $1975=100$} & \multicolumn{2}{|c|}{ Cape Town } & \multicolumn{2}{c|}{ Johannesburg } & \multicolumn{2}{c|}{ Overall } \\
\cline { 2 - 7 } & CPI & $\begin{array}{c}\text { Ave. Ann. } \\
\text { Inflation }\end{array}$ & \multicolumn{1}{c|}{ CPI } & $\begin{array}{c}\text { Ave. Ann. } \\
\text { Inflation }\end{array}$ & CPI & $\begin{array}{c}\text { Ave. Ann. } \\
\text { Inflation }\end{array}$ \\
\hline Black, R250-R499 p.a. & 246.0 & 13.7 & 242.7 & 13.5 & - & - \\
\hline Black, R500-R749 p.a. & 237.8 & 13.2 & 239.3 & 13.3 & - & - \\
\hline Black, R750-R999 p.a. & 237.9 & 13.2 & 238.1 & 13.2 & - & - \\
\hline White, R15 000+ p.a. & 231.7 & 12.8 & 233.2 & 12.9 & 229.4 & 12.6 \\
\hline Total & - & - & - & - & 233.7 & 12.9 \\
\hline
\end{tabular}

Source: Own calculations, Kahn (1985: 29) 
It is important to note that, even if the rate of inflation is lower for poor households than for higher income households, the former are likely to experience inflation more negatively, an issue highlighted by Kahn (1985: 11). The budgets of poor households are often significantly constrained, with relatively large shares devoted to necessities, such as food. Thus, these households are unable to shift expenditure away from luxury items in the face of price increases. At the same time, poor households are less able to substitute expenditure towards lower quality products during times of price increases as they are generally already consuming lower quality products. Finally, unlike higher income households, the poor are unable to access savings that would enable them to smooth consumption during periods of high inflation.

An unpublished study for South Africa does exist, in which Bhorat and Oosthuizen (2003) look at the period between 1997 and early 2002 and calculate democratic consumer price indices by expenditure decile and by race and gender of the household head. The study finds that the conventionally calculated inflation rate for urban households does not accurately reflect the inflation experiences of households at various points across the income distribution. It also confirms that no single income group experienced consistently higher or lower rates of inflation over the period under investigation.

The key finding in terms of the sources of inflation for the urban poor is the importance of household services, specifically water and electricity, in driving inflation. Further, the prices of paraffin and mealie meal are identified as having contributed significantly to inflation for the poor.

An important issue that arises in the literature is the extent to which conventionally calculated consumer price indices are representative of a population. In the definitions of official CPIs, reference is always made to a 'representative' or 'average' household or consumer. For example, according to Statistics South Africa (2002a: 1), the consumer price index "is a series of figures ... showing how the average price level of those goods and services ... bought by a typical consumer or household changes over time". However, few would argue that the "typical

consumer' exists in reality, and it is well known that the 'typical consumer' is not the 'average consumer' in the colloquial sense of the term.

There is very little consistent evidence in the studies cited that would substantiate claims that any given type of household experiences consistently higher or lower rates of inflation over time. Relative inflation rates are determined by the prevailing structure of inflation over a given period in combination with the expenditure patterns of households. Most studies, however, have one important conclusion in common, namely that, in most instances, the overall consumer price index is able to provide a reasonably good or, in some cases, a very good approximation of the inflation experience of various subgroups within the population over the longer term. Over shorter periods of time, however, there may be significant variations in the inflation rates and price indices for different groups of households, which may make the use of standard official consumer price indices problematic for certain purposes, such as 
indexation or wage negotiations, for example.

\subsection{Summary}

This study, therefore, takes into account the two main issues in the literature. Firstly, it is recognised that poor households, due to their unique spending patterns and the varying rates of price change across expenditure categories, are likely to experience rates of inflation that are not necessarily equal to those of higher-income households. In fact, depending on the underlying structure of inflationary pressures, the experiences of rich and poor households may vary dramatically. Therefore, group price indices are calculated using expenditure deciles as groups. Secondly, it is also recognised that the conventional construction of expenditure weights is biased towards those households or individuals whose expenditures are greatest in absolute terms. Thus, instead of representing the 'average household', these weights are more similar to higher-income households, particularly where income (and therefore expenditure) is highly unequally distributed.

There are, however, some problems that arise in calculating group price indices. Amble and Stewart (1994: 14) and Moulton and Stewart (1999: 147) detail four main issues that should temper any conclusions made on the basis of these indices. First, since the number of surveyed households or individuals included within a specific sub-group is relatively small, the calculated weights are subject to greater sampling error than those of the official population. Second, prices are collected from outlets that are generally chosen to be representative of the official population, while this is unlikely to be the case for a specific sub-group. Third, prices for expenditure categories are calculated based on the mix of individual items within those categories consumed by the official population. Again, this mix may not be applicable to all sub-groups. Fourth, the prices collected may not be the prices paid by all sub-groups. For example, Moulton and Stewart (1999: 147) note that in "the official CPI, senior-citizen discount rates are sampled in the CPI only in proportion to their use by the urban population as a whole", while a group price index for elderly people would require a different weighting of senior-citizen discount rates. 


\section{Data and Methodology}

\subsection{Data}

\subsubsection{Expenditure Data}

Statistics South Africa collects nationally representative, detailed expenditure data once every five years via the Income and Expenditure Survey (IES). Since the transition to a democratic dispensation, three IESs have been conducted, the first in 1995, the second in 2000 and the third in 2005/6, the latter being in the latter stages of finalisation prior to public release. These surveys form the basis for the official weights of the consumer price indices published by Statistics South Africa and are, therefore, the obvious choice for a study of this nature.

The edition of the survey used in this study is the IES 2000. This is the most recent published version of the survey and is conveniently situated more or less in the middle of the time period under investigation. The survey was conducted simultaneously with the September 2000 Labour Force Survey and covered more than 26000 households and 104000 individuals. At the time of the survey, the most recent census was that of 1996 and, thus, the survey was originally published with Census 1996 population weights. However, Statistics South Africa subsequently embarked on a process of reweighting their datasets based on the results of Census 2001 and this updated version of the Income and Expenditure Survey has been used in this study.

The IES 2000 is, however, not uncontroversial. Since the publication of the dataset, numerous inconsistencies and problems with the dataset have been uncovered by researchers. Perhaps primary amongst these is the fact that the aggregate income estimate from the IES 2000 does not align with national accounts estimates (Vermaak, 2005: 2). Further, according to Simkins (2004: 3), "a considerable number of observations in the 2000 IES are seriously inaccurate and/or incomplete", while Whites are under-represented in the survey (Hoogeveen \& Ozler, 2004: 41, as quoted in Van der Berg et al., 2006: 11).

Despite these problems with the dataset, it was used by Statistics South Africa to reweight the official CPI, the new weights having been applied in 2002. Therefore, this study has utilised the IES 2000 as its source of expenditure data for the calculation of weights for the price indices. There is, however, one data problem in the IES 2000 that is not easily resolved, namely the exceptionally poor recording of interest on mortgage bonds. Of the 26263 households in the cleaned dataset, only 2006 households reported non-zero values for the previous month's bond instalment. Of these, the instalments of only 816 households equalled the sum of the reported capital and interest components, while this was not true of 1190 households. Further, 180 households reported total capital and interest components in excess of the instalment. A decision was, therefore, made to exclude interest on mortgage bonds from the study. Fortunately, this aligns the consumer price index calculated in this paper with the official 
CPIX index, the CPI excluding interest on mortgage bonds, which is also the inflation indicator targeted by the South African Reserve Bank.

As will be detailed later, use is made of expenditure deciles to facilitate the analysis. These deciles are constructed by arranging households in ascending order of household expenditure and dividing them into ten equally sized groups. Decile one contains the ten percent of households with the lowest household expenditures, while decile ten contains the ten percent of households with the highest household expenditures. Table 2 presents some descriptive statistics about these ten groups, as well as for the population as a whole. ${ }^{2}$ The expenditure range for metropolitan and other urban areas is very wide, rising from zero reported expenditure to over R1.5 million. Expenditure ranges for individual deciles are narrowest in deciles two and three. Intra-decile inequality is generally very low, with Gini coefficients for deciles two through nine being below 0.09 , where zero represents absolute equality and one represents absolute inequality. Deciles one and ten have Gini coefficients of 0.205 and 0.242 respectively, indicating a relatively higher degree of inequality in those deciles. Overall, however, expenditure inequality is very high, with the overall Gini coefficient equalling 0.571 .

Table 2: Descriptive Statistics of Dataset, by Expenditure Decile, 2000

\begin{tabular}{|c|c|c|c|c|c|c|c|c|}
\hline \multirow{2}{*}{ Group } & \multicolumn{2}{|c|}{ No. of Households } & \multicolumn{2}{|c|}{ Expenditure Range } & \multirow{2}{*}{ Mean } & \multirow{2}{*}{ Median } & \multirow{2}{*}{$\begin{array}{l}\text { Standard } \\
\text { Deviation }\end{array}$} & \multirow{2}{*}{$\begin{array}{c}\text { Gini } \\
\text { Coeff. }\end{array}$} \\
\hline & Obs. & Weighted & Lower & Upper & & & & \\
\hline Decile 1 & 1745 & 682484 & 0 & 5289 & 3493 & 3726 & 1273.817 & 0.205 \\
\hline Decile 2 & 1723 & 681346 & 5290 & 8140 & 6663 & 6641 & 805.256 & 0.070 \\
\hline Decile 3 & 1627 & 681822 & 8141 & 10974 & 9563 & 9539 & 783.243 & 0.047 \\
\hline Decile 4 & 1670 & 681852 & 10975 & 14489 & 12628 & 12574 & 1003.686 & 0.046 \\
\hline Decile 5 & 1608 & 681713 & 14490 & 19137 & 16680 & 16628 & 1314.370 & 0.045 \\
\hline Decile 6 & 1644 & 681803 & 19138 & 26338 & 22488 & 22386 & 2005.032 & 0.051 \\
\hline Decile 7 & 1508 & 681752 & 26339 & 37303 & 31553 & 31499 & 3126.064 & 0.057 \\
\hline Decile 8 & 1348 & 681629 & 37304 & 56249 & 45548 & 44926 & 5547.326 & 0.070 \\
\hline Decile 9 & 1145 & 681859 & 56250 & 93012 & 72259 & 70842 & 10728.940 & 0.085 \\
\hline Decile 10 & 920 & 681645 & 93013 & 1507322 & 162543 & 132274 & 94167.150 & 0.242 \\
\hline Total & 14938 & 6817905 & 0 & 1507322 & 38338 & 19130 & 54884.240 & 0.571 \\
\hline
\end{tabular}

Source: Own calculations, IES 2000 (Statistics South Africa 2002b)

Note: The dataset used includes metropolitan and other urban areas only.

\subsubsection{Price Data}

Statistics South Africa collects extremely detailed price data on a monthly basis for the calculation of the CPI in their monthly Survey of Retail Prices. Prices are collected for all "consumer goods and services in the basket sold by ... retail trade and service outlets to consumers in the 14 metropolitan and 39 other urban areas" across the country (Statistics

2 It is important to note that descriptive statistics presented here and elsewhere are based on the cleaned, reconstructed dataset that does not include all expenditure categories, and not on the original version of the IES 2000. 
South Africa, 2002a: 1). It is from this data that the official consumer price indices are calculated. This means that the official inflation rate is an urban-based inflation rate, and can not be assumed to accurately reflect the situation in rural areas with respect to price movements. ${ }^{3}$

There are two types of price data available from Statistics South Africa that would be of use in this study, namely actual raw price data and calculated price indices, both at a very detailed level. The detailed raw price data, however, is problematic in that there often exist multiple series of price data for a single expenditure weight linked to a single expenditure category in the IES, which necessitates the application of some type of weighting system within a single expenditure category in order to combine prices. For example, there is a weight in the CPI for 'white bread', but in the raw price data there are separate mean prices for 700 gram loaves and 800 gram loaves of white bread, with little public information available on the relative importance of these types of loaves within total white bread consumption. Consequently, price indices for each expenditure category were utilised. These indices already take into account the extensive information that Statistics South Africa has on the various types, quantities and qualities purchased by consumers for any given expenditure category.

The price data utilised in this study covers the period from January 1997, which is the start of the majority of these price series, to December 2006, a total of ten years or 120 months. This allows for the construction of a relatively long inflation series of 108 months, or nine years.

\subsubsection{Matching Expenditure and Price Data}

Expenditure categories as contained in the IES 2000 and the price data obtained from Statistics South Africa do not correspond exactly. In fact, the price data does not correspond directly with the expenditure categories as published in the CPI release by Statistics South Africa (Statistics South Africa, 2002a). Consequently, the expenditure data and, in some cases, the price data needed to be realigned to provide a proper match across datasets.

The most common adjustment required the consolidation of expenditure items in the IES to match a given price item as contained in Statistics South Africa's price data utilised in this study. For example, within the Fruit and Nuts expenditure category of the IES 2000, separate expenditure categories exist for Apples and Other deciduous fruit respectively. In the price dataset, however, there exists only a single price for deciduous fruit and, consequently, expenditures in the IES 2000 for these two items are combined to form a single item, Deciduous fruit. This procedure is followed to construct many of the various 'other' expenditure categories.

3 The rural consumer price index that Statistics South Africa began publishing in 2003 is also calculated on the basis of prices in urban areas, specifically on prices collected from outlets in the 'smaller towns' or 'other urban areas' (Statistics South Africa 2007: 7). Thus, it is also technically not necessarily an accurate reflection of rural inflation. 
Statistics South Africa does not collect monthly data on all items included in the CPI calculation and, where items lack price data, they assume that the price changes of the expenditure category can proxy for the actual price changes of individual items for which no price data is collected. In these instances, where expenditure items in the IES 2000 lack corresponding price data, it is assumed in this study that the price changes for the relevant (sub-)category proxy that of the specific expenditure item. For example, within the Transport expenditure category, Statistics South Africa does not collect price data on taxi transport. To create a price series for taxi transport, a price index is created using other items within the public transport subcategory (bus, train and air transport) and this price series is then applied to the taxi transport weight when calculating the overall price index. Obviously, there may be issues as to the suitability of this calculation. In the case of taxi transport, it may be argued that the cost of taxi transportation is more likely to vary in line with the petrol price than some index of other modes of public transport. However, since this is the method followed by Statistics South Africa, it is used in this study.

In some instances, price data is available for only part of the period under investigation. In this instance, a similar method as described above is employed to complete the price series. It is assumed that the price of the item with an incomplete price series moves in line with price index for the relevant (sub-)category, with the calculated index being applied to the missing section of the item's price series, whether at the start or the end of the series.

Some expenditure categories are more aggregated than the corresponding price data, meaning that two or more price series refer to a single expenditure weight. In such cases, the price relatives are averaged across the price series and a new consolidated price series is generated and applied to the expenditure weight in the price index calculation. For example, there are separate price indices for brown bread and wholewheat bread, while in the IES 2000 there is a single expenditure category, brown and wholewheat bread. Each price series is converted to a series of price relatives (the price in a given period being divided by the price in the previous period) and the individual series are then averaged in each period. This averaged series is then used to construct a price index for the single expenditure category.

\subsection{Methodology}

\subsubsection{Weight Construction}

Consumer price indices are calculated for various applications, such as the monitoring of the general price level in the economy for monetary policy purposes, the indexation of wages and social spending benefits, and for deflating incomes and prices for comparisons over time. For national statistical agencies, perhaps the most important application is the consumer price index as an input for the monetary policymaking process, the CPI reflecting general or economy-wide inflation. This provides monetary authorities with both a target for monetary policy and a measure of the success of anti-inflationary policy. However, consumer price 
indices on their own do not necessarily accurately reflect an economy's price inflation, since they do not take into account the prices of "capital goods, such as houses, or the goods and services consumed by enterprises or the government" (International Labour Organisation, 2004: 36).

Apart from this criticism, consumer price indices are unable to provide an indication of average consumer inflation, where the term 'average' is applied across households or consumers. Statistics South Africa defines the consumer price index as "a series of figures (numbers) showing how the average price level of those goods and services (basket of goods and services) bought by a typical consumer or household changes over time" (Statistics South Africa, 2002a: 1). As a result, CPI inflation is interpreted by economic agents, from individuals and households, to the media and government, as the inflation rate experienced by the 'average' household. This, however, is not true, the structure of the expenditure weights of commonly calculated consumer price indices being biased towards those at the upper end of the expenditure distribution. In South Africa, for example, the structure of the expenditure weights for historical metropolitan and other urban areas most closely reflects the spending patterns of the higher income groups. For the main expenditure categories (for example, Food, Alcoholic Beverages and Transport), the official CPI weights consistently fall between those of the upper two quintiles, referred to by Statistics South Africa as the High and Very High income groups for both 1995 and 2000.

This bias is linked to the fact that the Very High income group (the top quintile) accounts for more than two-thirds of the weight of the official CPI in both 1995 and 2000, with this proportion actually having risen from 68.4 percent to 71.3 percent over the period (Statistics South Africa, 2002a: 3). In contrast, the lowest three quintiles accounted for approximately 12 percent of the weight in 2000 , despite accounting for 60 percent of households and, in all likelihood, an even greater proportion of the population, given the greater average household size amongst poorer households.

\section{a. Plutocratic Weights}

The conventional method of deriving expenditure weights for official consumer price indices employed by Statistics South Africa and all other national statistical agencies internationally entails the aggregation of expenditure on a specific item across all households and then calculating the share of this aggregate within total consumer expenditure. For example, the sum of all households' expenditures on paraffin is calculated and the sum of all households' expenditures on all goods and services is calculated, with the share of the former within the latter being the weight of paraffin in the consumer price index. Mathematically, this is stated as: 


$$
w_{i}^{p}=\frac{\sum_{h=1}^{H} e_{i}^{h}}{\sum_{i=1}^{n} \sum_{h=1}^{H} e_{i}^{h}}
$$

where $w_{i}$ is the weight of product $i$ for $i=1, \ldots, n$ items, $e_{i}$ represents the expenditure on product $i$, and the superscript $h$ denotes the household for $h=1, \ldots, H$. This implies that the $\mathrm{CPI}$ "can be interpreted as a weighted average of household price indexes ... [the] weight of each household [being] its total expenditure" (Ley, 2005: 635). This, then, is the mathematical reason for the fact that the top quintile in South Africa accounts for more than 70 percent of the weight of the $\mathrm{CPI}$ in the 2000 weights. Such weights are termed plutocratic weights and are currently used by virtually all countries.

This bias towards the characteristics of the expenditure patterns of those at the upper end of the expenditure distribution does not, however, invalidate the plutocratic method as used by statistical agencies around the world. As the CPI is used as an indicator of economy-wide inflation or as a deflator of national account and other such aggregates, it is preferable that the index is weighted according to total consumer spending, as the plutocratic index is. It merely points to the fact that where the analysis involves households in the middle of the distribution, or even at the lower end of the distribution, plutocratic weights are no longer the most suitable option.

\section{b. Democratic Weights}

An alternative method of calculating weights eliminates the bias that arises from the fact that plutocratic weights are a weighted mean of individual household price indices, where the weight is that household's expenditure. Democratic weights entail a change in the unit of analysis, from the product to the household. In order to arrive at an index that approximates the inflation experience of households in the middle of the expenditure distribution, differential weighting of households must be eliminated so that each household's structure of expenditure contributes equally to the overall weights. Essentially, the expenditure weights for each individual household are derived and these are then averaged to obtain the democratic weights. Mathematically, this is represented as:

$$
w_{i}^{d}=\frac{1}{H} \sum_{h=1}^{H}\left(\frac{e_{i}^{h}}{\sum_{i=1}^{n} e_{i}^{h}}\right)
$$

utilising the same notation as above. Thus, the democratic weight for white sugar, for example, 
is the mean across all households of the share of white sugar within each household's total expenditure. The bias towards the upper end of the distribution is eliminated since the poorest 20 percent of households and the richest 20 percent of households each account for 20 percent of the democratic index's weight.

A given product's income elasticity will determine the difference between the plutocratic and democratic estimates of its weight within a price index. Items with income elasticities in excess of one (referred to as 'luxuries') will account for a greater proportion of expenditure amongst higher income households, while those with elasticities of below one (referred to as 'necessities' if the elasticity is positive, and 'inferior goods' if the elasticity is negative) will account for a smaller proportion of expenditure as income rises. Thus, as Prais (1959: 127) points out, plutocratic weighting structures attach greater importance to luxury items and less importance to necessities than the democratic method.

\subsubsection{Calculation of Inflation Rates}

Official South African consumer price indices, as in most other countries, are fixed-weight Laspeyres-type indices. Expenditure weights are calculated at a given point in time and are used until such time as further use would compromise the weights' ability to accurately reflect expenditure patterns in reality, at which time new expenditure weights are calculated. This reestimation of expenditure weights typically occurs once every five years in South Africa on the basis of data collected in the Income and Expenditure Surveys. The price indices are not true Laspeyres indices due to the fact that updates to expenditure weights on the one hand, and prices on the other are not synchronised, the weights being updated quinquennially and prices monthly.

The Laspeyres price index is calculated as:

$$
L_{t, 0}=\sum_{i=1}^{n} w_{i, 0} \cdot\left(\frac{p_{i, t}}{p_{i, 0}}\right) \times 100
$$

where $w_{i, 0}$ is the average expenditure share for item $i$ for the sample of households in period 0 , and $p_{i, t}$ and $p_{i, 0}$ are the prices of good $i$ in periods $t$ and 0 respectively. The use of unchanging weights is the target of one of the main critiques of Laspeyres(-type) price indices, since they do not allow for substitution by consumers in response to price changes. Thus, although rising relative prices may induce consumers to substitute away from a given product, the Laspeyres index does not reflect this behavioural change. Consequently, this type of index reflects an upper bound for the true change in the cost of living. This problem, though, will not affect decile-specific price indices in the same way, since poorer households and consumers have more limited scope to alter their spending patterns in the face of price increases. Thus, amongst the poorest groups, the gap between the true value of the price index and the actual measured value will be relatively narrower. 
Once the price indices have been calculated, year-on-year inflation rates are calculated according to the standard percentage change formula.

\subsection{Comparability with Official CPI Statistics}

Although one may wish to compare the CPI inflation figures presented below with official inflation data as calculated and published by Statistics South Africa, the consumer price indices that are calculated in this paper are not strictly comparable with official CPI figures. This is due to a number of factors, which are discussed below.

Firstly, Statistics South Africa employed the 1996 Census to construct the sample frame and to weight the data collected in the Income and Expenditure Survey of 2000, since that was the most recent Census at that time. Subsequently, the 2001 Census has been conducted and Statistics South Africa has gradually begun reweighting recent surveys, most notably the Labour Force Surveys and very recently the 2000 IES, with 2001 Census weights. For the purposes of this study, it was decided that the 2001 Census weights would be most appropriate and consequently the indices presented below differ from official indices in terms of survey weighting

Secondly, while all expenditure data used to construct the expenditure weights in this paper have derived from the IES 2000, this is not true of official statistics. For numerous expenditure categories, Statistics South Africa employs supplementary data that enable it to provide greater detail and texture to the data. For example, data from the South African Meat Board is utilised to establish precisely which cuts and of which types of meat are sold to consumers. These types of breakdowns are then used to establish more precise weights to attach to the very detailed price information, thereby constructing the price indices used in this study. Further, use of the International Trade Classification results in a redistribution of expenditures as measured in the IES to different CPI categories. For example, beef mince is moved from 'Beef and Veal' to 'Other Meat and Meat Products', while baby foods containing meat or cereal products, for example, are reclassified under meat and cereal products respectively (Bennett, 2006). In the process, there is some shifting of expenditure between categories and, therefore, the official CPI weights do not always correspond exactly to the IES weights.

The CPI presented in the following section is essentially akin to the CPIX (CPI less interest on mortgage bonds) published by Statistics South Africa on a monthly basis. 


\section{Results}

\subsection{Overall Expenditure Weights}

For the purposes of this study, both plutocratic and democratic expenditure weights were calculated for households located in the so-called historical metropolitan and other urban areas of South Africa. Figure 1 presents the plutocratic weights for urban areas in 2000 for the 17 expenditure categories. From the figure, it is clear that three expenditure categories account for the bulk of expenditure by urban households, namely Food, Housing and Transport. Expenditure on food accounts for almost one-quarter (23.7 percent) of total expenditure, followed by housing at 18.6 percent and transport at 15.0 percent. Thus, these three expenditure categories account for 57.4 percent of total household expenditure. Nine expenditure categories account individually for between three and six percent of total household expenditure, with Clothing and Footwear (5.0 percent) being the most important expenditure category. Reading Material, at 1.0 percent of expenditure, is the least important group, apart from the Other Goods and Services group (0.9 percent).

Figure 1: Plutocratic Expenditure Weights for Urban Areas, 2000

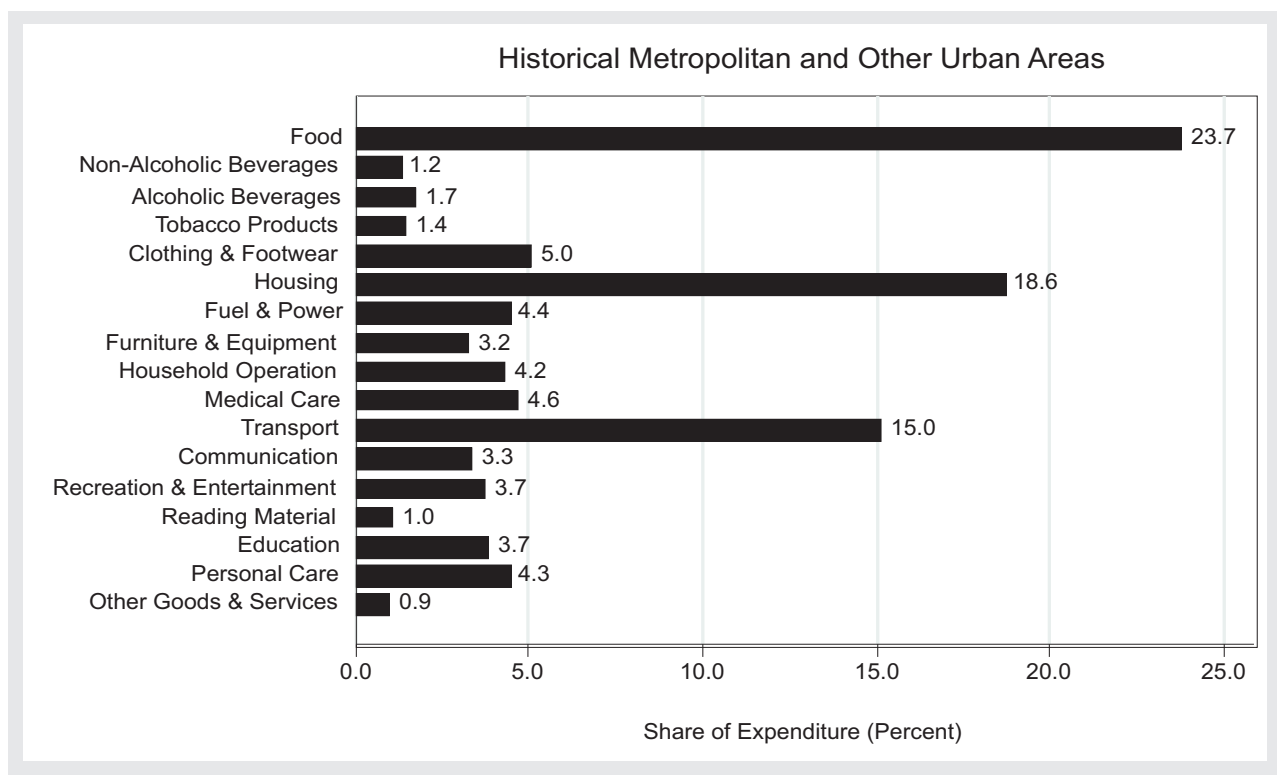

Source: Own calculations, IES 2000 (Statistics South Africa)

Democratic expenditure weights for 2000 differ quite considerably from the plutocratic weights. On average, expenditure on food accounts for the largest share of total expenditure, the weight of 36.6 percent being more than 50 percent higher than the plutocratic weight. Other categories that see increases in their weights when calculated democratically include Fuel and Power (4.4 percent to 6.2 percent) and Personal Care (4.3 percent to 6.1 percent). Similarly, both alcoholic and non-alcoholic beverages and tobacco products are more important within the democratic weight structure compared to the plutocratic structure. The importance of housing 
and transport is much reduced in the democratic bundle, falling from 18.6 percent and 15.0 percent to 10.9 percent and 9.5 percent respectively. Similarly, Medical Care, Communication, Recreation and Entertainment and Education are less important within the democratic weight structure.

Figure 2: Democratic Expenditure Weights for Urban Areas, 2000

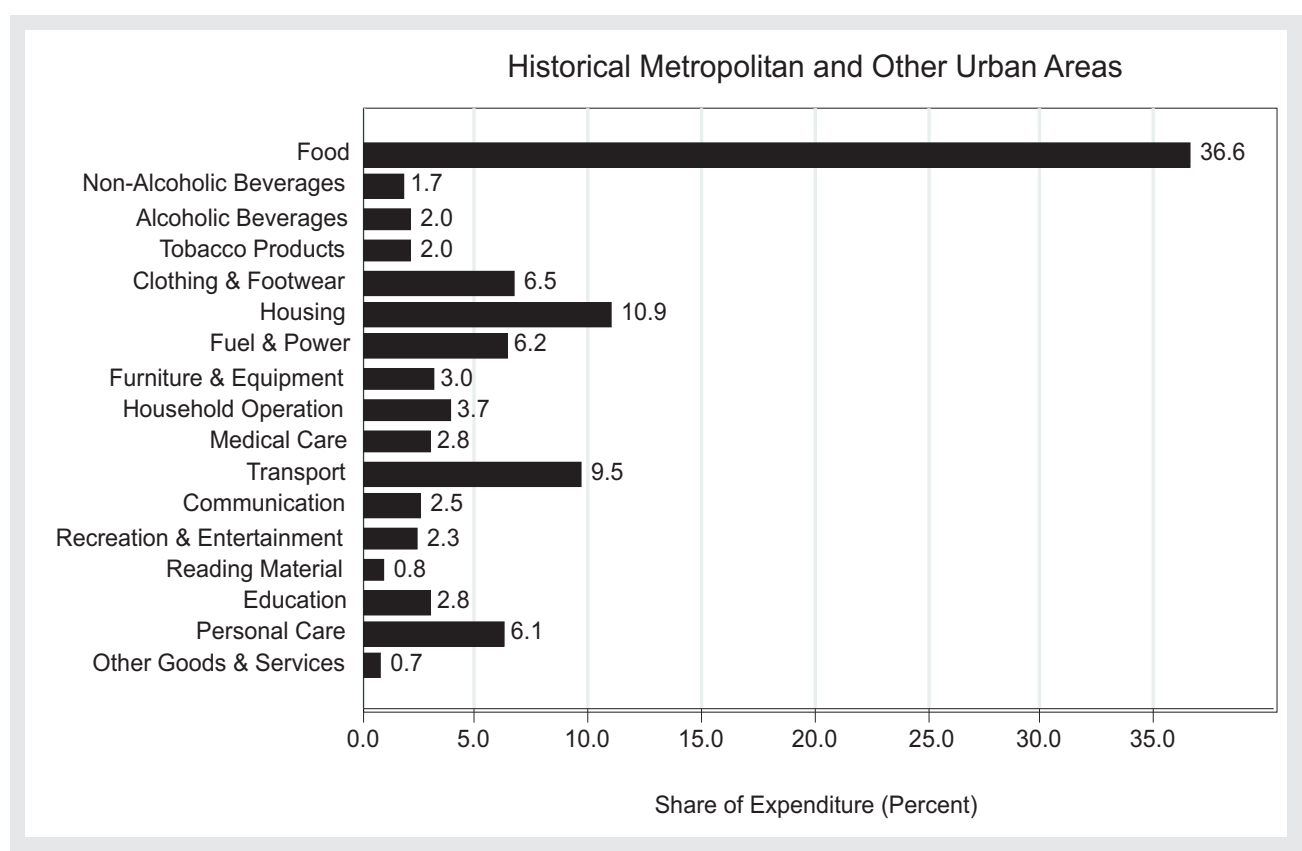

Source: Own calculations, IES 2000 (Statistics South Africa)

While the 'representative household' of the conventional definition of consumer price indices does not exist, it is worth investigating which households' expenditure patterns most closely resemble the plutocratic and democratic weight structures. This is done through the simple calculation of correlation coefficients between a given pattern of expenditure and the plutocratic or democratic weighting structures. Figure 3 presents the moving average of the correlation coefficients calculated across 1000 expenditure quantiles. 
Figure 3: Correlation of Urban Household Expenditure Patterns with Mean Expenditure Pattern

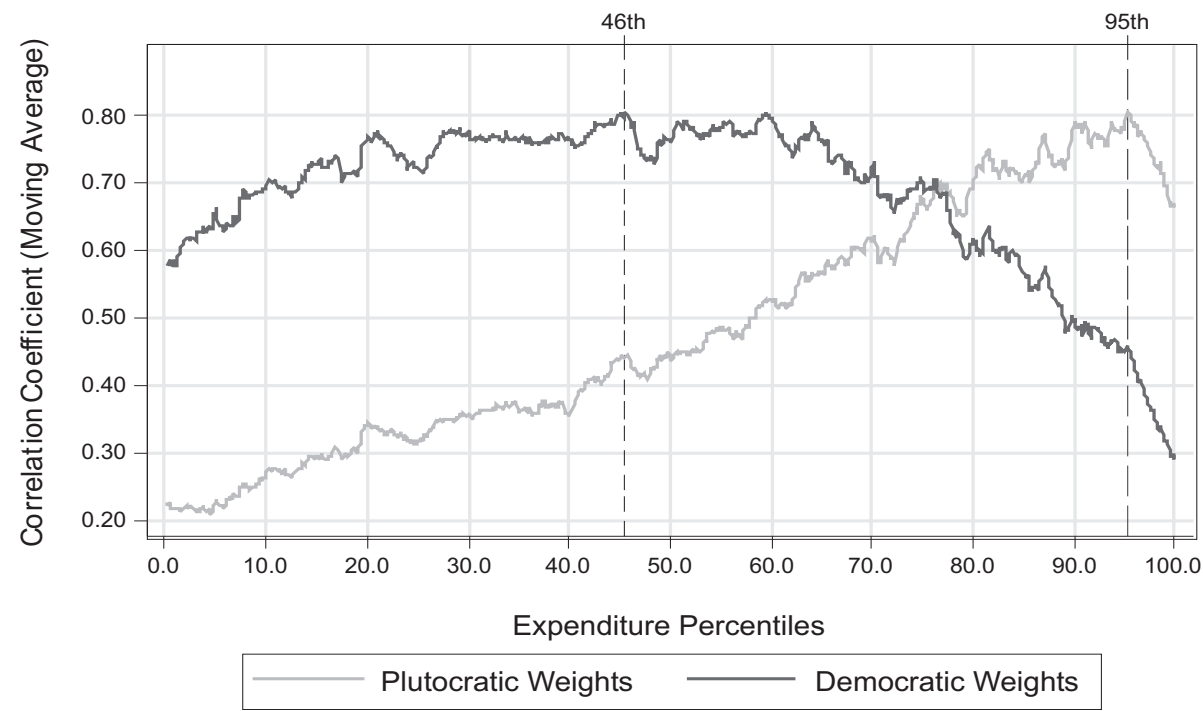

Source: Own calculations, IES 2000 (Statistics South Africa)

Note: Mean correlation coefficients are calculated as 21 observation moving averages of the correlation coefficients of the 1000 expenditure quantiles.

The figure clearly demonstrates the varying ability of both the plutocratic and the democratic weighting structures to reflect the patterns of expenditure at different points of the distribution. Specifically, as one moves up the expenditure distribution, the plutocratic weighting structure provides a continually improving match with the relevant households' expenditure patterns. It is only at the very top end of the distribution that the correlation weakens. The plutocratic weight structure most closely resembles the expenditure patterns of households in the $95^{\text {th }}$ percentile of the expenditure distribution. This clearly confirms that the official inflation rate as calculated by Statistics South Africa cannot reflect the experience of "a typical consumer or household" (Statistics South Africa, 2002a: 1). In contrast, the composition of expenditure according to the democratic weighting method is closest to the expenditure patterns observed at the $46^{\text {th }}$ percentile.

This problem is not unique to South Africa, although the extreme levels of inequality in South African society do accentuate it. Muellbauer (1974) found that the plutocratic weighting structure in the UK most closely resembled households in the $71^{\text {st }}$ percentile, while in the United States, using the 1990 Consumer Expenditure Survey, Deaton (1998: 43) finds that households in the $75^{\text {th }}$ percentile were best represented by the plutocratic weights. Izquierdo et al. (2003: 149) find, during the 1990s in Spain, "the CPI-represented consumer in the sixty-first percentile of the mean-adjusted household expenditure distribution". 
One important question, particularly given the extreme levels of inequality in South Africa, is whether this problem of bias extends to indices for subpopulations. Of particular interest in the context of this study is which of the plutocratic or democratic indices are superior in reflecting the average expenditure patterns in the ten expenditure deciles. The correlation coefficients between the expenditure patterns across the distribution and the relevant decile's plutocratic and democratic weight structures reveal very similar patterns of correlation for both weighting structures. Specifically, it is only in deciles one and ten that there are noticeable differences in correlations. This should not be totally unexpected, given the low levels of intra-decile inequality highlighted in Table 2.

\section{Figure 4: Correlation of Urban Household Expenditure Patterns with Mean Decile Expenditure Pattern}

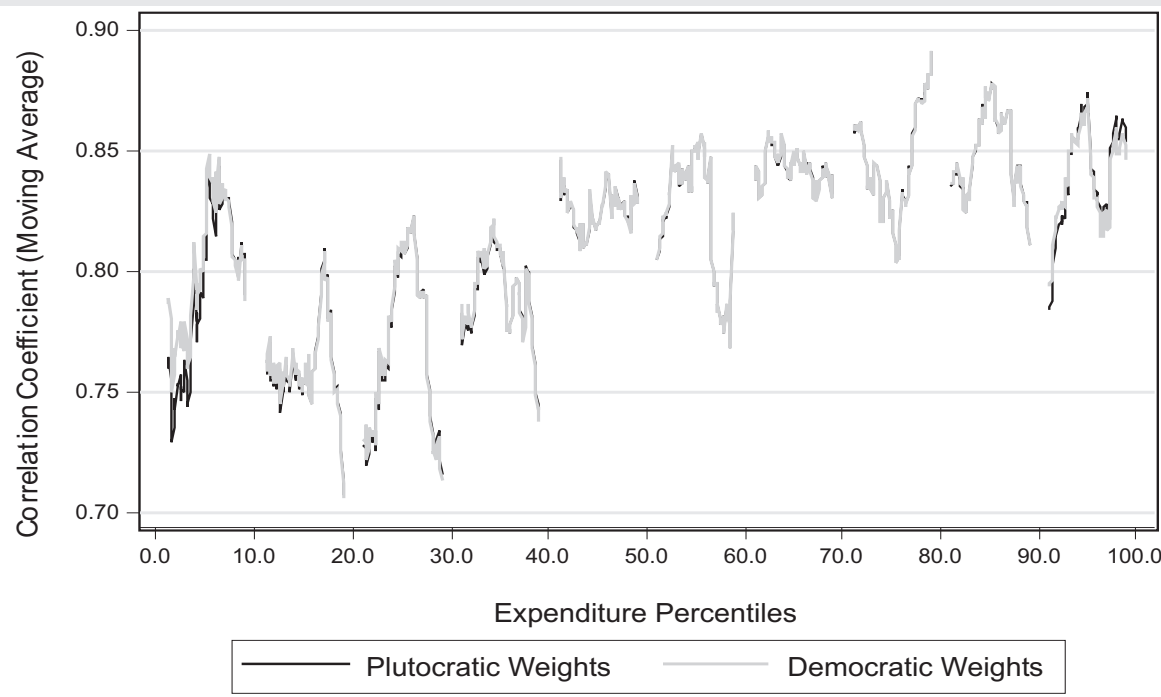

Source: Own calculations, IES 2000 (Statistics South Africa)

Note: $\quad$ Mean correlation coefficients are calculated as 21 observation moving averages of the correlation coefficients of the 1000 expenditure quantiles.

The figure does make it clear that no aggregated 'average' weight structure is able to reflect the experience of each individual household equally well. For most of the deciles, the correlations tend to peak somewhere towards the middle of the decile (for example in deciles one, three, four, six, seven, nine and ten). Perhaps most interesting, is the fact that for the middle eight deciles, the correlation patterns for plutocratic and democratic indices are virtually identical. This is not unexpected given the very low Gini coefficients for the middle eight deciles. Nevertheless, even in the two extreme deciles, the correlation coefficients are rarely very different. Consequently, it would appear that constructing plutocratic price indices by expenditure decile may be sufficient in most cases to accurately reflect their respective inflation experiences, making disaggregated democratic indices superfluous. 
Plutocratic weights and the inflation rates based on them do have their advantages though relative to democratic weights. "[Expenditure] shares for each good by all households are treated as if they were those of one aggregate 'super-households' [and thus] the index can be constructed from information just on the prices and aggregated mean expenditure shares of all households" (Artsev et al., 2006: 4). A true democratic price index requires the aggregation of household level price indices, requiring household-specific data on expenditures and prices, which is an extremely complex undertaking.

\subsection{Decile-Specific Expenditure Weights}

Given that this paper focuses on the differences in inflation experiences across the distribution, it is important to assess how the structure of expenditure varies as income, proxied here by expenditure, rises. Figure 5 presents the structure of expenditure for each expenditure decile, including only the largest expenditure categories and revealing a number of distributionsensitive expenditure patterns. Details of all the main product categories can be found in the Appendix.

First and foremost is the dominance of spending on food within total expenditure across households in all deciles, but particularly in deciles one through eight. Half of all spending in deciles one and two went to food, while this proportion was above two-fifths for deciles three through five. This is compared to an average expenditure share for all households of 36.6 percent. Even in decile nine, food accounted for 21.8 percent of expenditure.

Secondly, a number of expenditure categories are revealed to decline in importance relative to total expenditure as expenditure increases. These are food, fuel and power, personal care and tobacco products. Personal care expenditures account for nearly ten percent of total expenditure in decile one, falling to around six percent in deciles five through seven, and to 3.1 percent in decile ten. Similarly, household fuel and power accounts for 8.7 percent of expenditure in the poorest decile and only 3.1 percent in decile ten. The proportion of expenditure on tobacco products, however, only really declines above decile seven, from over two percent to 0.9 percent amongst the richest decile.

Thirdly, most other expenditure categories are increasingly important within total expenditure as total expenditure increases. Chief amongst these is housing. Housingrelated expenditures increase from under six percent for deciles one and two (5.8 and 5.9 percent respectively), to 8.7 percent in decile six, and to 22.9 percent in decile ten. Relative to total expenditure, decile ten households spend nearly four times more than decile one households on housing. Similarly, spending on transport rises from 5.0 percent of expenditure in decile one, to 7.9 percent in decile five, and to 20.7 percent in decile ten. 
Other expenditure categories that exhibit this pattern include furniture and equipment, medical care, communication, recreation and entertainment, reading material and education.

Figure 5: Democratic Structure of Household Expenditure by Expenditure Decile, 2000

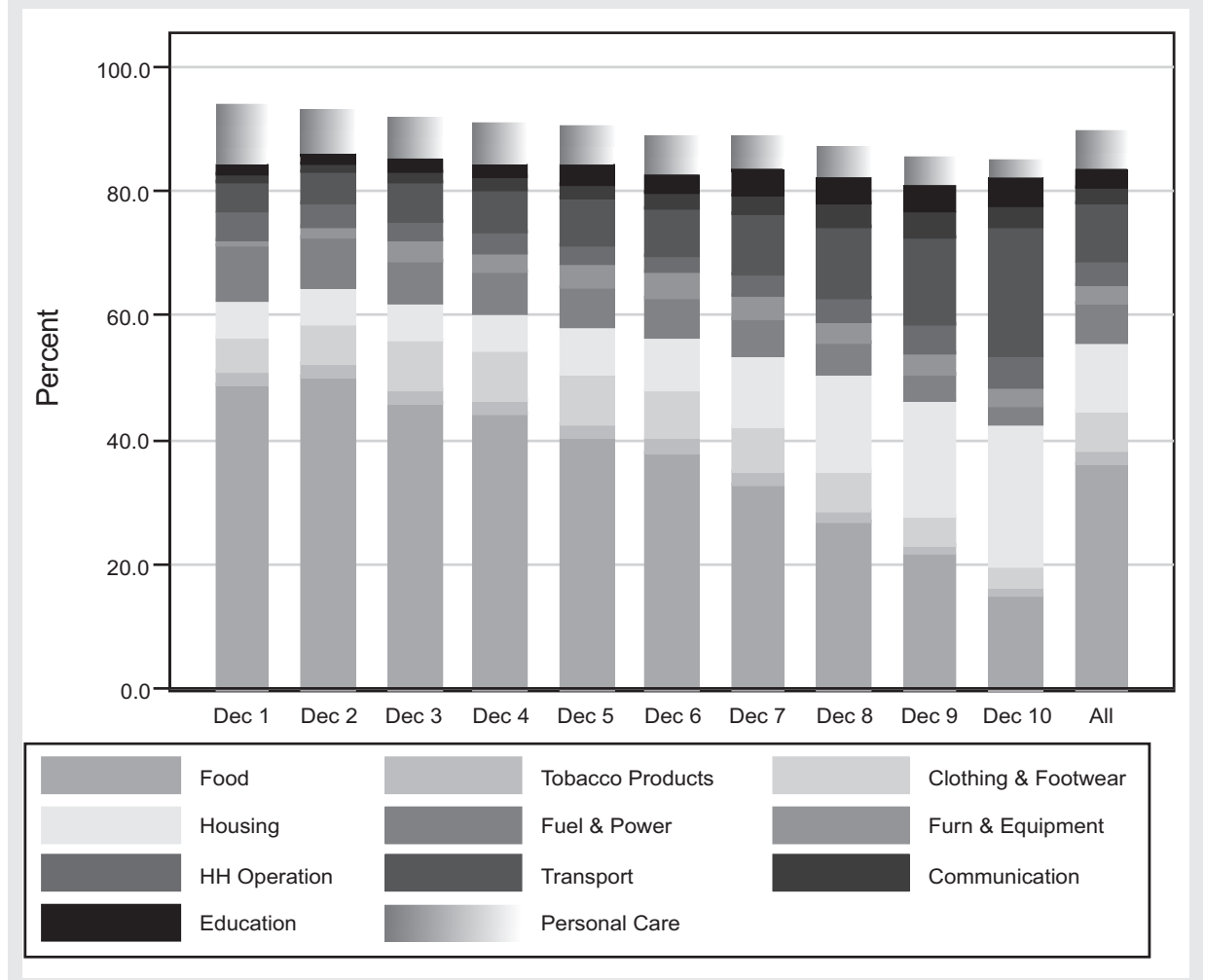

Source: Own calculations, IES 2000 (Statistics South Africa).

Note: $\quad$ Main expenditure category democratic weights can be found in the Appendix. This figure includes only those expenditure categories that account for two percent or more of the total weight in the majority of deciles.

Lower income households also tend to have their expenditures concentrated in relatively few categories. Thus, two-thirds (67.6 percent) of expenditure in decile one households is located in just three categories, namely food, personal care and fuel and power. In deciles seven through nine, this proportion falls to between 54 percent and 55 percent, rising slightly to 58.8 percent in decile ten. The top five expenditure categories account for nearly four-fifths (78.9 percent) of decile one expenditure. Consequently, it can be expected that poorer households are more vulnerable to inflation originating in their main expenditure categories than higher income households.

\subsection{Official and Calculated CPIX Inflation Rates}

Applying an identical set of price series to these varying expenditure weights, gives rise to the pattern of inflation presented in Figure 6. The official CPIX inflation rate, as published by 
Statistics South Africa on a monthly basis, is represented by the thick line, while the calculated plutocratic and democratic inflation rates are represented by the thinner lines. The dashed line, measured on the reversed secondary axis, represents the US Dollar-Rand exchange rate.

For much of the four years from the beginning of 1998 until the end of 2001, official CPIX inflation ranged between six and eight percent on a year-on-year basis, only breaching the eight percent mark briefly in mid-2000 and the six percent mark in mid-2001. Thereafter, the inflation rate rose rapidly and peaked at 11.3 percent in November 2002. This spike was spurred by the sudden depreciation of the Rand due to global economic uncertainty following the attacks in New York and Washington DC in September 2001. This inflationary episode was rooted in this depreciation, along with rapid price increases for food and fuel, and accelerating unit labour costs (South African Reserve Bank, 2002: 2). This was considerably higher than the South African Reserve Bank's inflation target of between three and six percent. However, within ten months, CPIX inflation was once again within the target range. For the rest of the period, inflation remained well within the target range, only rarely exceeding five percent. For the last two years of the period, inflation has trended upwards, levelling at around five percent during the latter half of 2006. The influence of the Rand exchange rate is also clearly discernible, with local peaks in inflation typically preceded by rapid depreciation of the Rand.

Figure 6: Official and Calculated CPIX Inflation Rates and Dollar Exchange Rate, 1998-2006

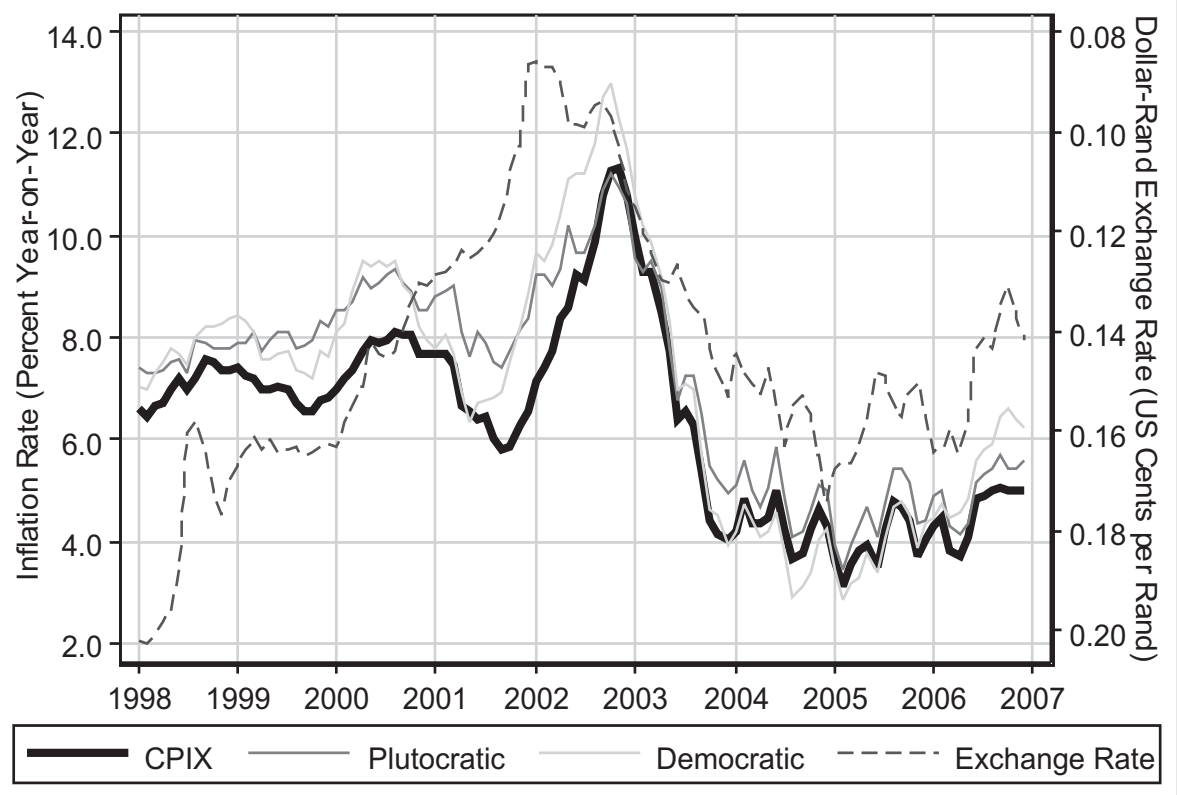

Source: Own calculations, IES 2000 (Statistics South Africa 2002b), South African Reserve Bank (2007)

In terms of the calculated inflation rates, although they are not strictly comparable as mentioned above, the pattern has been very similar. The CPIX pattern of increased amplitudes 
from 1998 to 2003, followed by relative stability thereafter is mimicked by both the calculated inflation rates. For both the plutocratic and the democratic inflation rates, the correlation with the official inflation rate is very high, with correlation coefficients of respectively 0.966 and 0.970. It is, however, important to remember that the weights for the published inflation rate were based on the 1995 Income and Expenditure Survey prior to 2002. Hence, there is a considerably weaker relationship in the first part of the period. ${ }^{4}$ Interestingly, the democratic inflation rate is generally more volatile than either the official CPIX or the calculated plutocratic inflation rates.

The fact that the three inflation rates move very similarly is encouraging as it indicates that, even though the exact methodology of Statistics South Africa could not be followed, the aggregated price indices do not follow significantly different trajectories. This is particularly true for the period from 2002 onwards.

\subsection{The Plutocratic Gap}

The difference between the inflation rates calculated using plutocratic and democratic budget shares defines the plutocratic gap. Mathematically, the gap is represented as:

$$
G_{t} \equiv \prod_{t}^{p}-\prod_{t}^{D}
$$

using the notation above, where $\Pi_{t}$ is the inflation rate for period $t$, and the superscripts $P$ and $D$ refer to the plutocratic and democratic weights.

The plutocratic gap will be different from zero if three conditions are met (Ley, 2005: 638). Firstly, there must exist inequality in the distribution of household expenditures. Secondly, households with different expenditures must display different consumption patterns. Finally, there must exist differences in the price movements of at least some of the goods consumed in varying amounts across the distribution, according to the different consumption patterns observed. Should any one of these conditions not hold, the plutocratic gap will not differ from zero.

The evidence presented above, however, confirms that a non-zero plutocratic gap is expected for South Africa. The country is characterised by exceptionally high levels of inequality. Recent estimates of inequality are extremely high: 0.56 in 2000 (Hoogeveen \& Ozler, 2006: 59), 0.577

$4 \quad$ Considering the period 1998 to 2001 only, the correlation coefficients for the plutocratic and democratic inflation rates were 0.720 and 0.778 respectively. In stark contrast, the coefficients for the period 2002 to 2006 were 0.982 and 0.977 respectively. 
in 2000 (Ozler, 2006), and 0.635 in 2001 (United Nations Development Programme, 2003: 43). Based on the cleaned IES 2000 used for this study, it is estimated that the Gini coefficient for the country as a whole is 0.601 , while that of metropolitan and other urban areas is 0.571 . As illustrated in Figure 5 expenditure patterns do vary quite substantially according to income or expenditure level, while the analysis below confirms the varying patterns of price changes over the period.

Figure 7 presents estimates of the plutocratic gap for South Africa for the period 1998 to 2006. It is immediately confirmed that the plutocratic gap fluctuates from positive to negative and back again repeatedly over the period. From 1998 to September 2001, the trough of the plutocratic inflation cycle, the gap fluctuated relatively quickly between positive and negative, spending 27 out of 45 months, or more than one-half of the period, in positive territory. For the last 13 months of that period, the gap turned quite strongly positive, peaking at a value of +1.391 in March 2001 and averaging +0.812. Thereafter, there was a clear change in inflation dynamics with the gap falling rapidly into negative territory and remaining there for 20 months. By September 2002, the gap had fallen as far as -1.805 and averaged -0.920 for this period. Another change in inflation dynamics occurred in mid-2003, when the gap once again turned positive. While this positive plutocratic gap lasted somewhat longer than any of the preceding cycles since 1998, it was not characterised by particularly high values, averaging +0.744 . Finally, in early 2006, the gap fell below zero and remained there until the end of that year, where the data series ends. The changing value of the plutocratic gap from positive to negative and vice versa coincides with the lines representing the plutocratic and democratic inflation rates crossing each other.

Since the plutocratic gap is defined simply as the difference between the rates of inflation using plutocratic and democratic weight structures respectively, the interpretation of the gap is straightforward. A positive plutocratic gap signifies that the plutocratic inflation rate is higher than the democratic inflation rate. Thus, the prices of items consumed disproportionately more by wealthier households (and which are, therefore, more dominant in the plutocratic weight structure) are rising more rapidly compared to prices of other goods. Conversely, a negative plutocratic gap occurs when the democratic inflation rate exceeds the plutocratic inflation rate. In this case, the prices of items consumed disproportionately more by poorer households are rising more rapidly than the prices of other goods. This information allows one to determine which income group experienced the higher rate of inflation in a given period. In January through March 1998, households with higher expenditures generally experienced higher rates of inflation relative to households with lower expenditures. This was also true of the periods between April 1999 and February 2000, between October 2000 and October 2001 and between July 2003 and February 2006. In contrast, poorer households experienced relatively higher inflation rates between April 1998 and March 1999, between March 2000 and September 2000, between November 2001 and May 2003, and after February 2006 until the end of the data series in December 2006. 
Figure 7: The Plutocratic Gap, 1998-2006

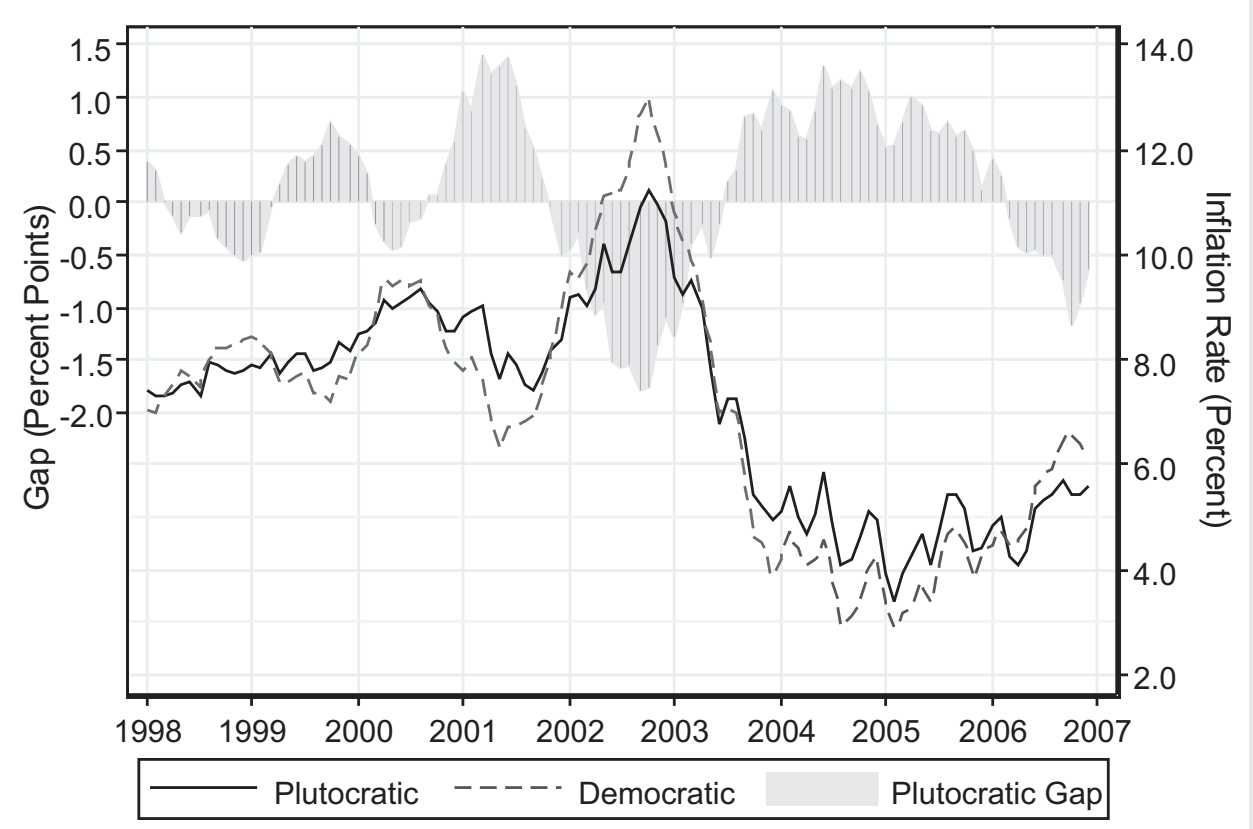

Source: Own calculations, IES 2000 (Statistics South Africa)

Interestingly, negative plutocratic gaps appear to be related to higher levels of inflation. As consumer price inflation rises, so it appears that the gap turns negative, while falls in the rate of inflation are related to a positive plutocratic gap. In fact, the correlation coefficient between the plutocratic inflation rate and the plutocratic gap is -0.510 while that between the democratic inflation rate and the plutocratic gap is -0.724 . This is a similar finding to that of Kokoski (2000: 33), who finds what is a relatively large negative plutocratic gap for the period 19901992, during which the "inflation rates for most commodities appear to be somewhat higher ... compared with other rates within the study period".

\subsection{Inflation Rates Across the Distribution ${ }^{5}$}

While the plutocratic gap provides useful insight as to which segment of the income distribution is relatively worse off due to inflation, the actual inflation rates provide a clearer indication of the degree to which the inflation experiences of the deciles differ. Figure 8 presents the rates of year-on-year inflation experienced by households in selected expenditure deciles between 1998 and 2006.

$5 \quad$ Unless otherwise stated, all price indices and inflation rates presented are calculated using democratic expenditure weights for households in urban and historical metropolitan areas. 
The general pattern observed in Figure 6 and Figure 7 is again evident here. The 108 month period can be divided into three sub-periods. The first period until mid-2001 includes close to two full inflation cycles and saw inflation rates fluctuating in a relatively narrow band between six and nine percent. Decile one experienced the highest rates of inflation at the peaks of both cycles and relatively low, but not necessarily the lowest, rates of inflation at the troughs. The experience of decile ten households was very different, with relatively low rates of inflation during the peaks of the cycles and relatively higher rates during the troughs.

\section{Figure 8: Democratic Inflation Rate by Decile, 1998-2006}

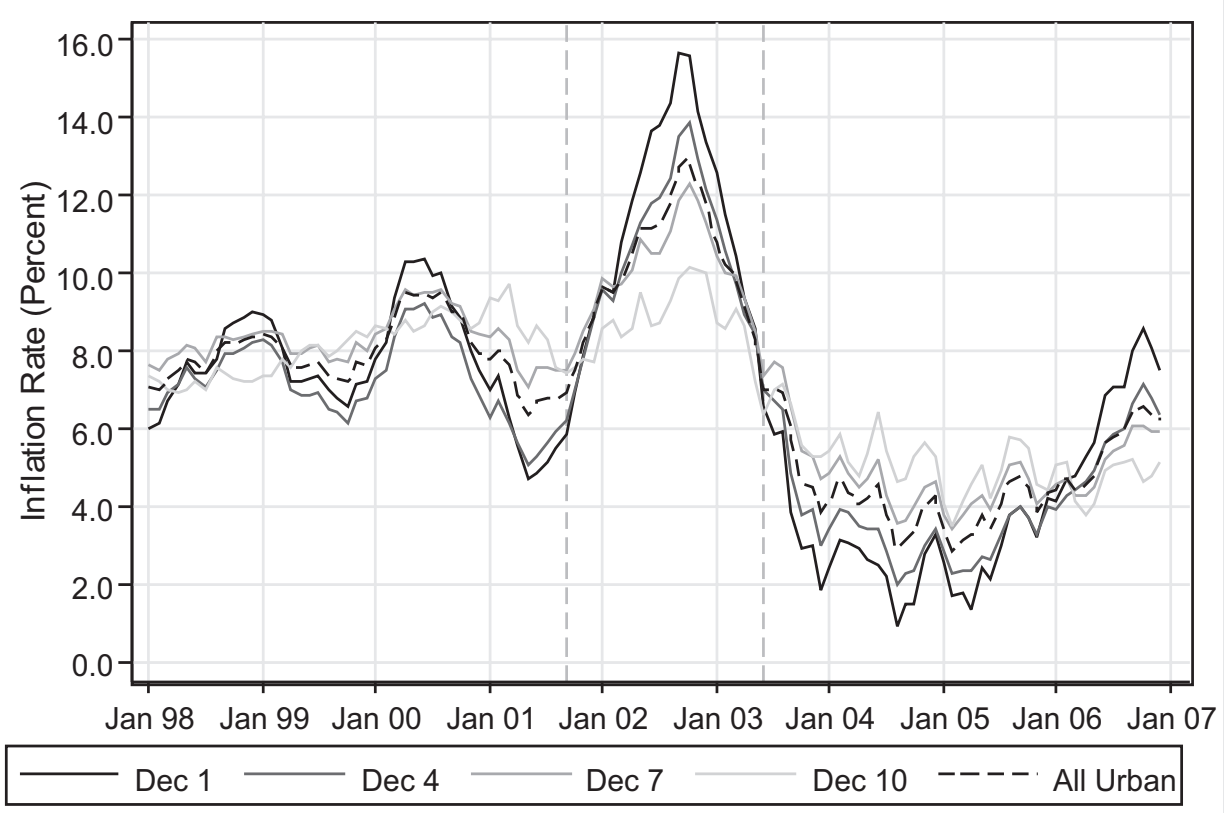

Source: Own calculations, IES 2000 (Statistics South Africa)

The second sub-period comprises the inflation cycle following the global economic turmoil sparked by the attacks of September 11 in the United States. During the first part of this period, the rate of inflation amongst all deciles increased to levels not seen since before January 1998. However, the most marked increases in the rate of inflation were to be found amongst the poorest deciles. Starting in May 2001, decile one saw its rate of inflation increase from 4.7 percent to 5.9 percent in September 2001 and to a peak of 15.6 percent in September and October 2002, an increase of almost 11 percentage points or over 230 percent within 17 months. Similarly, the inflation rate for decile four increased by nearly nine percentage points, or over 170 percent, from 5.1 percent to 13.9 percent over the same period. In contrast, the increase for decile ten households was from 8.2 percent to 10.2 percent, only 2.0 percentage points or 24 percent. Fortunately, however, this inflation episode was short-lived, having been caused by completely exogenous factors and, by June 2003, inflation had fallen to its earlier levels of around six to seven percent. 
The third period saw a further decline in the rates of inflation of all income groups, particularly for poorer households, with the overall price level being driven downwards by food prices generally and grain prices in particular. By August 2004, overall inflation had declined to under three percent (and to under one percent for decile one), generally remaining in that range until mid-2005. December 2005 saw the range in which decile inflation rates varied shrink to 0.8 percentage points, the narrowest for the period under review apart from the 0.6 percentage points that occurred three months later. At this point, however, the inflation dynamic changed again, with decile one inflation accelerating to over 8.5 percent and ending 2006 at 7.5 percent. It appears that South Africa has since seen inflation follow a similar type of trajectory as it did during the second period described above during early 2007 , as the country faced rising international oil prices and an expected poor maize harvest.

Figure 8, in combination with other analysis presented earlier, indicates the weak ability of the official consumer price index to describe the inflation experiences of different income groups at any given point in time. As Ley (2005: 644) notes, "the larger the income (expenditure) inequality, the more different the consumption patterns by income group, and the larger the variance in individual price behaviour, the less appealing is a single plutocratic CPI as the only policy adjustor". Thus, even the provision of plutocratic expenditure quintile consumer price indices by Statistics South Africa allows for a superior understanding of the differing experiences of inflation across various groups in society.

For the decade between January 1997 and December 2006, the aggregate democratic price index increased from 76.6 to 149.6 with the average index for 2000 equalling 100 (Table 3 ). This equates to an increase of 95.2 percent over the period, or an average annual rate of increase of 7.0 percent. The average annual inflation rates for the five two-year periods conform with the trends presented above: relatively stable inflation around 7.8 percent per annum for the first four years, followed by two years of inflation averaging 10.2 percent per annum, followed by a four-year period characterised by low inflation, particularly in the first two years when inflation fell to 3.8 percent per annum, but rising thereafter. 
Table 3: Democratic Decile Price Indices and Inflation Rates, January 1997 - December 2006

\begin{tabular}{|c|c|c|c|c|c|c|c|}
\hline & \multicolumn{6}{|c|}{ Indices $(2000=100)$, Average Annual Inflation Rate over Two Years in Italics } & \multirow{2}{*}{$\begin{array}{c}\text { Period } \\
\text { Change } \\
\text { (Percent) }\end{array}$} \\
\hline & Jan 1997 & Jan 1999 & Jan 2001 & Jan 2003 & Jan 2005 & Dec 2006 & \\
\hline \multirow{2}{*}{ Overall } & 76.605 & 88.906 & 103.586 & 125.892 & 135.624 & 149.552 & 95.2 \\
\hline & & 7.7 & 7.9 & 10.2 & 3.8 & 5.0 & \\
\hline \multirow{2}{*}{ Decile 1} & 77.199 & 89.148 & 102.802 & 126.952 & 133.368 & 148.636 & 92.5 \\
\hline & & 7.5 & 7.4 & 11.1 & 2.5 & 5.6 & \\
\hline \multirow{2}{*}{ Decile 2} & 77.539 & 89.636 & 102.608 & 126.668 & 133.797 & 148.370 & 91.3 \\
\hline & & 7.5 & 7.0 & 11.1 & 2.8 & 5.3 & \\
\hline \multirow{2}{*}{ Decile 3} & 78.118 & 90.074 & 102.603 & 125.717 & 133.257 & 146.697 & 87.8 \\
\hline & & 7.4 & 6.7 & 10.7 & 3.0 & 4.9 & \\
\hline \multirow{2}{*}{ Decile 4} & 78.051 & 90.026 & 102.680 & 125.348 & 133.288 & 146.669 & 87.9 \\
\hline & & 7.4 & 6.8 & 10.5 & 3.1 & 4.9 & \\
\hline \multirow{2}{*}{ Decile 5} & 77.339 & 89.508 & 103.006 & 125.307 & 134.339 & 148.027 & 91.4 \\
\hline & & 7.6 & 7.3 & 10.3 & 3.5 & 5.0 & \\
\hline \multirow{2}{*}{ Decile 6} & 76.607 & 89.267 & 103.466 & 126.074 & 136.120 & 149.475 & 95.1 \\
\hline & & 7.9 & 7.7 & 10.4 & 3.9 & 4.8 & \\
\hline \multirow{2}{*}{ Decile 7} & 75.736 & 88.472 & 104.015 & 126.212 & 137.390 & 151.088 & 99.5 \\
\hline & & $8 . \overline{1}$ & 8.4 & 10.2 & 4.3 & 4.9 & \\
\hline \multirow{2}{*}{ Decile 8} & 74.261 & 87.424 & 104.765 & 127.228 & 140.083 & 154.617 & 108.2 \\
\hline & & 8.5 & 9.5 & 10.2 & 4.9 & 5.1 & \\
\hline \multirow{2}{*}{ Decile 9} & 74.839 & 87.414 & 104.947 & 125.584 & 138.447 & 152.892 & 104.3 \\
\hline & & 8.1 & 9.6 & 9.4 & 5.0 & 5.1 & \\
\hline \multirow{2}{*}{ Decile 10} & 76.571 & 88.243 & 104.833 & 123.801 & 135.771 & 148.644 & 94.1 \\
\hline & & 7.4 & 9.0 & 8.7 & 4.7 & 4.6 & \\
\hline
\end{tabular}

Source: Own calculations, IES 2000 (Statistics South Africa)

Interestingly, however, the table reveals that the highest and lowest rates of inflation are not necessarily experienced by deciles one and ten. Over the decade, prices rose most for households in decile eight - 108.2 percent in total, or 7.7 percent per annum - while prices rose least for households in decile three -87.8 percent in total - followed closely by decile four (87.9 percent). The average annual inflation rate for these two deciles was approximately 6.6 percent. Further, it is clear that deciles change position from period to period. Generally, the overall pattern of inflation is mirrored across all ten deciles: rates of between seven and nine percent during the first four years, rates above ten percent in the middle two years and rates below five percent in the latter four years.

\subsection{Important Inflation Contributors}

\subsubsection{Identifying Key Products Responsible for Inflation amongst Poor Households}

One of the objectives of this study is to isolate the key contributors to inflation for poor South African households over the period 1997 to 2006. This is a relatively straightforward exercise once the decile specific inflation rates have been calculated. Mathematically, the overall inflation between period $t$-s and period $t$ attributable to item $z$ for sub-population $x$ can be calculated as: 


$$
\frac{w_{x}^{z} \cdot\left(\frac{p_{t}^{z}}{p_{t-s}^{z}}-1\right)}{\sum_{i=1}^{N} w_{x}^{i} \cdot\left(\frac{p_{t}^{i}}{p_{t-s}^{i}}-1\right)} \times 100
$$

where $p$ is the price (index), superscripts $z$ and $i$ indicating the specific item(s) referred to, and $w$ the expenditure weight, and subscripts $x, t-s$, and $t$, the sub-population, the start date and end date respectively.

Thus calculated, overall and by decile, items were ranked according to the size of their contribution to the overall increase in the sub-group's decile. The top 20 items contributing the largest shares to the total increase in the consumer price indices for all urban households and by expenditure category are presented in Table 4. While some of the items included in the lists are expected, there are certainly some interesting inclusions. For all urban households, the number one contributor to inflation over the decade has been flat rent, followed by tuition and attendance fees and cigarettes. Of the overall increase in the price index over the decade of 95.2 percent, these three items alone contributed 5.1, 4.5 and 4.3 percentage points respectively, or 13.9 percentage points altogether. This is equivalent to 14.5 percent of overall inflation. Four of the top twenty items are food items (poultry; beef and veal; brown and wholewheat bread; and white bread), while a fifth is an aggregate sundry food item (other food products). Two beverage items, beer (including sorghum beer) and aerated cooldrinks, are included in the list, as are two household fuel items, electricity and paraffin. Medical aid contributions, petrol and diesel, water, house and townhouse rent, taxi and hired transport, assessment rates and taxes and domestic workers complete the list.

Comparisons of households at opposite ends of the expenditure distribution reveal substantial differences in the rankings of items, solely due to the difference in relative expenditure weights. The most important source of inflation for poor households is paraffin, which contributes between 9.2 percentage points and 4.3 percentage points to inflation in deciles one and four respectively. Paraffin is one of the top two items in each of the lowest four deciles and only falls out of the top 20 contributors to inflation from decile seven upwards. Food products are particularly dominant for poor households: seven of decile one's top twenty items were food items, white sugar and potatoes moving into the top twenty alongside poultry, brown and wholewheat bread, mealie meal, beef and veal, and white bread. Other necessities, such as electricity, water, and taxi transport, and addictive products, notably cigarettes, other tobacco products and beer, are also important contributors to inflation for poor households.

For households in the uppermost decile, the largest contributors to inflation over the decade were contributions to medical aid funds (10.5 percentage points), petrol and diesel (8.5 
percentage points) and tuition and attendance fees (6.9 percentage points). These three items contributed more than one-quarter of decile ten inflation, or 25.9 percentage points, over the decade. For upper-income households, housing (flat, townhouse and house rent), and services (medical aid contributions, tuition fees, domestic workers, insurance covering mortgage debt, medical insurance, servicing of vehicles and landline phonecalls) were some of the other important contributors to inflation. For decile ten households, the only food items that are to be found amongst the 20 largest contributors to inflation are the aggregated 'other food products' category, beef and veal and mutton and lamb.

Table 4: Main Inflation Contributors by Expenditure Group, Democratic Indices, 1997-2006

\begin{tabular}{|c|c|c|c|c|c|c|}
\hline & AlI & Decile 1 & Decile 2 & Decile 3 & Decile 4 & Decile 5 \\
\hline 1 & Flat rent & Paraffin & Paraffin & Paraffin & Cigarettes & Cigarettes \\
\hline 2 & $\begin{array}{l}\text { Tuition \& } \\
\text { attendance fees }\end{array}$ & Poultry & Cigarettes & Cigarettes & Paraffin & $\begin{array}{l}\text { Tuition \& } \\
\text { attendance } \\
\text { fees }\end{array}$ \\
\hline 3 & Cigarettes & $\begin{array}{l}\text { Brown \& } \\
\text { wholewheat } \\
\text { bread }\end{array}$ & $\begin{array}{l}\text { Brown \& } \\
\text { wholewheat } \\
\text { bread }\end{array}$ & $\begin{array}{l}\text { Brown \& } \\
\text { wholewheat } \\
\text { bread }\end{array}$ & Electricity & Water \\
\hline 4 & $\begin{array}{l}\text { Contributions to } \\
\text { medical aid } \\
\text { funds }\end{array}$ & Mealie meal & Water & Poultry & Poultry & Electricity \\
\hline 5 & Petrol \& diesel & Cigarettes & Poultry & Water & Water & Flat rent \\
\hline 6 & Water & Beef \& veal & Electricity & Electricity & $\begin{array}{l}\text { Brown \& } \\
\text { wholewheat } \\
\text { bread }\end{array}$ & Beef \& veal \\
\hline 7 & Electricity & $\begin{array}{l}\text { Other tobacco } \\
\text { products }\end{array}$ & Beef \& veal & Beef \& veal & Beef \& veal & Poultry \\
\hline 8 & Paraffin & House rent & Mealie meal & $\begin{array}{l}\text { Tuition \& } \\
\text { attendance } \\
\text { fees }\end{array}$ & $\begin{array}{l}\text { Beer, incl. } \\
\text { sorghum beer }\end{array}$ & Paraffin \\
\hline 9 & Poultry & Water & White bread & $\begin{array}{l}\text { Taxi \& hired } \\
\text { transport }\end{array}$ & $\begin{array}{l}\text { Taxi \& hired } \\
\text { transport }\end{array}$ & Petrol \& diesel \\
\hline 10 & Beef \& veal & Electricity & White sugar & Flat rent & $\begin{array}{l}\text { Tuition \& } \\
\text { attendance } \\
\text { fees }\end{array}$ & $\begin{array}{l}\text { Brown \& } \\
\text { wholewheat } \\
\text { bread }\end{array}$ \\
\hline 11 & $\begin{array}{l}\text { Brown \& } \\
\text { wholewheat } \\
\text { bread }\end{array}$ & White sugar & $\begin{array}{l}\text { Beer, incl. } \\
\text { sorghum beer }\end{array}$ & $\begin{array}{l}\text { Aerated non- } \\
\text { alcoholic } \\
\text { beverages }\end{array}$ & $\begin{array}{l}\text { Aerated non- } \\
\text { alcoholic } \\
\text { beverages }\end{array}$ & $\begin{array}{l}\text { Beer, incl. } \\
\text { sorghum beer }\end{array}$ \\
\hline 12 & House rent & $\begin{array}{l}\text { Beer, incl. } \\
\text { sorghum beer }\end{array}$ & $\begin{array}{l}\text { Taxi \& hired } \\
\text { transport }\end{array}$ & $\begin{array}{l}\text { Beer, incl. } \\
\text { sorghum beer }\end{array}$ & Flat rent & $\begin{array}{l}\text { Taxi \& hired } \\
\text { transport }\end{array}$ \\
\hline 13 & Townhouse rent & $\begin{array}{l}\text { Soap, washing } \\
\text { powder, } \\
\text { detergents }\end{array}$ & $\begin{array}{l}\text { Tuition \& } \\
\text { attendance } \\
\text { fees }\end{array}$ & White bread & White bread & House rent \\
\hline 14 & $\begin{array}{l}\text { Beer, incl. } \\
\text { sorghum beer }\end{array}$ & $\begin{array}{l}\text { Taxi \& hired } \\
\text { transport }\end{array}$ & $\begin{array}{l}\text { Aerated non- } \\
\text { alcoholic } \\
\text { beverages }\end{array}$ & Mealie meal & $\begin{array}{l}\text { Other food } \\
\text { products }\end{array}$ & White bread \\
\hline 15 & $\begin{array}{l}\text { Taxi \& hired } \\
\text { transport }\end{array}$ & Toilet soap & $\begin{array}{l}\text { Soap, washing } \\
\text { powder, } \\
\text { detergents }\end{array}$ & White sugar & White sugar & $\begin{array}{l}\text { Aerated non- } \\
\text { alcoholic } \\
\text { beverages }\end{array}$ \\
\hline 16 & $\begin{array}{l}\text { Other food } \\
\text { products }\end{array}$ & $\begin{array}{l}\text { Tuition \& } \\
\text { attendance } \\
\text { fees }\end{array}$ & Flat rent & Fresh milk & Fresh milk & $\begin{array}{l}\text { Assessment } \\
\text { rates }\end{array}$ \\
\hline 17 & $\begin{array}{l}\text { Assessment } \\
\text { rates }\end{array}$ & $\begin{array}{l}\text { Matches \& } \\
\text { candles }\end{array}$ & Fresh milk & House rent & House rent & $\begin{array}{l}\text { Other food } \\
\text { products }\end{array}$ \\
\hline 18 & $\begin{array}{l}\text { Aerated non- } \\
\text { alcoholic } \\
\text { beverages }\end{array}$ & Potatoes & House rent & $\begin{array}{l}\text { Soap, washing } \\
\text { powder, } \\
\text { detergents }\end{array}$ & Mealie meal & Mutton \& lamb \\
\hline 19 & White bread & White bread & $\begin{array}{l}\text { Other tobacco } \\
\text { products }\end{array}$ & $\begin{array}{l}\text { Other food } \\
\text { products }\end{array}$ & Boerewors & Fresh milk \\
\hline 20 & $\begin{array}{l}\text { Domestic } \\
\text { workers }\end{array}$ & $\begin{array}{l}\text { Aerated non- } \\
\text { alcoholic } \\
\text { beverages }\end{array}$ & Toilet soap & Eggs & $\begin{array}{l}\text { Soap, washing } \\
\text { powder, } \\
\text { detergents }\end{array}$ & Boerewors \\
\hline
\end{tabular}


Table 4: Main Inflation Contributors by Expenditure Group, Democratic Indices, 1997-2006 (Continued...)

\begin{tabular}{|c|c|c|c|c|c|}
\hline & Decile 6 & Decile 7 & Decile 8 & Decile 9 & Decile 10 \\
\hline 1 & Flat rent & Flat rent & Flat rent & $\begin{array}{l}\text { Contributions to } \\
\text { medical aid funds }\end{array}$ & $\begin{array}{l}\text { Contributions to } \\
\text { medical aid funds }\end{array}$ \\
\hline 2 & Cigarettes & $\begin{array}{l}\text { Contributions to } \\
\text { medical aid funds }\end{array}$ & $\begin{array}{l}\text { Contributions to } \\
\text { medical aid funds }\end{array}$ & Petrol \& diesel & Petrol \& diesel \\
\hline 3 & $\begin{array}{l}\text { Tuition \& } \\
\text { attendance fees }\end{array}$ & $\begin{array}{l}\text { Tuition \& } \\
\text { attendance fees }\end{array}$ & Petrol \& diesel & Flat rent & $\begin{array}{l}\text { Tuition \& } \\
\text { attendance fees }\end{array}$ \\
\hline 4 & Electricity & Cigarettes & $\begin{array}{l}\text { Tuition \& } \\
\text { attendance fees }\end{array}$ & $\begin{array}{l}\text { Tuition \& } \\
\text { attendance fees }\end{array}$ & Domestic workers \\
\hline 5 & Water & Petrol \& diesel & Townhouse rent & Domestic workers & Townhouse rent \\
\hline 6 & $\begin{array}{l}\text { Contributions to } \\
\text { medical aid funds }\end{array}$ & Electricity & Electricity & Townhouse rent & Vehicles \\
\hline 7 & Beef \& veal & Water & Cigarettes & Electricity & $\begin{array}{l}\text { Insurance covering } \\
\text { mortgage debt }\end{array}$ \\
\hline 8 & Poultry & House rent & Water & Cigarettes & $\begin{array}{l}\text { Home repairs \& } \\
\text { maintenance }\end{array}$ \\
\hline 9 & Petrol \& diesel & Beef \& veal & Assessment rates & Water & Water \\
\hline 10 & $\begin{array}{l}\text { Beer, incl. sorghum } \\
\text { beer }\end{array}$ & $\begin{array}{l}\text { Other food } \\
\text { products }\end{array}$ & Domestic workers & Assessment rates & Assessment rates \\
\hline 11 & $\begin{array}{l}\text { Taxi \& hired } \\
\text { transport }\end{array}$ & Poultry & House rent & House rent & House rent \\
\hline 12 & $\begin{array}{l}\text { Brown \& } \\
\text { wholewheat bread }\end{array}$ & Assessment rates & $\begin{array}{l}\text { Other food } \\
\text { products }\end{array}$ & $\begin{array}{l}\text { Other food } \\
\text { products }\end{array}$ & Electricity \\
\hline 13 & $\begin{array}{l}\text { Other food } \\
\text { products }\end{array}$ & Townhouse rent & Beef \& veal & $\begin{array}{l}\text { Insurance covering } \\
\text { mortgage debt }\end{array}$ & $\begin{array}{l}\text { Other food } \\
\text { products }\end{array}$ \\
\hline 14 & White bread & Mutton \& lamb & Mutton \& lamb & $\begin{array}{l}\text { Home repairs \& } \\
\text { maintenance }\end{array}$ & Cigarettes \\
\hline 15 & $\begin{array}{l}\text { Aerated non- } \\
\text { alcoholic } \\
\text { beverages }\end{array}$ & $\begin{array}{l}\text { Taxi \& hired } \\
\text { transport }\end{array}$ & Poultry & Beef \& veal & Flat rent \\
\hline 16 & Assessment rates & White bread & $\begin{array}{l}\text { Aerated non- } \\
\text { alcoholic } \\
\text { beverages }\end{array}$ & Mutton \& lamb & Medical Insurance \\
\hline 17 & Mutton \& lamb & $\begin{array}{l}\text { Aerated non- } \\
\text { alcoholic } \\
\text { beverages }\end{array}$ & $\begin{array}{l}\text { Beer, incl. sorghum } \\
\text { beer }\end{array}$ & Vehicles & Vehicles servicing \\
\hline 18 & House rent & $\begin{array}{l}\text { Beer, incl. sorghum } \\
\text { beer }\end{array}$ & White bread & Medical Insurance & Beef \& veal \\
\hline 19 & Fresh milk & Domestic workers & Newspapers & Telephone calls & Mutton \& lamb \\
\hline 20 & Paraffin & $\begin{array}{l}\text { Brown \& } \\
\text { wholewheat bread }\end{array}$ & Fresh milk & $\begin{array}{l}\text { Aerated non- } \\
\text { alcoholic } \\
\text { beverages }\end{array}$ & Telephone calls \\
\hline
\end{tabular}

Source: Own calculations, IES 2000 (Statistics South Africa)

Only six items appear in the top 20 contributors for each of the ten expenditure deciles, although their relative positions vary. These items are beef and veal, cigarettes, electricity, house rent, tuition and attendance fees, and water. To the extent that most of these items are considered necessities by the various income groups, it is unlikely, though still possible given the lack of supporting data, that households would have substituted expenditure significantly away from these items, thus reducing the extent to which inflation may be overestimated by the reliance on fixed-weight indices. However, within item categories, higher-expenditure households would certainly be able to substitute towards lower quality and lower priced brands, thereby limiting their exposure to inflation. In all the expenditure groupings presented, the top 20 items account for a significant share of total inflation (Table 5). For all urban households, these items contributed 55.0 percentage points of the 95.2 percent increase in the group price index, or 57.7 percent of inflation over the decade. For the poorest decile, the top 20 
items accounted for 63.0 percent of inflation over the period, while for the richest decile this proportion was 72.1 percent. The proportion of inflation explained by the top 20 items in each decile was lowest in deciles three, four and five at between 58 and 59 percent, and highest in decile ten.

Table 5: Contribution of Top 20 Items to Total Change in CPI, by Decile, 1997-2006

\begin{tabular}{|l|c|c|c|}
\hline & Change in Total CPI & $\begin{array}{c}\text { Change Due to } \\
\text { Top 20 Items }\end{array}$ & $\begin{array}{c}\text { Share of Change Due to } \\
\text { Top 20 Items }\end{array}$ \\
\hline All & 95.2 & 55.0 & 57.7 \\
\hline Decile 1 & 92.5 & 58.3 & 63.0 \\
\hline Decile 2 & 91.3 & 55.2 & 60.4 \\
\hline Decile 3 & 87.8 & 51.7 & 58.8 \\
\hline Decile 4 & 87.9 & 51.4 & 58.4 \\
\hline Decile 5 & 91.4 & 53.4 & 58.4 \\
\hline Decile 6 & 95.1 & 58.1 & 61.1 \\
\hline Decile 7 & 99.5 & 63.2 & 63.5 \\
\hline Decile 8 & 108.2 & 73.5 & 67.9 \\
\hline Decile 9 & 104.3 & 71.8 & 68.9 \\
\hline Decile 10 & 94.1 & 67.9 & 72.1 \\
\hline
\end{tabular}

Source: Own calculations, IES 2000 (Statistics South Africa)

Inflation drivers are defined as items that contribute large proportions of total inflation over a given period. As noted earlier, an item's share of inflation is determined by the item's weight within the expenditure basket as well as the item's price increase over the period. Thus, an item may be identified as an inflation driver due either to a relatively large expenditure weight, or to a very large price increase over the period, or a combination of the two factors. Figure 9 presents the main contributors to inflation for urban households between 1997 and 2006 . The figure includes only those items that contribute 2.0 percent or more to total inflation. The vertical line at 2.0 percent, divides the figures into two segments signifying lower and higher weight items. This is arbitrarily calculated as approximately twice the mean weight of the top third of items in the urban democratic bundle, which is 1.083 percent. The horizontal line, dividing the figure into lower and higher inflation regions, is located at a rate of 100 percent, slightly above the average rate of inflation for urban households of 95.2 percent. These two lines, therefore, create four quadrants: high weights and high inflation in the upper righthand quadrant, low weights and high inflation in the upper lefthand quadrant, low weights and low inflation in the lower lefthand quadrant and high weights and low inflation in the lower righthand quadrant.

The one major constraint of this exercise, however, that should be noted before proceeding is that the prices - Statistics South Africa's price indices - are not tailored to a specific income group. Thus, one set of prices has been applied to all households, ignoring the fact that households in different areas and different income groups are likely to face different sets of prices. This is an issue particularly for items where the quality range is quite broad and where the pricing rules and structures of retailers and producers differ. Ideally, Figures 9 and 10 would be able to detail the average prices faced by deciles of different income groups, but this is not possible. However, a similar problem arises in the construction of the consumer price index itself and should generally not be serious enough to discredit the findings presented. 
Thirteen items are plotted on Figure 9, all accounting for 2.0 percent or more of total inflation for all urban households between 1997 and 2006. As noted above, flat rent (FLAT in Figure 9) accounts for the largest share of total inflation for urban households over the decade of 5.4 percent. Although flat rent accounts for a relatively small proportion of expenditure - it falls in the low weight area of the figure - its price level almost quintupled over the decade, resulting in its large share of inflation. Tuition and attendance fees (TUITN) is the second largest contributor to overall inflation and, along with petrol and diesel (PETROL), and beef and veal $(B E E F)$, falls in the high weight-high inflation quadrant. Townhouse rent (TOWNH), medical aid (MEDAID), cigarettes (CIGS), paraffin (PARAFF) and water (WATER) are high inflation-low weight items, all accounting for more than 2.0 percent of overall inflation. House rent (HOUSE) hovers around the intersection of the lines forming the quadrants, neither having a particularly high weight nor experiencing particularly high inflation. Poultry (POULTR) and electricity (ELECTR) are two items whose high expenditure weights have combined with below average inflation rates to account for a relatively high proportion of inflation over the period.

Figure 9: Main Contributors to Inflation for Urban Households, 1997-2006

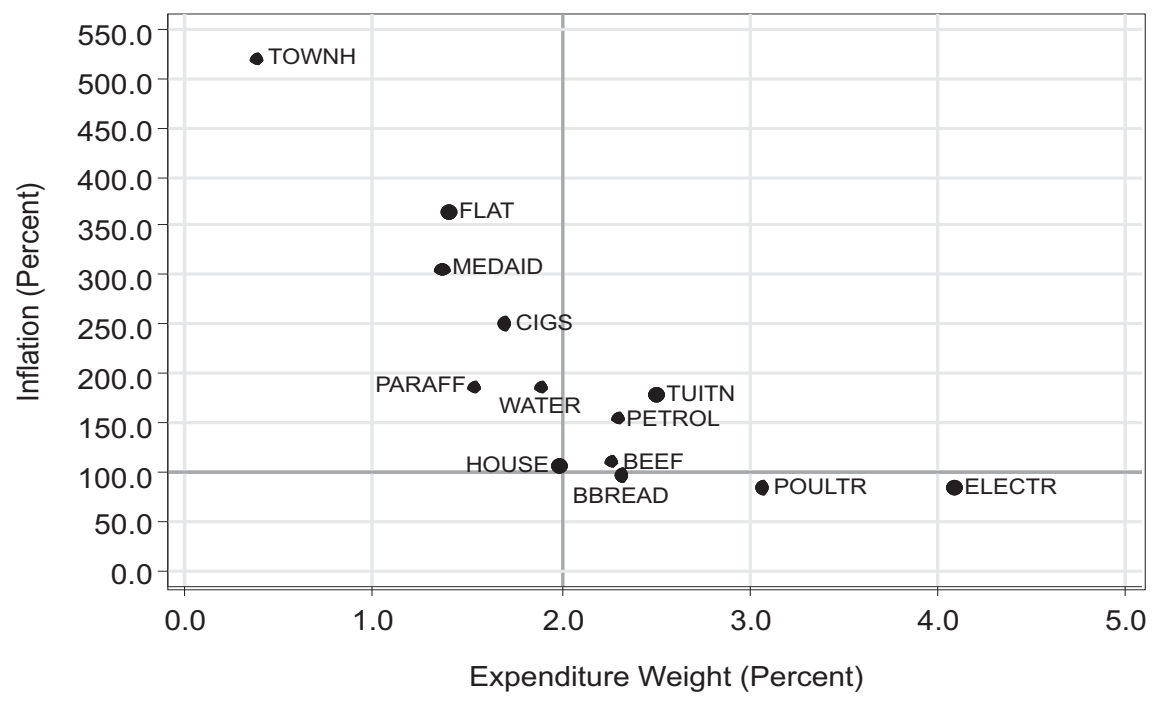

Source: Own calculations, IES 2000 (Statistics South Africa)

Note: Only items contributing 2.0 percent or more to total inflation over the period are included.

For decile one households, the main driver of inflation is clear. Paraffin (PARAFF) stands alone: a high inflation item at the upper end of the weight range. On its own, paraffin accounted for 9.9 percent of decile one inflation over the decade, more than twice the contribution of the second most important item, namely poultry (4.3 percent). Paraffin's relatively high weight of 4.9 percent within total expenditure, and poor households' reliance on paraffin for heating and cooking, means that poor households are particularly vulnerable to paraffin price increases. From its position on the upper right side of the figure, paraffin is clearly the single most important driver of inflation amongst the poorest urban households. Decile one households 
are potentially even more vulnerable to inflation deriving from mealie meal with its expenditure weight of 6.1 percent. Although mealie meal is classified as a low inflation item, its price having risen by 60.5 percent over the decade, it remains one of the top contributors to inflation amongst the poorest of urban households.

Inflation drivers for decile one households are generally food items (brown and wholewheat bread, mealie meal, beef and veal, and white sugar (WSUGAR)), household and other necessities (paraffin, house rent, water, electricity, and taxi and hired transport), and addictive substances (cigarettes, other tobacco products (OTHTOB), and alcoholic beverages $(A L C B E E)$ ). Making the situation of the poorest households even more difficult is the fact that sometimes substitutes for major inflation drivers are themselves inflation drivers. Thus, both paraffin and electricity each contribute more than 2.0 percent of inflation for decile one households, as do beef and veal and poultry.

Figure 10: Main Contributors to Decile One Inflation, 1997-2006

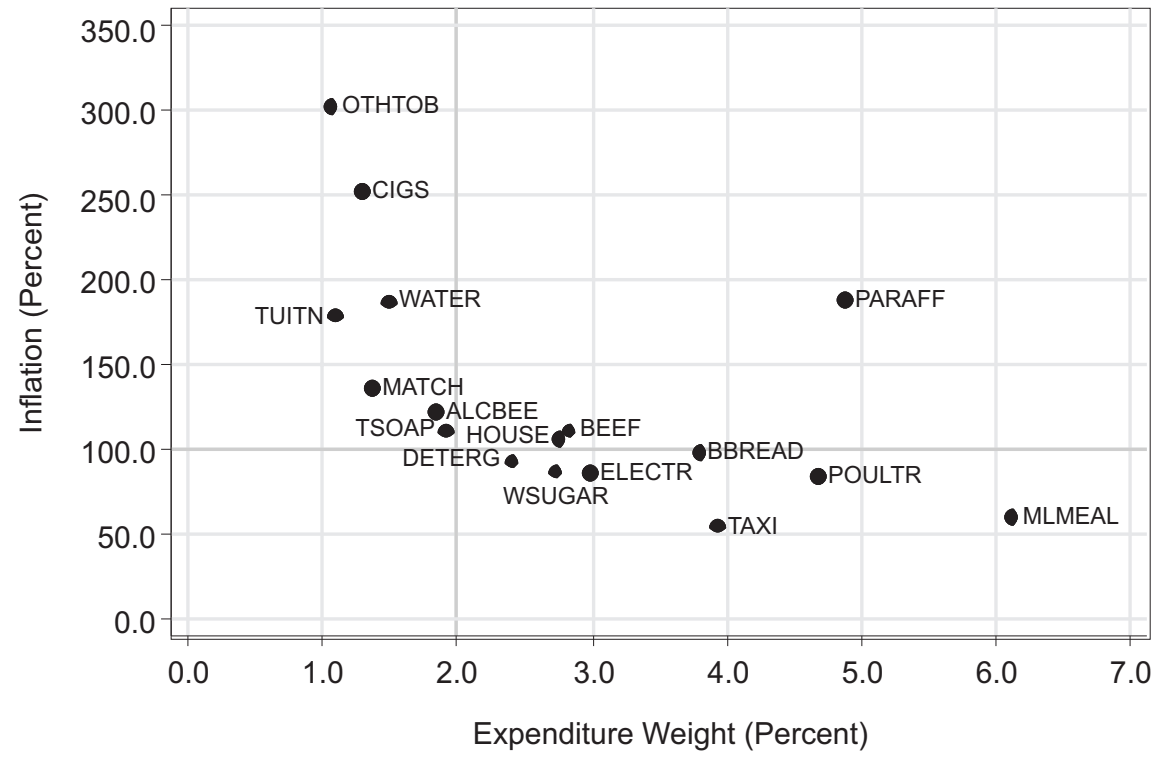

Source: Own calculations, IES 2000 (Statistics South Africa)

Note: Only items contributing 2.0 percent or more to total inflation over the period are included.

Households in decile two are exposed to inflation from generally similar sources compared to decile one households, although there are a greater number of strong inflation drivers accounting for upwards of 3.5 percent of inflation for decile two. Paraffin again accounts for the largest share of inflation, at 7.0 percent of the decile's 91.3 percent inflation between 1997 and 2006 and, although paraffin's dominance is evident in the figure, the difference between it and other items is not as marked as it is for decile one. Three other items account for more than 4.0 percent of total inflation for this group, namely brown and wholewheat bread (4.6 percent), 
water (4.6 percent) and poultry (4.3 percent). Decile two urban households are less exposed to inflation in key products such as paraffin, mealie meal and taxi and hired transport compared to decile one households, but more exposed to inflation in items such as water, cigarettes, electricity and white bread. Eight of the 15 items in the figure are classified as low inflation items and include two of the top five items, brown and wholewheat bread and poultry.

A broadly similar group of items is responsible for a large proportion of decile three inflation (Figure 12), although there are some important differences. The dominance of paraffin within overall inflation is declining due to the falling expenditure weight for this item as income increases, contributing 5.0 percent of the decile's inflation over the period. Cigarettes, brown and wholewheat bread, and poultry, however, remain important contributors to overall inflation for this decile, each item accounting for between 4.0 and 4.5 percent of inflation, while the prices of taxis and other hired transport are relatively more important drivers of inflation for this group. Decile three is also the lowest decile for which tuition and attendance fees account for more than 3.0 percent of inflation. This high inflation item has a relatively low expenditure weight, lower than any of the decile's main inflation drivers, with the weight being even lower amongst poorer households.

Figure 11: Main Contributors to Decile Two Inflation, 1997-2006

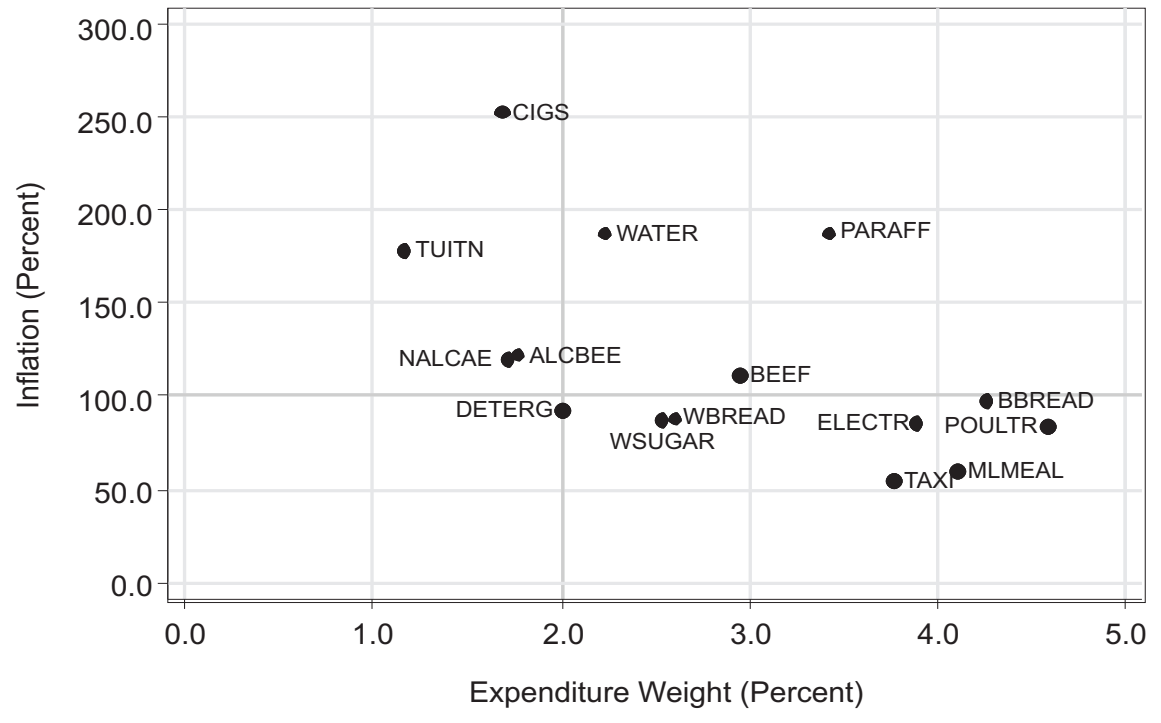

Source: $\quad$ Own calculations, IES 2000 (Statistics South Africa)

Note: Only items contributing 2.0 percent or more to total inflation over the period are included. 
Figure 12: Main Contributors to Decile Three Inflation, 1997-2006

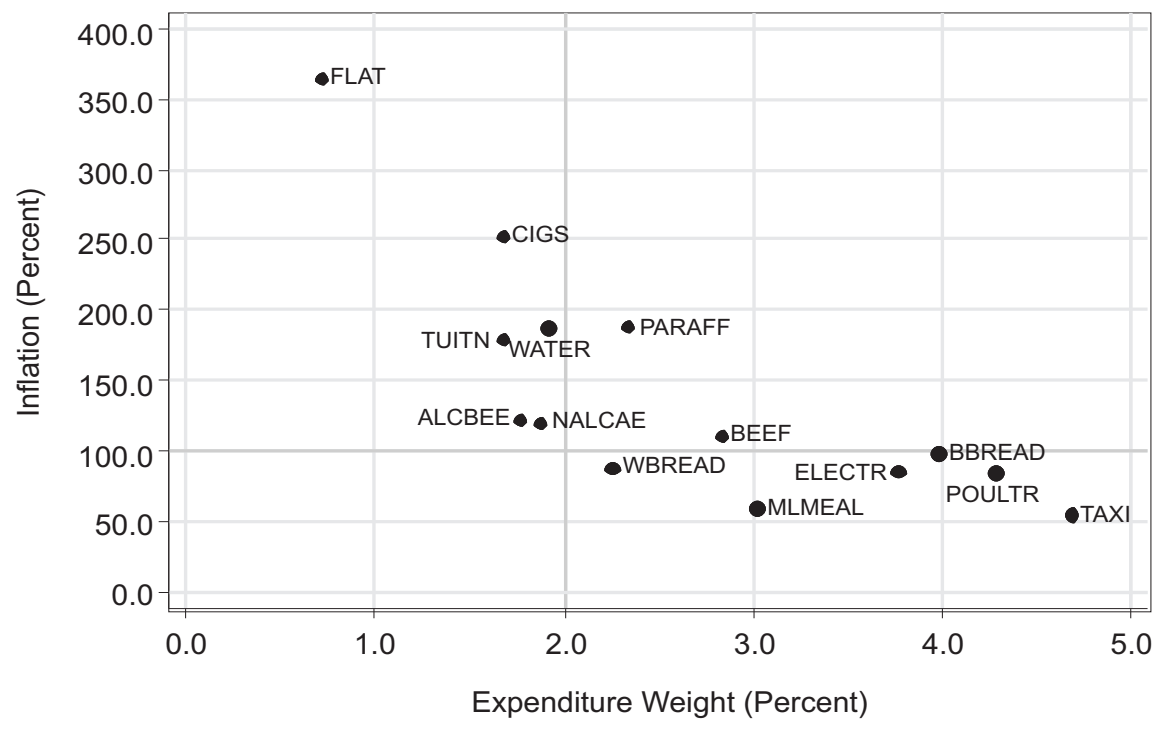

Source: Own calculations, IES 2000 (Statistics South Africa)

Note: Only items contributing 2.0 percent or more to total inflation over the period are included.

Decile four has a more even spread of importance across the top ten inflation drivers than is the case in most other deciles (Figure 13). Cigarettes contribute 5.8 percent of inflation - a contribution surpassed only in deciles five and six where cigarettes account for 6.2 percent and 5.8 percent of those deciles' inflation respectively. The two major household fuel sources, paraffin and electricity, each account for more than four percent of inflation. The former's large contribution stemming from its rapid price increases over the period, and the latter's from its relatively large expenditure weight. The seven remaining items in the top ten inflation drivers, namely poultry, water, brown and wholewheat bread, beef and veal, beer, taxi and hired transport and tuition and attendance fees, all account for between three and four percent of overall inflation. Apart from tuition and attendance fees and water, which are both low weighthigh inflation items, these items have relatively high weights and tend to range around and below 100 percent inflation mark for the period. 
Figure 13: Main Contributors to Decile Four Inflation, 1997-2006

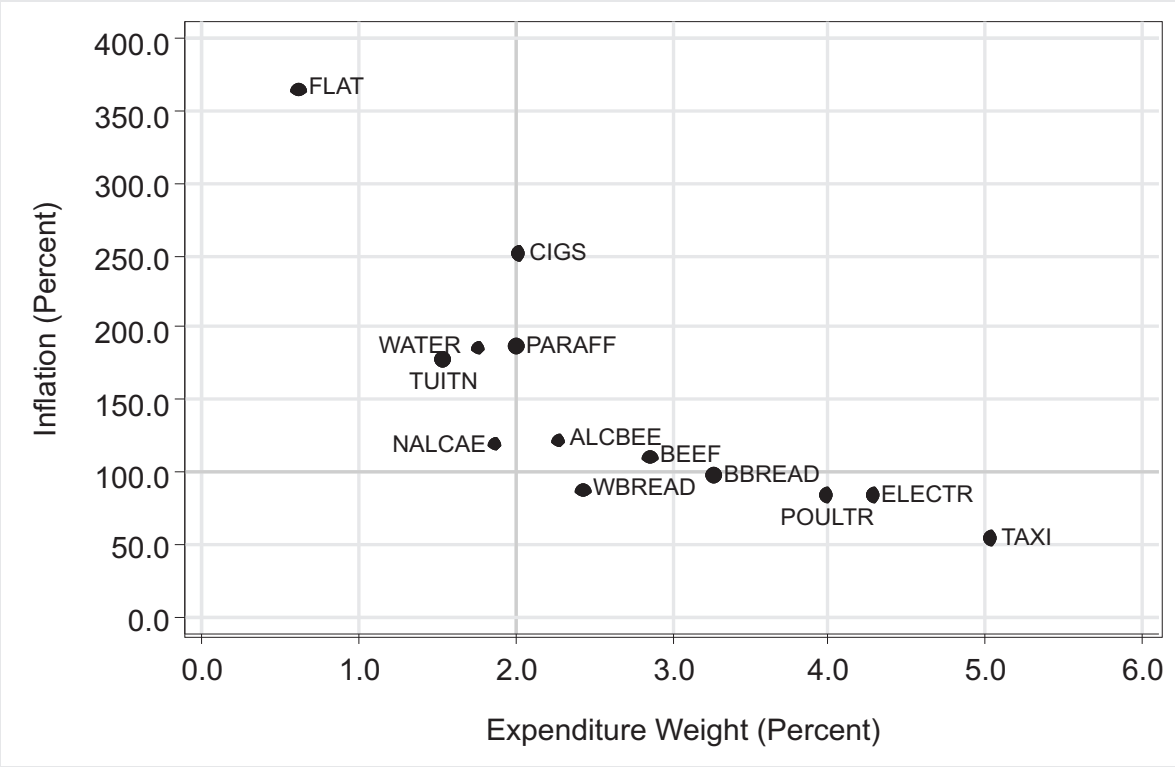

Source: Own calculations, IES 2000 (Statistics South Africa)

Note: Only items contributing 2.0 percent or more to total inflation over the period are included.

The contrast between the figures for deciles one through four and that of decile ten is stark. The top inflation driver amongst the richest ten percent of households is contributions to medical aid funds, which accounts for 11.1 percent of this group's inflation over the decade. This is followed by petrol and diesel ( 9.0 percent) and tuition and attendance fees (7.4 percent). These three items accounted for 25.9 percentage points of the decile's 94.1 percent inflation between 1997 and 2006. Interestingly, domestic workers, a high weight-high inflation item at the lower end of the high inflation range, accounted for 5.5 percent of decile ten inflation. The majority of items contributing more than two percent of inflation are related to housing. Townhouse, flat and house rent, insurance covering mortgage debt (MINSUR), housing repairs and maintenance (HREPAIR), water and assessment rates and taxes (RATES) accounted for over one-fifth (22.0 percent) of inflation, while electricity contributed a further 2.6 percent of inflation.

Two items, townhouse rent and new and used vehicles (VEHICL), clearly illustrate the ability of items to account for large shares of inflation despite either accounting for a small weight (townhouse rent) or having experienced relatively low rates of inflation (vehicles). Townhouse rent is a low weight-high inflation item, accounting for a mere 0.94 percent of decile ten expenditure. Yet, combined with price inflation of 522 percent over the decade, this item accounts for 5.2 percent of the decile's inflation. In contrast, the price index for new and used vehicles rose by a mere 39 percent over the period, barely two-fifths of the average inflation rate for urban households. However, its expenditure weight of 10.4 percent ensured that new 
and used vehicles accounted for 4.3 percent of inflation. The key difference between these two items, therefore, is that townhouse rent accounts for a far larger proportion of inflation than it does of expenditure (5.2 percent vs. 0.94 percent respectively), while the converse is true for new and used vehicles (4.3 percent vs. 10.4 percent respectively).

\section{Figure 14: Main Contributors to Decile Ten Inflation, 1997-2006}

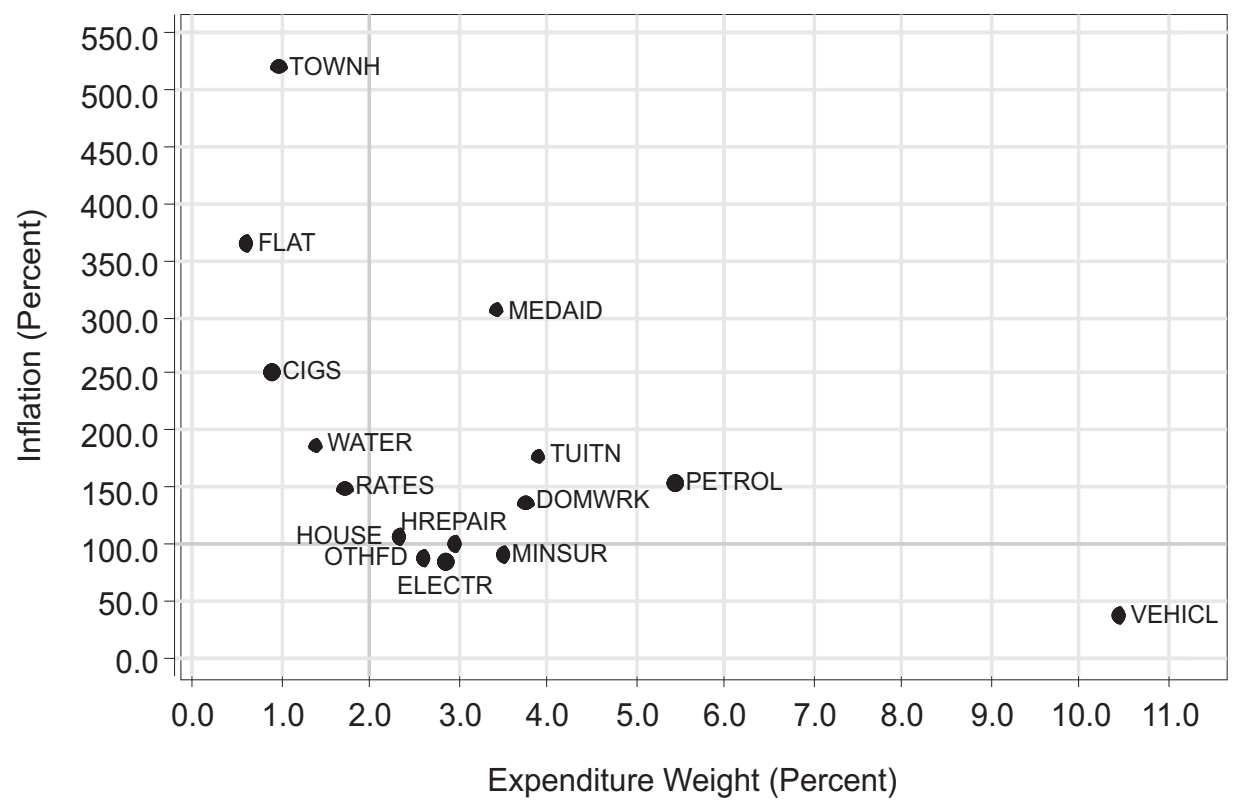

Source: Own calculations, IES 2000 (Statistics South Africa)

Note: Only items contributing 2.0 percent or more to total inflation over the period are included.

The differences in the inflation experiences of households clearly differ in terms of source. Although many items are major contributors to inflation in all the four poorest deciles and, as in the case of beef and veal, cigarettes, electricity, house rent, tuition and attendance fees, and water, sometimes in all deciles, the decile-specific weights determine the exact extent to which a change in price translates into an inflation share.

\subsubsection{The Changing Drivers of Inflation Across the Distribution between 1997 and 2006}

The overall picture presented in the previous section provides a sense of the items that were most important in driving inflation over the decade as a whole. However, the contributions of specific items vary over time, sometimes contributing substantially towards inflation for a group, sometimes contributing little towards inflation, and sometimes even contributing negatively to overall inflation. Thus, the analysis above is somewhat limited in its inability to reflect items' changing contributions to inflation at different points in time and in the fact that 
certain important contributors to inflation in a given sub-period may not be captured due to relative unimportance in other sub-periods.

This section aims to address this issue by shedding more light on the development of inflation over the decade, with particular emphasis on the poorest households. Figure 15 presents the contributions to overall inflation for deciles one, four, seven and ten made by the expenditure categories of food, housing, fuel and power and transport, represented by the stacked area graphs. If all expenditure items were to be graphed in this way, the uppermost boundary of the stacked area graphs would coincide with the path of overall inflation for the specific decile. However, since most items contribute relatively little to overall inflation, the figures in this section present only a selection of the most important. In Figure 15, the line graph represents the path of overall inflation for the four selected deciles, while the gap between it and the stacked area graphs represents the contribution to inflation made by those items that were not specifically included in the figure.

Food is clearly the dominant contributor to overall inflation in the lower expenditure groups, accounting for 33.4 percent of inflation for the average urban household and as much as 47.3 percent in decile two, but generally falling as total expenditure rises. It is only in decile eight that the contribution to overall inflation made by food is surpassed by any other expenditure category, in this case, housing. Averaging 3.0 percentage points of decile one inflation from January 1998 to June 2001, food inflation accounted for a rising proportion of inflation until September 2002, whereafter it declined. At its peak, food inflation accounted for three-quarters (11.7 percentage points) of the 15.6 percent inflation rate. Stated differently, had food prices remained constant between September 2001 and September 2002, inflation for decile one would have been just 3.9 percent instead of 15.6 percent. For the poorest deciles in particular, and even as high as decile seven, the source of the peaks in inflation in 1998, 2000, 2002 and 2006 is clearly food, with food responsible, in no small measure, for the very low rates of inflation towards the end of 2004. 
Figure 15: Contributions to Inflation by Main Expenditure Groups Across the Distribution, 19982006

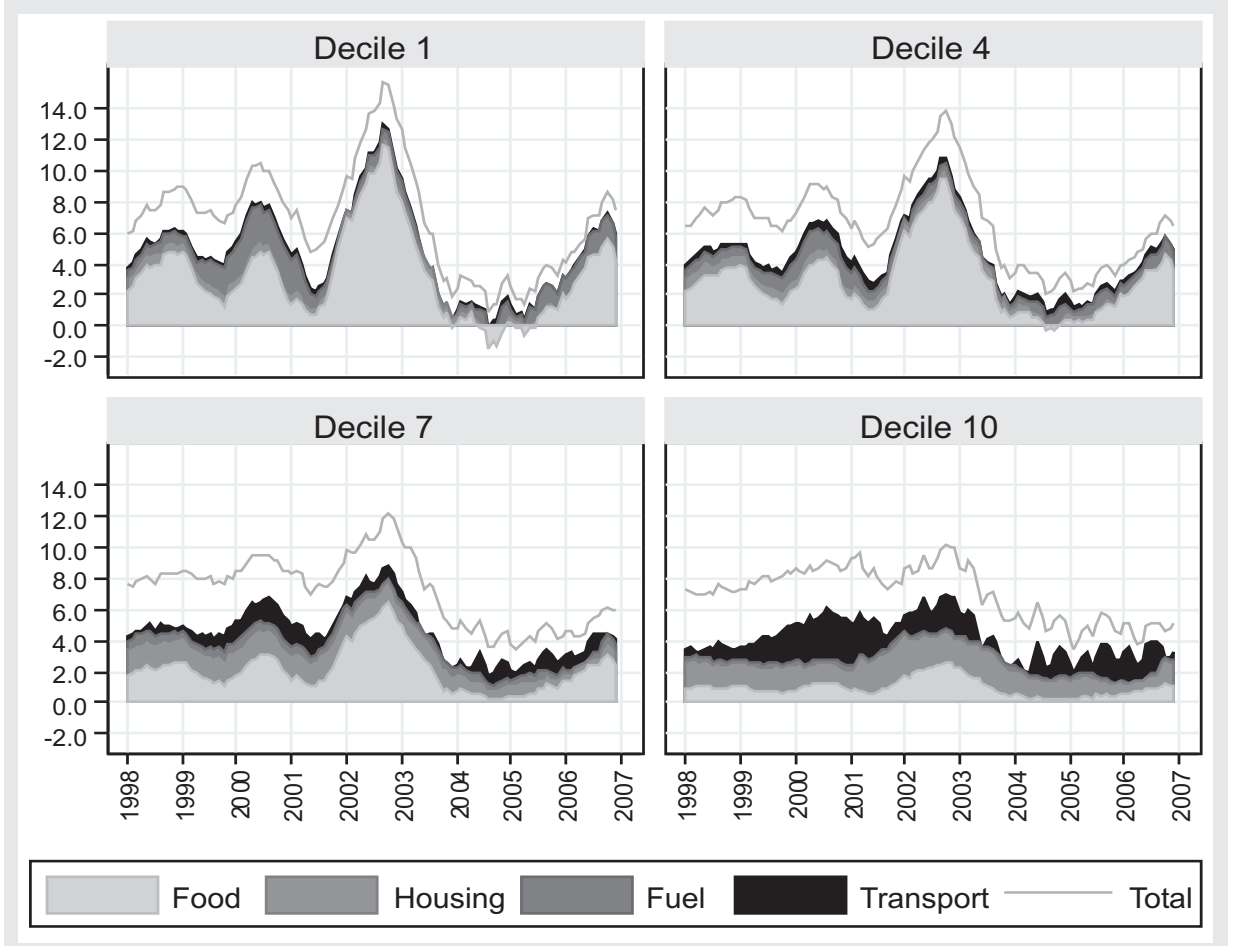

Source: Own calculations, IES 2000 (Statistics South Africa)

Housing, on the other hand, plays a particularly important role in driving inflation amongst higher expenditure groups. This expenditure category accounted for more than one quarter of inflation in decile eight over the period, falling slightly to 23.1 percent in decile ten, while accounting for just 9.7 percent of inflation in decile one. In decile ten, housing accounted for between 0.6 and 2.6 percentage points of inflation (May 2006 and January 2002 respectively), while in decile one it accounted for between 0.2 and 0.8 percentage points (June 2006 and May/June 1998 respectively). Interestingly, however, as will be shown below, high- and lowincome households are exposed to inflation from rather different sources in the housing category.

Household fuel, which includes electricity and paraffin, accounts for a substantial share of inflation for the poorest households (13.2 percent in decile one, compared to just 2.8 percent in decile ten). However, this contribution is not temporally stable, accruing during two specific periods namely between May 1999 and April 2001 (accounting for at least one percentage point of total decile one inflation in each month of that period), and between July 2005 and December 2006 (accounting for at least one percentage point of total decile one inflation in 11 of 18 months of that period, and averaging 1.1 percentage points). The contribution of fuel and power, however, declines relatively rapidly as expenditure rises, accounting for an average 
of just 0.2 percentage points, and never rising above 0.3 percentage points, of decile ten inflation.

Finally, transport-related items account for a relatively large proportion of inflation amongst better-off households, while also underlying to a large degree the volatility of inflation in the upper deciles. The relative contribution of transport expenditures to overall inflation is almost six times more in decile ten (at 17.8 percent of inflation) than it is in deciles one and two (at 3.0 percent of inflation). Transport inflation appears to have been most marked from 2000 to 2003 and again from mid-2004 onwards.

Thus, Figure 15 details four expenditure categories' contributions to inflation in four selected deciles. Two of these categories, namely food and household fuel and power, are particularly important for poor households, while transport and housing are more important for better-off households. Nevertheless, even within those expenditure categories that are relatively more important for inflation amongst wealthier deciles, there are some items that make significant contributions to inflation amongst the poor.

Within food, there are a number of expenditure categories, the most important of which in terms of their contribution to inflation being grain products, meat products, and vegetable products. These categories' contributions to food inflation are presented in the Appendix. As noted earlier, trends in food inflation underlie the movement of overall inflation amongst poorer deciles. However, by decile ten, the influence of food inflation on overall inflation is muted, only breaching the two percentage point level during the 2002/2003 inflation peak. For the average urban household, the bulk of food inflation between 1998 and 2006 is attributable to meat products, which account for 8.9 percent of overall inflation, followed by grain products at 7.4 percent. Relative to food inflation, meat and grain products account for 26.7 percent and 22.0 percent of inflation. However, from the perspective of poor households, grain products contributed relatively more. Between 1998 and 2006, grain products contributed 12.4 percent of total decile one inflation and 12.5 percent of decile two inflation, compared to 10.2 percent and 11.3 percent respectively accounted for by meat products. Figures 16 and 17 present the contributions of grain and meat products to food inflation in greater detail.

Grain products were the most important source of food inflation for poor households between 1998 and 2006, and changes in this category underlie some of the major trends in inflation for poorer households. Rising inflation amongst grain products occurred during three of the four spikes in the overall and food inflation rates. From June 1998 to March 1999, grain products contributed between 1.5 and 2.1 percentage points to total inflation monthly in decile one, while from March 2002 to March 2003 they contributed between 2.3 and 5.1 percentage points of inflation. Finally, in each month from July 2006 to the end of the period, grain products accounted for 1.6 to 2.3 percentage points of inflation. It is only during the inflation peak during 2000 that grain products did not experience particularly high rates of inflation. This pattern is 
also observed in decile four and, to a lesser extent, in decile seven. In decile ten, though, grain products contributed minimally to inflation and at no point over the period did it account for more than 0.5 percentage points of inflation.

Figure 16: Contributions to Grain Product Inflation Across the Distribution, 1998-2006

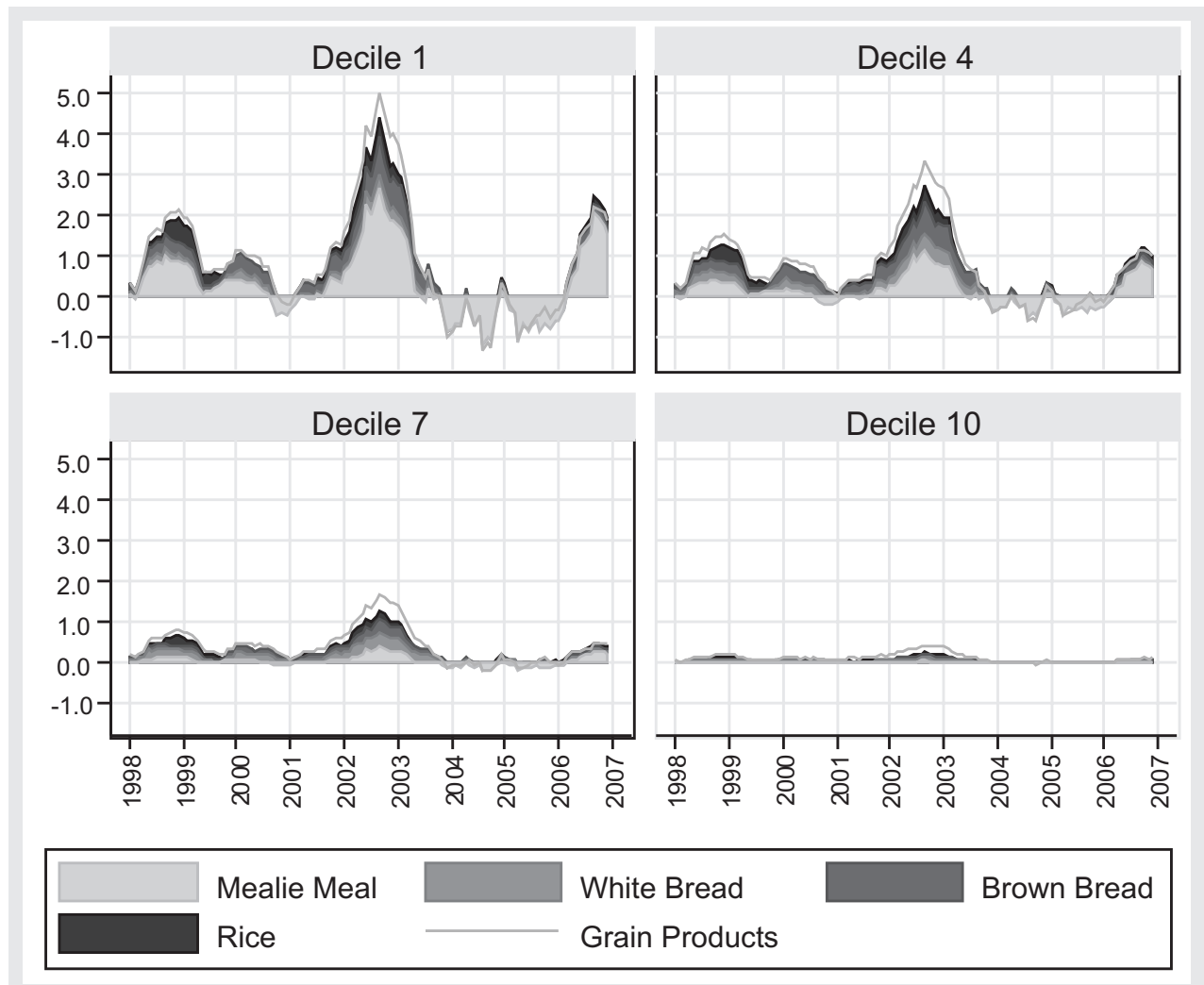

Source: $\quad$ Own calculations, IES 2000 (Statistics South Africa)

Within grain products, mealie meal is the dominant source of inflation for the poorest households, being largely responsible for the three main inflation spikes in decile one in 1998/9, 2002/3 and 2006. In the earliest of the three inflation spikes, mealie meal contributed up to one percentage point of the 2.0 percentage points of inflation contributed by all grain products, or more than one-fifth (21.9 percent) and more than one-tenth (11.6 percent) of decile one food and total inflation respectively. During the $2002 / 3$ inflation episode, mealie meal accounted for a peak of 2.6 percentage points of decile one inflation in September 2002, which is equivalent to 22.7 percent of food inflation and 16.9 percent of total inflation in that decile. Mealie meal's relative contribution to decile one inflation was even more pronounced in 2006, when in September it alone contributed 2.1 percentage points to inflation. This represents 40.5 percent of food inflation and 26.2 percent of total inflation in decile one. However, the contribution of mealie meal to inflation in other deciles is significantly lower due to this item's smaller weight in these deciles. Even at its peak in September 2002, mealie meal contributed 
only 1.1 percentage points to decile four inflation and just less than 0.4 percentage points in decile seven.

Between these four items, mealie meal, white bread, brown and wholewheat bread and rice, grain product inflation is almost fully accounted for. The inflation contributions from all four expenditure items were relatively closely synchronised, all tending to rise at the same time. This is unsurprising, particularly in the cases of white bread and brown and wholewheat bread, given that flour prices, an important cost component in the production of bread, would move closely with mealie meal prices. Rice inflation is likely to be linked to the Rand exchange rate given imports of rice to South Africa.

Meat products accounted for an average of 8.9 percent of total inflation for all urban households. Amongst poorer households, the share of inflation was highest at over 11.0 percentage points in deciles two through five, falling to just 4.1 percent in decile ten. The prices of meat products have tended to accelerate in line with those of grain products. The three main contributors to inflation within the meat products category are poultry, beef and veal, and mutton, lamb and goat, which together account for 6.8 percentage points of the category's share of total inflation for all urban households. Poultry and beef and veal account for very similar shares of average inflation (around 2.7 percent each), with poultry accounting for a particularly large share of inflation amongst the poorest households.

As noted above, meat inflation has tended to echo grain product inflation over the decade. This has been mainly due to surging beef and veal prices that coincided with rapid grain product inflation, since beef producers would, in all likelihood, be faced with price trends in cattle feed that mirror consumer prices of grain products. In instances where regional drought contributed to grain product inflation, such as in 2001 and 2002, beef production in the region is likely to have also been negatively impacted. Prior to December 2001, beef and veal accounted for between -0.2 and 0.4 percentage points of decile one inflation in each month, but ranged between 0.5 and 1.0 percentage points over the ensuing 15 month period. Following the subsequent fall in prices and low contribution to inflation, beef and veal again accounted for between 0.5 and 1.1 percentage points of inflation in decile one from March 2006 until the end of the period. The contribution of beef and veal to decile four inflation is virtually identical (only very marginally higher) due to the weights for this item in the two deciles being almost equal. By decile seven, the contribution of this expenditure item is somewhat lower, but not by a large margin, although in decile ten, beef and veal never contributed more than one-third of a percentage point to total inflation. 
Figure 17: Contributions to Meat Product Inflation across the Distribution, 1998-2006

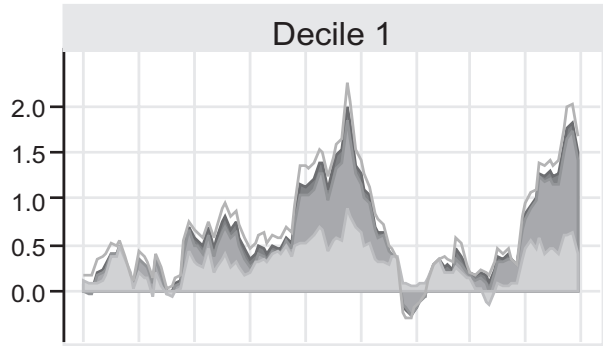

Decile 7

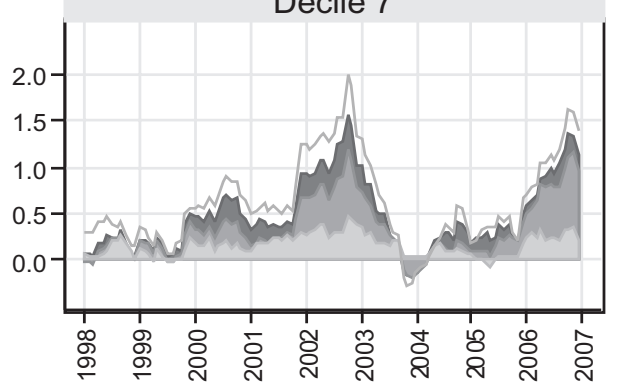

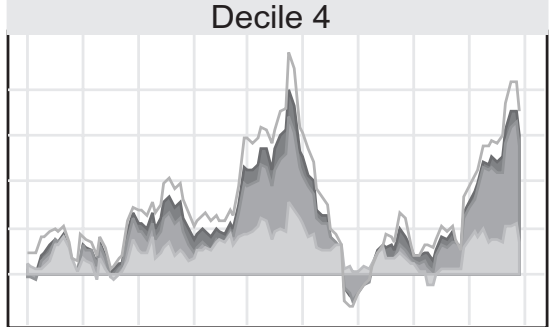

Decile 10

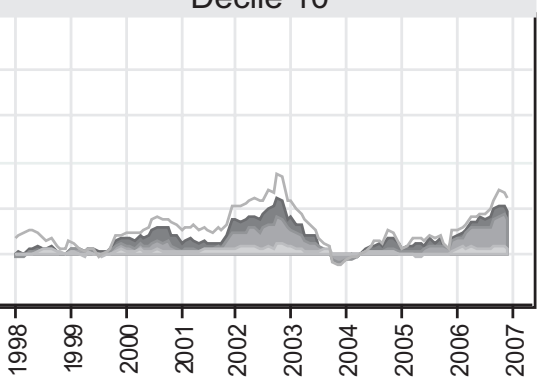

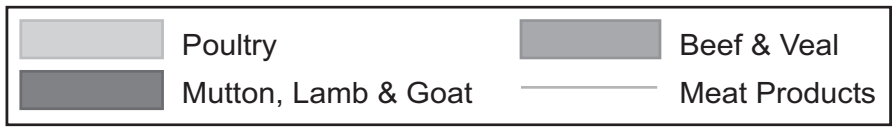

Source: $\quad$ Own calculations, IES 2000 (Statistics South Africa)

Poultry contributed to inflation more consistently over the period. Apart from low or negative contributions in 1999, late 2003 and 2005, poultry generally contributed between 0.3 and 0.7 percentage points to decile one inflation each month. Its contribution peaked at 0.9 percentage points in October 2002, during a twelve month period from February 2002 onwards in which poultry's contribution ranged between 0.5 and 0.9 percentage points, apart from one month. The lower expenditure weights for poultry in deciles four and seven resulted in slightly lower contributions to inflation in those deciles. By decile seven, poultry never contributed more than 0.5 percentage points of inflation and in the tenth decile, this statistic fell to less than 0.2 percentage points.

Finally, of the four deciles presented, mutton, lamb and goat made the largest contribution to inflation in decile seven, where its contribution peaked at just under 0.4 percentage points. Its contribution to inflation was relatively small during the first two years of the period, but increased substantially from January 2000 to June 2003. Apart from eight months in that period, during which it never fell below 0.1 percentage points, the contribution of mutton, lamb and goat to decile seven inflation ranged between 0.1 and 0.4 percentage points. Relatively speaking, however, this item accounted for 1.4 percent of average urban inflation, and more 
than 1.6 percent in deciles five through seven. In decile one, it accounted for 0.8 percent of inflation, compared to 1.0 percent in decile ten.

Housing accounts for a considerable proportion of inflation for households in the upper expenditure deciles, contributing at its peak 2.6 percentage points of inflation in decile ten in January 2002 (Figure 18). In contrast, housing contributed maxima of 1.8, 0.9 and 0.8 percentage points in deciles seven, four and one respectively. For poorer households, the main contributors to housing inflation are water and house rent, with flat rent contributing relatively more inflation in decile four than house rent.

Initially in decile one, water and house rent contributed relatively similarly to the decile's inflation, with house rent slightly more important. Water's importance declined slightly in mid2000 , followed by a decline in house rent's importance to zero by the end of 2001 . However, by mid-2003, house rent had once again grown in importance, contributing more than 0.4 percentage points of inflation monthly between July and October 2003. A similar pattern is observed for decile four, with water contributing slightly more to inflation (due to its larger expenditure weight relative to decile one) and house rent slightly less to inflation (due to its relatively smaller expenditure weight). At the same time, the contribution of flat rent to total inflation is considerably larger in decile four than in decile one, although it tapers off particularly after mid-2003. 
Figure 18: Contributions to Housing Inflation across the Distribution, 1998-2006

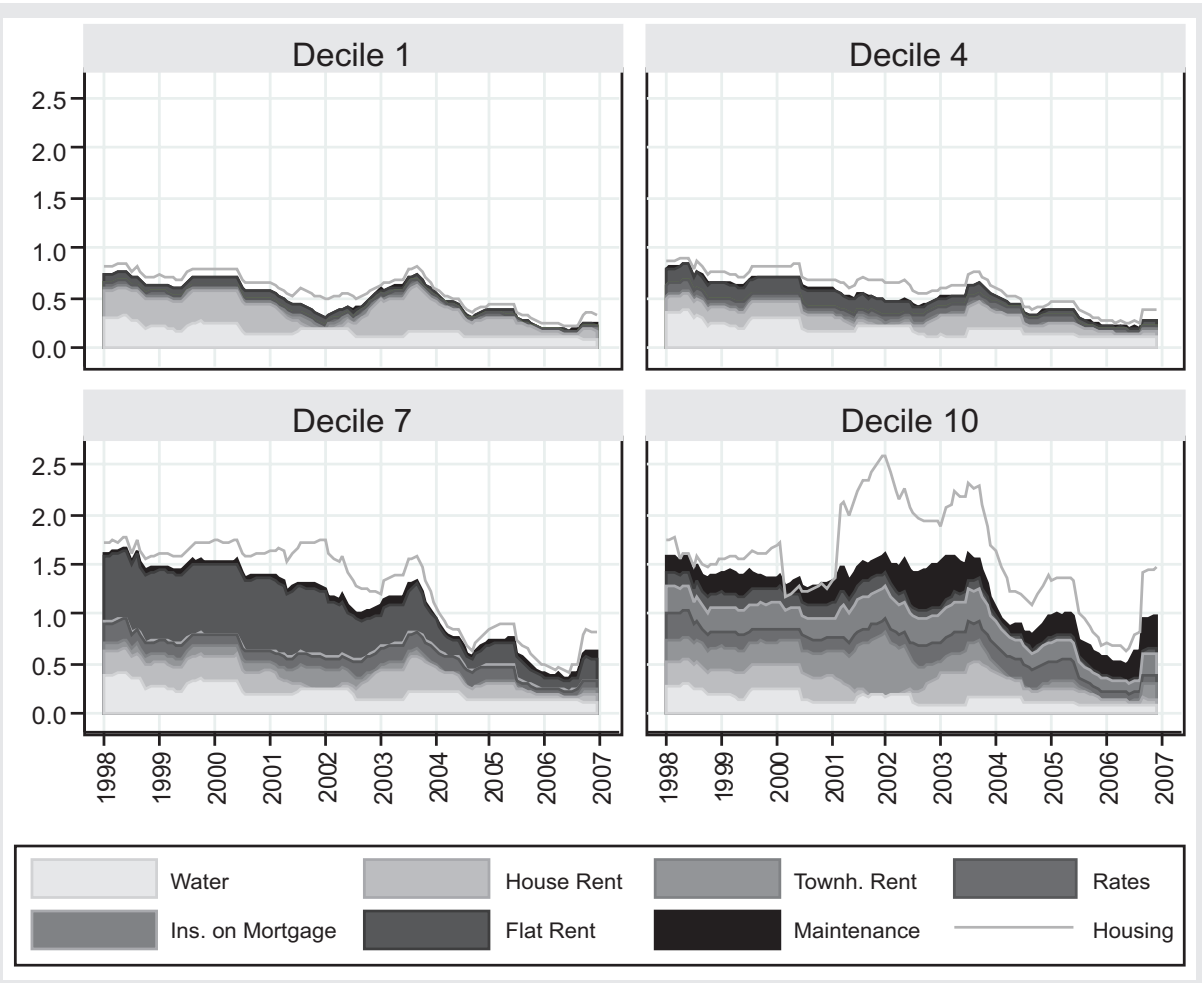

Source: $\quad$ Own calculations, IES 2000 (Statistics South Africa)

In absolute terms, the inflation contribution of housing in decile seven is significantly different from that of the poorer deciles and is driven largely by flat rent, with water making a slightly larger absolute contribution. From January 1998 to January 2002, flat rent contributed between 0.6 and 0.8 percentage points of inflation each month, its contribution diminishing slightly thereafter, but rising again to just under 0.5 percentage points in late 2003 . From January 2004 until the end of 2006, flat rent's contribution was somewhat smaller, averaging under 0.2 percentage points each month. In decile seven, assessment rates and taxes and townhouse rent also contribute somewhat to overall inflation, whereas in the lower two deciles these items' contributions were very small. This is also the first of the four deciles presented where the contribution to inflation of the graphed items diverges considerably from the total contribution from the housing expenditure category.

The composition of the overall contribution of housing to decile ten inflation is more diverse than it is in the other deciles, with all seven items contributing significantly to inflation. Townhouse rent, rates, insurance on mortgage debt and maintenance and repairs are all considerably larger contributors to inflation than in other deciles. Townhouse rent was particularly important in 2001 and the first half of 2002, contributing between 0.2 and 0.7 percentage points to decile ten inflation, but contributed little from 2004 onwards. Interestingly, 
its contribution to inflation is almost directly opposite to that of house rent, from the start of the period to the end of 2002: both were relatively stable until early 2001, whereafter townhouse rent's contribution to inflation climbed to 0.7 percentage points, while that of house rent fell to below zero in January 2002; the two items' contributions then moved back towards each other, townhouse rent falling to 0.1 percentage points and house rent moving back up to 0.3 percentage points. The two items then moved parallel to each other, falling from mid-2003 until mid-2006. This latter movement may have been related to the prevailing economic conditions at that time that were generally conducive to the purchase of homes, thereby resulting in a softening of the rental market, and which occurred simultaneously with falling flat rent inflation.

Assessment rates and taxes contributed between 0.1 and 0.3 percentage points of inflation each month in decile ten from 1998 to mid-2005, after which its contribution declined somewhat to under 0.1 percentage points. The contribution of water, while rising and falling cyclically, followed a downward trend, its contribution falling from a peak of 0.3 percentage points in June 1998 to under 0.1 percentage points by the end of 2006. The contribution of insurance on mortgage debt trends slowly downwards, apart from the period between March 2001 and October 2003, when it increased to between 0.2 and 0.4 percentage points in each month. The inflation contribution of house repairs and maintenance was quite unstable over the period, fluctuating quite widely. At its peak at the start of 2003 , it contributed 0.5 percentage points to inflation, but 13 months later contributed less than 0.1 percentage points. Overall, the contribution of repairs and maintenance to decile ten inflation followed a pattern broadly similar, although lagged by a couple of months, to the movements of average urban inflation.

Expenditures on household fuel and power, an expenditure category that includes paraffin and electricity, represent an important necessity for South African households. However, given the fact that they are necessities, their relative importance declines as expenditure levels rise and this results in the major differences in the contributions to total inflation across the distribution (Figure 19). Across all expenditure deciles, paraffin and electricity combined to account for virtually all of the inflation originating within this expenditure category. Paraffin was identified earlier as an important contributor to inflation for poorer deciles, accounting for 9.9 percent of decile one inflation, and its exact contribution over time is vividly displayed. From a relatively small contribution to the decile's inflation during 1998, paraffin prices soared in 1999, 2000 and early 2001. On its own, paraffin accounted for more than one percentage point of inflation in each month between May 1999 and March 2001 in decile one, and more than 1.7 percentage points between January and August 2000. Following a brief spell of declining paraffin prices in late 2001, paraffin accounted for a relatively small proportion of decile one inflation until mid2005 when its contribution ranged around 0.9 percentage points each month.

The steep drop in the importance of inflation is evident in the difference in the contributions of paraffin to inflation in deciles one and four. In the case of the latter, paraffin never accounted for more than one percentage point of inflation in any given month and in only 20 months out 
of 108 did it account for more than 0.5 percentage points. By decile seven, the contribution of paraffin to total inflation is negligible.

Figure 19: Contributions to Fuel and Power Inflation across the Distribution, 1998-2006

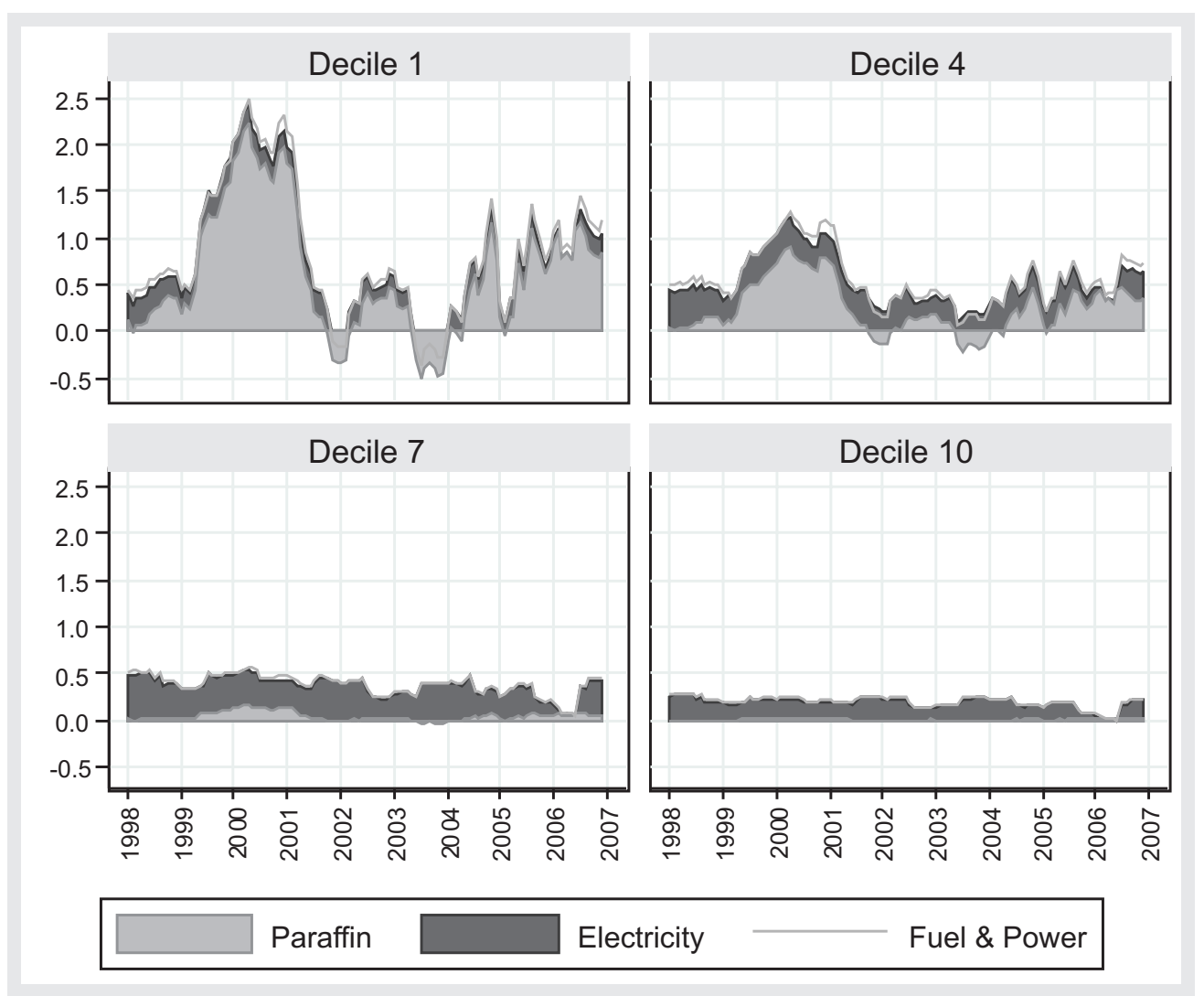

Source: $\quad$ Own calculations, IES 2000 (Statistics South Africa)

Poor households' relatively poor access to electricity (possibly combined with the effect of the free $50 \mathrm{kWh}$ allowance of electricity provided to households by Government) is illustrated in this item's relatively small contribution to inflation amongst the poorest households. By decile four, however, electricity makes a relatively significant contribution to both fuel and power inflation and overall inflation for the decile. However, even then, it does not account for more than 0.5 percentage points of inflation in any given month. In higher expenditure deciles household fuel and power inflation originates almost exclusively from electricity. In decile ten, in particular, electricity contributed 2.6 percentage points of the 2.8 percentage points (92 percent) of fuel and power inflation over the period.

The contrast across the deciles in terms of transport inflation is as stark as it is for fuel and power inflation, except that in this case, it is decile one households that are barely impacted (Figure 20). In the upper deciles, petrol and diesel is the major driver of inflation, with new and 
used vehicles also making a significant contribution to inflation. Petrol and diesel inflation is relatively unstable, fuel prices being determined by international prices and the Rand-Dollar exchange rate. The depreciation of the Rand in 2000 led to a spike in the inflation contribution of petrol and diesel from late 1999 to early 2001, while rising international oil prices led to a relatively large contribution from around mid-2004 onwards. This was experienced directly in decile ten particularly, but also in decile seven. However, by decile four the impact was minimal. Between October 1999 and March 2001, petrol and diesel accounted for between 1.0 and 2.0 percentage points of inflation for decile ten and between 0.6 and 1.1 percentage points of inflation in decile seven. Similarly, between May 2004 and August 2006, petrol and diesel contributed an average of 1.0 percentage points of inflation each month in decile ten and 0.6 percentage points in decile seven. In contrast, in decile four petrol and diesel never accounted for more than 0.2 percentage points of inflation in any given month.

Figure 20: Contributions to Transport Inflation across the Distribution, 1998-2006
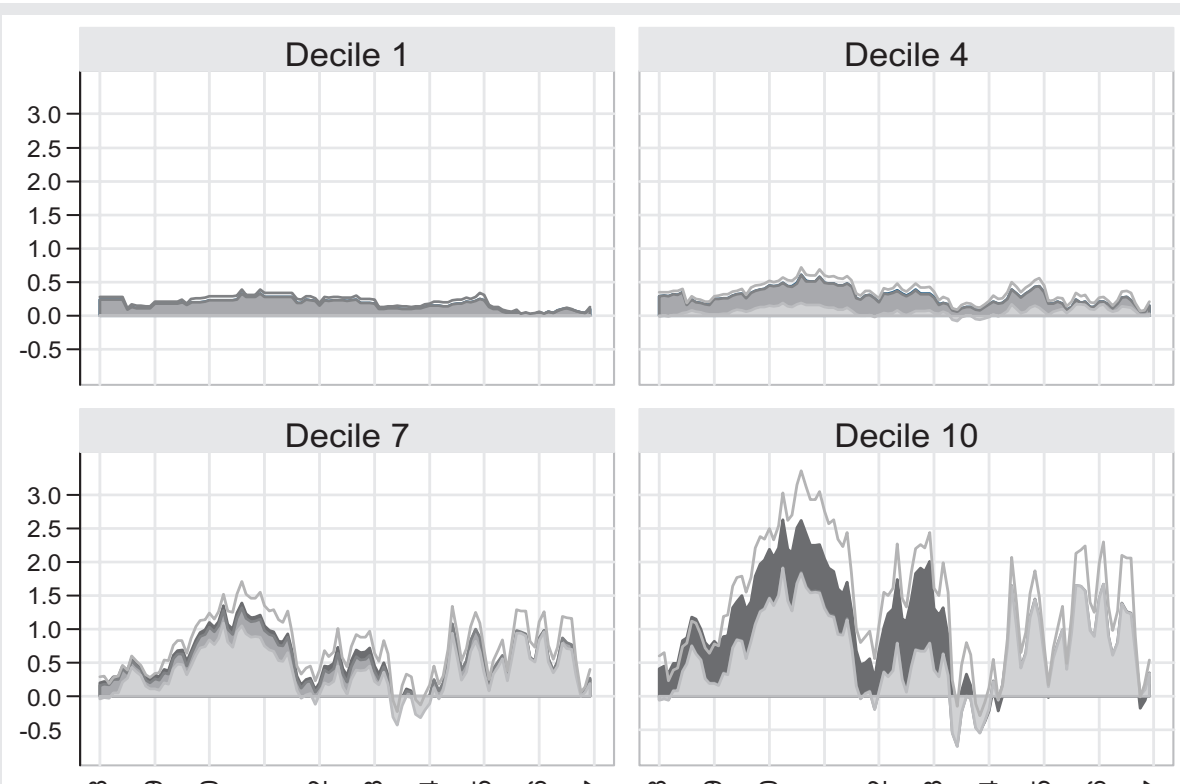

๙

\begin{tabular}{|l|lll|}
\hline & Petrol/Diesel & Taxi & Vehicles \\
\end{tabular}

Source: $\quad$ Own calculations, IES 2000 (Statistics South Africa)

Particularly up to early 2003, expenditure on new and used vehicles was an important driver of inflation for decile ten households. From January 1998 to June 2003, new and used vehicles accounted for between 0.3 and 1.3 percentage points of inflation each month for decile ten households, with inflation from this source being greatest in the second half of 2002 . Thereafter, however, this expenditure category contributed little to inflation, and actually turned negative from December 2003 until the end of the period. This expenditure item is almost 
uniquely important to decile ten, as it contributed no more than 0.4 percentage points of inflation to decile nine households in any month.

The only transport item that contributed a relatively significant proportion of inflation amongst the poorest deciles was taxi and hired transport. Amongst decile one households, taxi and hired transport accounted for 2.3 percent of inflation over the entire period. The contribution of this item rose to as much as 3.2 percent in decile four, but dropped to under one percent from decile eight upwards. However, taxi and hired transport never accounted for more than 0.4 percentage points of inflation in decile one in any given month and even in decile four its largest contribution to inflation was 0.4 percentage points.

Between food, housing, household fuel and power and transport, two-thirds (66.2 percent) of average urban inflation is accounted for. The four inflation peaks, particularly visible for lower expenditure deciles, are well explained by rapid increases in inflation of food products, specifically grain and meat products, and household fuel and power, of which paraffin is the most important for poorer households. Amongst the upper deciles, transport inflation was relatively more important, with petrol and diesel and new and used vehicles largest amongst these.

\subsubsection{Identifying Key Products Responsible for the Difference in Inflation For Poor Households Compared to Other Groups}

While the preceding analysis demonstrates the sources of inflation for poor households, it does not explain the differences between the inflation rates of poor households on the one hand and non-poor or wealthy households on the other hand. In his study of the US between 1976 and 1982, Hagemann (1982: 502) employs a procedure, developed by Bohdan Szulc (1980), that decomposes the difference between two price indices, obtained from different baskets of goods and services, and isolates those items that contribute towards widening or narrowing the gap between the two indices.

The total relative discrepancy $(R D)$ between two price indices in period $t, I_{t c}$ and $I_{t r}$, the comparison and reference indices respectively, using the same notation as above, equals

$$
\begin{aligned}
R D & =\left[\left(I_{t c}-I_{t r}\right) \div I_{t r}\right] \times 100 \\
& =\left[\left(\frac{\sum_{i=1}^{n} p_{j t} q_{j 0, c}}{\sum_{i=1}^{n} p_{j 0} q_{j 0, c}}-\frac{\sum_{i=1}^{n} p_{j t} q_{j 0, r}}{\sum_{i=1}^{n} p_{j 0} q_{j 0, r}}\right] \div \frac{\sum_{i=1}^{n} p_{j t} q_{j 0, r}}{\sum_{i=1}^{n} p_{j 0} q_{j 0, r}}\right] \times 100
\end{aligned}
$$


Thus, the relative discrepancy is decomposable, per expenditure item, into two components: "the relative differences between the rates of price change of each commodity and the average rate of change, and ... the relative differences in the weights of each commodity in the two market baskets" (Hagemann 1982: 503). Assuming that prices are similar in both baskets, the above can be shown to equal

$$
R D=\sum_{i=1}^{n}\left[\frac{I_{i, t}}{I_{t r}}-1\right] \cdot\left[\frac{w_{i c}}{w_{i r}}-1\right] \cdot\left[w_{i r} \cdot 100\right]
$$

where $I_{i, t}$ is price index for expenditure item $i$ in period $t$, and $w_{i c}$ and $w_{i r}$ are the expenditure weights of item $i$ in the comparison and reference group baskets respectively.

The relative discrepancy, or the gap between the price indices for two groups, can be widened and narrowed in two ways respectively. The relative discrepancy can be widened if the weight of a high inflation item in the comparison group basket is higher than the weight of that item in the reference group basket. The relative discrepancy can also be widened if the weight of a low inflation item in the comparison group basket is lower than the weight of that item in the reference group basket. Simply stated, the gap between the price indices of one group and another can be widened if the former group is over-exposed to high inflation items or under-exposed to low inflation items compared to the latter. The relative discrepancy can be narrowed if the weight of a high (low) inflation item in the comparison group basket is lower (higher) than the weight of that item in the reference group basket. In other words, the gap between the price indices of one group and another can be narrowed if the former group is over-exposed to low inflation items or under-exposed to high inflation items compared to the latter.

By the end of 2006, the price indices for decile one households and for all urban households were 192.5 and 195.2 respectively. Thus, the relative discrepancy was -1.378 percent. Table 6 presents the items responsible for the largest shares of the relative discrepancy. The table differentiates between those items that served to widen the gap in the inflation rates - the upper left and lower right quadrants - and those that served to narrow the gap - the upper right and lower left quadrants.

As noted earlier, paraffin is an important driver of inflation for poor households, and the relative discrepancy decomposition reveals it as the expenditure item that contributes most to widening the gap between the inflation rate of decile one households and that of the average urban household. This is due to decile one households' relative over-exposure to paraffin, which is a high inflation product. Other tobacco products and matches and candles widen the gap in the same way. In contrast, insurance of buildings, for example, serves to widen the gap between decile one households and the average urban household due to the former's relative underexposure to this low inflation item. Other items in this group tend to be luxuries - vehicles, computers and telecommunications equipment, holiday accommodation - and furniture and 
appliances - televisions, bedroom furniture, fridges. The 14 items listed here serve to increase the relative discrepancy by 5.4 percentage points.

The size of the relative discrepancy between decile one households and the average urban household is decreased by the relative under-exposure of the poorest households to a number of high inflation items. Flat rent narrows the relative discrepancy by 1.5 percentage points, while medical aid contributions narrow it by slightly less than 1.5 percentage points. Various housing-related expenditures, such as townhouse rent, domestic workers, assessment rates and taxes and water, all serve to narrow the gap between the inflation rates of decile one households and the average urban household. Interestingly, despite the fact that cigarettes are identified as an important inflation driver for decile one households, these households are relatively under-exposed to this high inflation item and it therefore helps reduce the relative discrepancy. Similarly, mealie meal helped reduce the relative discrepancy, but this was due to decile one households being relatively over-exposed to what was shown above to be a relatively low inflation item. The same is true of three other food items - rice, potatoes and bread flour - as well as taxi and hired transport.

Table 6: Source of the Difference in Inflation between Decile One and All Urban Households

\begin{tabular}{|c|c|c|c|}
\hline & \multicolumn{2}{|c|}{ Price Increase of Item Relative to OverallInflation for All Urban Households } \\
\hline & & Higher & Lower \\
\hline 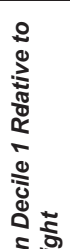 & 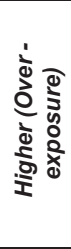 & $\begin{array}{l}\text { Widening the Gap between Decile } 1 \text { \& Overall } \\
\text { Paraffin }(+1.594) \\
\text { Other tobacco products }(+0.809) \\
\text { Matches and candles }(+0.203)\end{array}$ & $\begin{array}{l}\text { Narrowing the Gap between Decile } 1 \text { \& Overall } \\
\text { Mealie meal }(-0.714) \\
\text { Rice }(-0.199) \\
\text { Skin creams and preparations }(-0.162) \\
\text { Taxi and hired transport }(-0.155) \\
\text { Toothpaste and toothbrushes }(-0.123) \\
\text { Potatoes }(-0.103) \\
\text { Bread flour }(-0.102)\end{array}$ \\
\hline 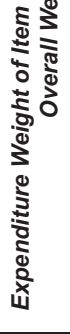 & 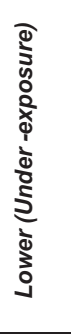 & $\begin{array}{l}\text { Narrowing the Gap between Decile } 1 \text { \& Overall } \\
\text { Flat rent }(-1.517) \\
\text { Contributions to medical aid funds }(-1.461) \\
\text { Petrol and diesel }(-0.709) \\
\text { Tuition and attendance fees }(-0.608) \\
\text { Townhouse rent }(-0.520) \\
\text { Cigarettes }(-0.329) \\
\text { Domestic workers }(-0.239) \\
\text { Assessment rates and taxes }(-0.230) \\
\text { Water }(-0.191) \\
\text { Medical insurance }(-0.161)\end{array}$ & $\begin{array}{l}\text { Widening the Gap between Decile } 1 \text { \& Overall } \\
\text { Insurance of buildings }(+0.663) \\
\text { New and used vehicles }(+0.489) \\
\text { Mens clothing }(+0.382) \\
\text { Computers \& telecomm. equipment }(+0.269) \\
\text { Televisions }(+0.187) \\
\text { Mens shoes }(+0.181) \\
\text { Bedroom furniture }(+0.180) \\
\text { Levy (sectional titles etc) }(+0.125) \\
\text { Fridges }(+0.109) \\
\text { Radios, tape recorders, CDs }(+0.105) \\
\text { Boarding }\end{array}$ \\
\hline
\end{tabular}

Source: Own calculations, IES 2000 (Statistics South Africa)

Decile ten experienced 94.1 percent inflation between 1997 and 2006, compared to 92.5 percent for decile one. The relative discrepancy between the price indices of these two groups was, therefore, 0.827 percent. Table 6 presents the main items responsible for this difference. Paraffin is, interestingly, not the most important item contributing to a widening of the gap between the indices of the two groups. At 2.3 percentage points, it is surpassed by building insurance (3.5 percentage points) and new and used vehicles (3.0 percentage points). The latter two items, however, widen the gap because decile one households are under-exposed to their low price increases over the period. Decile one households are over-exposed to items 
such as other tobacco products, cigarettes, beer and beef and veal, which are high inflation items.

A number of items serve to narrow the gap between the inflation rates of deciles one and ten. Decile one households' low level of contributions to medical aid funds, a high inflation item, reduces the relative discrepancy by 3.7 percentage points. Other high inflation items to which poor households are underexposed and which reduce the relative discrepancy most are townhouse rent (reducing the relative discrepancy by 1.8 percentage points), petrol and diesel (1.7 percentage points) and tuition and attendance fees (1.2 percentage points). Other high inflation items to which poor households are under-exposed are luxury items in that betteroff households spend relatively more on them, such as domestic workers, housing-related expenditures, and vehicle maintenance expenditures.

\section{Table 7: Source of the Difference in Inflation between Decile One and Decile Ten Households}

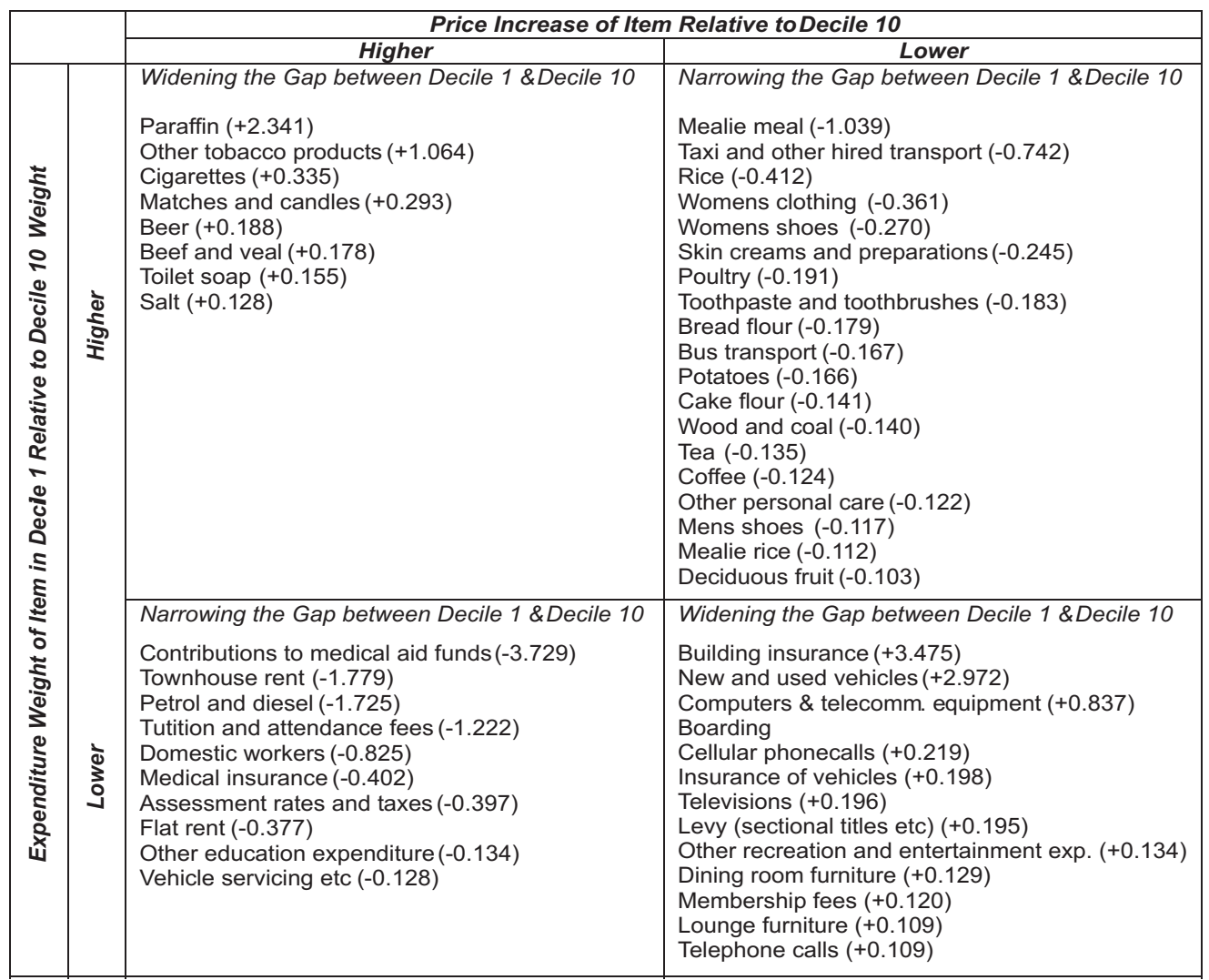

Source: Own calculations, IES 2000 (Statistics South Africa)

In the instance of mealie meal, the relative discrepancy is reduced by the fact that decile one households are relatively over-exposed to this relatively low inflation item. Thus, mealie meal reduced the relative discrepancy by 1.0 percentage points. The majority of items in this quadrant are necessities, such as food, clothing, and public transport. In terms of food 
items, rice, poultry and bread flour make the largest contributions to reducing the relative discrepancy between these two income groups, reducing it by $0.4,0.2$ and 0.2 percentage points respectively. In terms of public transport expenditures, taxi and other hired transport reduced the relative discrepancy by 0.7 percentage points over the period, while bus transport contributed to narrowing the gap by 0.2 percentage points.

This type of analysis provides a clearer understanding of the plight of poor households in terms of inflation that a pure inflation driver analysis can and does not. Paraffin emerged earlier as a key driver of inflation for poor households and this analysis confirms that it widens the gap between the aggregate price indices for decile one relative to the average urban household and relative to decile ten households. However, the same is not true for mealie meal. Mealie meal was identified as an important inflation driver, but actually contributes to a reduction in the relative discrepancy because, over the period, prices increased by less than the overall rate of inflation. Similarly, poultry is classified as an inflation driver for poor household, yet does not contribute significantly to the relative discrepancy between decile one households and the average urban household, and narrows the relative discrepancy between decile one and decile ten households.

This analysis also points again to the potential threats to poor households based on their relative over-exposure to certain items. Since inflation dynamics may change over time, low inflation items may become high inflation items in the future. Thus, amongst the items to which poor households are overexposed, may switch from the low inflation to the high inflation quadrant. A key example of this, demonstrable for the 2001-2003 sub-period, is mealie meal. For the overall period, mealie meal has contributed towards narrowing the gap between the price indices of deciles one and ten respectively by 1.0 percentage points, between 2001 and 2003 , it would have contributed substantially to a widening of the gap. 


\section{Conclusion}

Poor households' welfare levels depend crucially on two things: their incomes, be they in the form of wages, remittances or social grants, and the prices they face. The fact that households at different income or expenditure levels have different spending patterns leads to two important conclusions. Firstly, different households may face different prices because they purchase the various items in their baskets from different sources, such as supermarkets, convenience stores, or informal (street) traders. Secondly, different households devote varying proportions of their spending to given items, making them relatively more or less exposed to price changes in specific expenditure categories. Even assuming away the difference in actual prices, variation in spending patterns results in varying inflation rates across the expenditure distribution.

This paper has investigated the differences in the inflation rates between households at varying points of the expenditure distribution, and identified some of the important items responsible for inflation amongst the poor between 1997 and 2006. Some important conclusions can be drawn from the analysis.

The conventionally calculated, plutocratic weight structure does not reflect the 'average' household as is commonly believed. Being related to the level of inequality within a given society, the plutocratic weights calculated above most closely reflect the spending patterns of households in the $95^{\text {th }}$ percentile of the expenditure distribution. As a result, price indices and inflation rates calculated on the basis of these weights can not accurately reflect the rates of inflation experienced by what would be viewed as the 'average' household.

This study concurs with the majority of the literature surveyed in that neither rich nor poor households are found to have experienced rates of inflation consistently higher or lower than average, with the plutocratic gap shifting from positive values to negative values (or vice versa) seven times between January 1998 and December 2006. The preceding sections have shown that the inflation rate calculated using conventional plutocratic weights does not differ substantially over longer periods of time from the democratically weighted inflation rate. However, over shorter time periods, the difference between the two inflation rates can be significant, indicating a marked divergence in the rates of inflation experienced by households at different points of the income distribution. Although the official CPI in South Africa is, like those in other countries, unable to accurately reflect the rates of inflation experienced by households of different income levels at all points in time, it is not suggested that the current methodology be abandoned in favour of a democratically weighted consumer price index, for example. Official price indices play an important role in macroeconomic policymaking, with the official $\mathrm{CPI}$ providing an accurate reflection of economy-wide inflation. Plutocratic inflation rates are biased towards the expenditures of wealthier households, but this bias is in line with 
the overall structure of consumer spending. As such, it would be irresponsible to abandon conventional CPIs in favour of democratic alternatives.

What is clear, however, is that the purpose for which a price index or inflation rate is used should determine the type of weighting structure employed. In the case of monitoring economywide consumer price inflation, the price index should reflect the structure of economy-wide consumer spending. In contrast, where the price index is to be used for adjusting state welfare benefits, or merely for the monitoring of the rate of inflation experienced by the poor, the price index should reflect price changes that are relevant to poorer households. As Ley (2005: 644) notes, there "is a crucial tradeoff between the simplicity of the current prevailing one-size-fits-all approach and the conceptual superiority of a piecemeal-menu approach to index numbers ... [and the] best resolution may well vary in different places and at different times". Further, it is acknowledged that democratic weights are just one of numerous possible weighting structures that would result in a price index that more accurately reflects the experience of poorer households. "One way of overcoming [the bias of plutocratic weights] is to proceed according to the democratic calculation ... another would be to use the median method. Clearly, there must be many other methods that may be suggested. Any choice among them will depend on assessing the balance of political considerations (What sort of wage negotiations is the index to be used for? Can more than one index numbers be tolerated without confusion?) and that of numerical feasibility (Is a more complicated calculation worth the extra cost?)" (Prais, 1959: 131).

An item can make a significant contribution to a given group's inflation via two routes: either the item's price must rise rapidly relative to average inflation, or the item must have a large weight relative to other items in the expenditure basket. In instances where items both have a large expenditure weight and experienced relatively high inflation, the contribution to inflation will be even larger. Thus, although electricity was found to be an important driver of inflation for the average urban household, this was more a result of a very large expenditure weight, since the price of electricity rose less than the average rate of inflation. Over the period as a whole, for poorer deciles, the same was true of mealie meal, poultry, and taxi and hired transport. Cigarettes, tuition and attendance fees, water and beef and veal, in contrast, tended to be inflation drivers because of their very high rates of price increase. This distinction has an important implication for policymaking that attempts to mitigate the experience of inflation amongst poor households. In the case of high-weight low-price increase drivers of inflation, policy should perhaps be targeted at changing spending patterns in order to reduce households' vulnerability to inflation from this source, rather than focussing on reducing the rate at which the price of the item increases. Conversely, for low-weight high-price increase drivers of inflation, appropriate policy might focus on lowering the rate of price increases rather than attempting to change spending patterns.

Inflation amongst poor households over the period was concentrated in three main expenditure categories, namely food, housing and household fuel and power. Within these, the major 
culprits are easily identifiable: mealie meal and brown and wholewheat bread, poultry and beef and veal, water and house rent, and paraffin and electricity. These eight items accounted for 34.5 percent of decile one inflation and 26.9 percent of decile four inflation and were responsible in large part for the acceleration of inflation during the four inflation peaks over the period. This demonstrates the vulnerability of poor households to inflation deriving from necessities, but also highlights the fact that a targeted response to accelerating inflation may have a significant impact. Thus, during the high inflation episode of 2002/3, Government's policy of subsidising mealie meal would have helped dampen the impact on poor households.

While unarguably monetary policy decisions should be based on the conventional consumer price index or, in the case of South Africa, CPIX, monetary policy that aims to be sensitive to the plight of the poor needs to be informed by alternative measures of inflation that more accurately reflect the experiences of poor households. The publishing by Statistics South Africa of expenditure quintile inflation rates is an important step in this regard and serves to create greater awareness of the different experiences of inflation across the income distribution. It is hoped that this paper will contribute to this better understanding of the varying experiences of inflation. 


\section{REFERENCES}

Amble, N. and Stewart, K. (1994), "Experimental Price Index for Elderly Consumers", Monthly Labor Review 117(5): 11-16.

Artsev, Y., Roshal, V. and Finkel, Y. (2006), Consumer Price Indices - Measuring Across Households. Paper presented at Nineth Ottawa Group Meeting on Prices, 14-16 May 2006, London, United Kingdom, Available (online): http://www.statistics.gov.uk/ events/ottawa_group/downloads/Session7.2.pdf. Accessed: 21 December 2006.

Bennett, M. (2006), Personal communications. Statistics South Africa, 23 August.

Bhorat, H. and Oosthuizen, M. (2003), The Differential Impact of Inflation on Poor South African Households. Unpublished research report for South African Reserve Bank. Development Policy Research Unit, Cape Town.

Crawford, I. and Smith, Z. (2002), "Distributional Aspects of Inflation". The Institute for Fiscal Studies Commentary, No. 90. Available (online): http://www.ifs.org.uk/comms/ comm90.pdf. Accessed: 15 January 2007.

Deaton, A. (1998), "Getting Prices Right: What Should Be Done?" Journal of Economic Perspectives 12(1): 37-46.

Garner, T. I., Johnson, D. S. and Kokoski, M. F. (1996), "An Experimental Consumer Price Index for the Poor", Monthly Labor Review 119(9): 32-42.

Hagemann, R. P. (1982), "The Variability of Inflation Rates Across Household Types", Journal of Money, Credit and Banking 14(4): 494-510.

Hobijn, B. and Lagakos, D. (2005), "Inflation Inequality in the United States", Review of Income and Wealth 51(4): 581-606.

Hollister, R. G. and Palmer, J. L. (1972), "The Impact of Inflation on the Poor", in Boulding, K. E. and Pfaff, M., eds. Redistribution to the Rich and the Poor. California: Wadsworth Publishing Company, pp. 240-270.

Hoogeveen, J. G. and Ozler, B. (2006), "Poverty and Inequality in Post-Apartheid South Africa: 1995-2000", in Bhorat, H. and Kanbur, R., eds. Poverty and Policy in Post-Apartheid South Africa. Cape Town: HSRC Press, pp. 59-94.

Idson, T. and Miller, C. (1999), "Calculating a Price Index for Families with Children: Implications for Measuring Trends in Child Poverty", Review of Income and Wealth 45(2): 217-234. Available (online): http://www.roiw.org/1999.asp. Accessed: 24 January 2007.

International Labour Organisation (2004), Consumer Price Index Manual: Theory and Practice. Available (online): http://www.ilo.org/public/english/bureau/stat/guides/cpi/index.htm. Accessed: 11 January 2007.

Izquierdo, M., Ley, E. and Ruiz-Castillo, J. (2003), "The Plutocratic Gap in the CPI: Evidence from Spain”. IMF Staff Papers Vol. 50, No. 1. Available (online): http://www.imf.org/ external/pubs/ft/staffp/2003/01/PDF/lzqui.pdf. Accessed: 21 December 2006. 
Kahn, B. (1985), "The Effects of Inflation on the Poor in South Africa". Economic Learning Resources Series, No. 5. School of Economics, University of Cape Town.

Kokoski, M. (2000), “Alternative CPI Aggregations: Two Approaches”, Monthly Labor Review 123(11): 31-39.

Ley, E. (2005), "Whose Inflation? A Characterization of the CPI Plutocratic Gap", Oxford Economic Papers 47(4): 634-646.

Lieu, P.-T., Chang, C. and Chang, J.-r. (2004), "Inflation Rate Variations Across Household: Empirical Evidence from Taiwan", International Journal of Business 9(1): 103-124. Available (online): http://papers.ssrn.com/sol3/papers.cfm?abstract_id=490457. Accessed: 11 January 2007.

McGranahan, L. and Paulson, A. (2006), "Constructing the Chicago Fed Income Based Economic Index - Consumer Price Index: Inflation Experiences by Demographic Group: 1983-2005”. Federal Reserve Bank of Chicago Working Paper, No. 200520. Available (online): http://www.chicagofed.org/economic_research_and_data/ publication_display.cfm?Publication=6\&year=2000\%20AND\%202005. Accessed: 25 January 2007.

McKay, A. and Sowa, N. K. (2004), Does Inflation in Ghana Hit the Poor Harder? (preliminary draft). Available (online): http://www.isser.org/Inflation\%20\&\%20Ghanaian\%20Poor. pdf. Accessed: 21 December 2006.

Michael, R. T. (1979), "Variation Across Households in the Rate of Inflation", Journal of Money, Credit and Banking 11(1): 32-46.

Moulton, B. R. and Stewart, K. J. (1999), "An Overview of Experimental US Consumer Price Indexes", Journal of Business and Economic Statistics 17(2): 141-151. Available (online): http://links.jstor.org/sici?sici=0735-0015\%28199904\%2917\%3A2\%3C141\% 3AAOOEUC\%3E2.0.CO\%3B2-\%23. Accessed: 25 January 2007.

Murphy, E. and Garvey, E. (2004), "A Consumer Price Index for Low-Income Households in Ireland (1989-2001)". Combat Poverty Agency Working Paper, No. 04/03. Available (online): http://www.cpa.ie/publications/workingpapers.htm. Accessed: 11 January 2007.

Ozler, B. (2006), Not Separate, Not Equal: Poverty and Inequality in Post-Apartheid South Africa. The World Bank. Unpublished paper.

Prais, S. J. (1959), "Whose Cost of Living?” The Review of Economic Studies 26(2): 126-134.

Simkins, C. (2004), What Happened to the Distribution of Income in South Africa Between 1995 and 2001? University of the Witwatersrand. Unpublished paper. Available (online): http://www.sarpn.org.za/documents/d0001062/index.php. Accessed: 7 March 2007.

South African Reserve Bank, 2002. Quarterly Bulletin. No. 226, December. Available (online): http://www.reservebank.co.za/. Accessed: 5 March 2007.

South African Reserve Bank (2007), Quarterly Bulletin - Historic Macroeconomic Information. 
Database available (online): http://www.reservebank.co.za. Accessed: 1 June 2007.

Statistics South Africa (2002a), "Consumer Price Index (CPI): 2000 Weights (Historical metropolitan and other urban areas)." Statistical Release P0141.5. Available (online): http://www.statssa.gov.za/publications/statsdownload.asp?ppn=P0141.5\&SCH=148 4. Accessed: 11 January 2007.

Statistics South Africa (2002b), Income and Expenditure Survey 2000. Dataset.

Statistics South Africa (2007), "Consumer Price Index (CPI) - Rural Areas and Total Country (December 2006)". Statistical Release P0141.2. Available (online): http://www.statssa. gov.za. Accessed: 25 January 2007.

Taktek, N. (1998), "Comparative Study of Analytical Consumer Price Indexes (CPI) for Different Subgroups of the Reference Population". Analytical Series, No. 13. Statistics Canada. Available (online): http://www.statcan.ca/cgi-bin/downpub/listpub.cgi?catno=62F0014 MIB1998013. Accessed: 11 January 2007.

United Nations Development Programme (2003), South Africa Human Development Report. Cape Town: Oxford University Press.

Van der Berg, S., Burger, R., Burger, R., Louw, M. and Yu, D. (2006), "Trends in Poverty and Inequality since the Political Transition". Development Policy Research Unit Working Paper, No. 06/104. Available (online): http://www.commerce.uct.ac.za/Research_ Units/DPRU/WorkingPapers/wpapers.asp. Accessed: 5 March 2007.

Vermaak, C. (2005), Trends in Income Distribution, Inequality and Poverty in South Africa, 1995 to 2003. Paper presented at Economic Society of South Africa Conference, Durban, 7-9 September. Available (online): http://www.essa.org.za/download/papers2005. htm. Accessed: 5 March 2007. 


\section{Appendix A}

Table A-1: Democratic Expenditure Weights Across Deciles, Metropolitan and Other Urban Areas, 2000

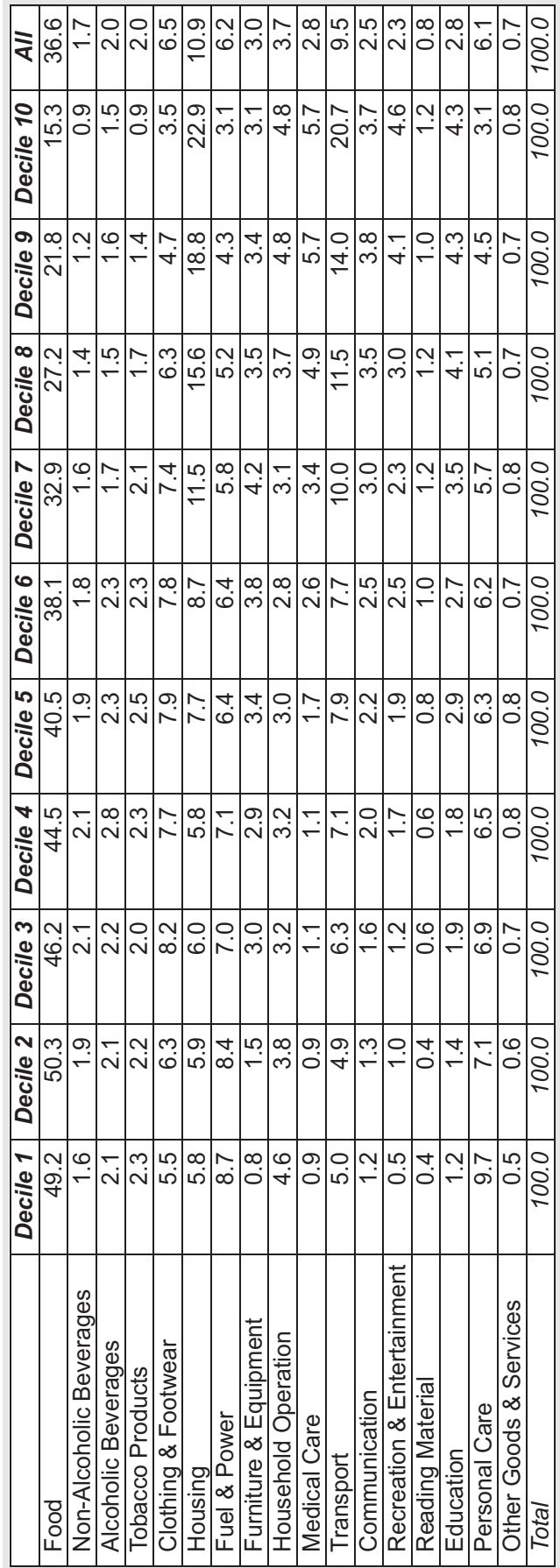

Source: Own calculations, IES 2000 (Statistics South Africa) 


\section{Appendix B}

Figure B-1: Contributions to Food Inflation Across the Distribution, 1998-2006
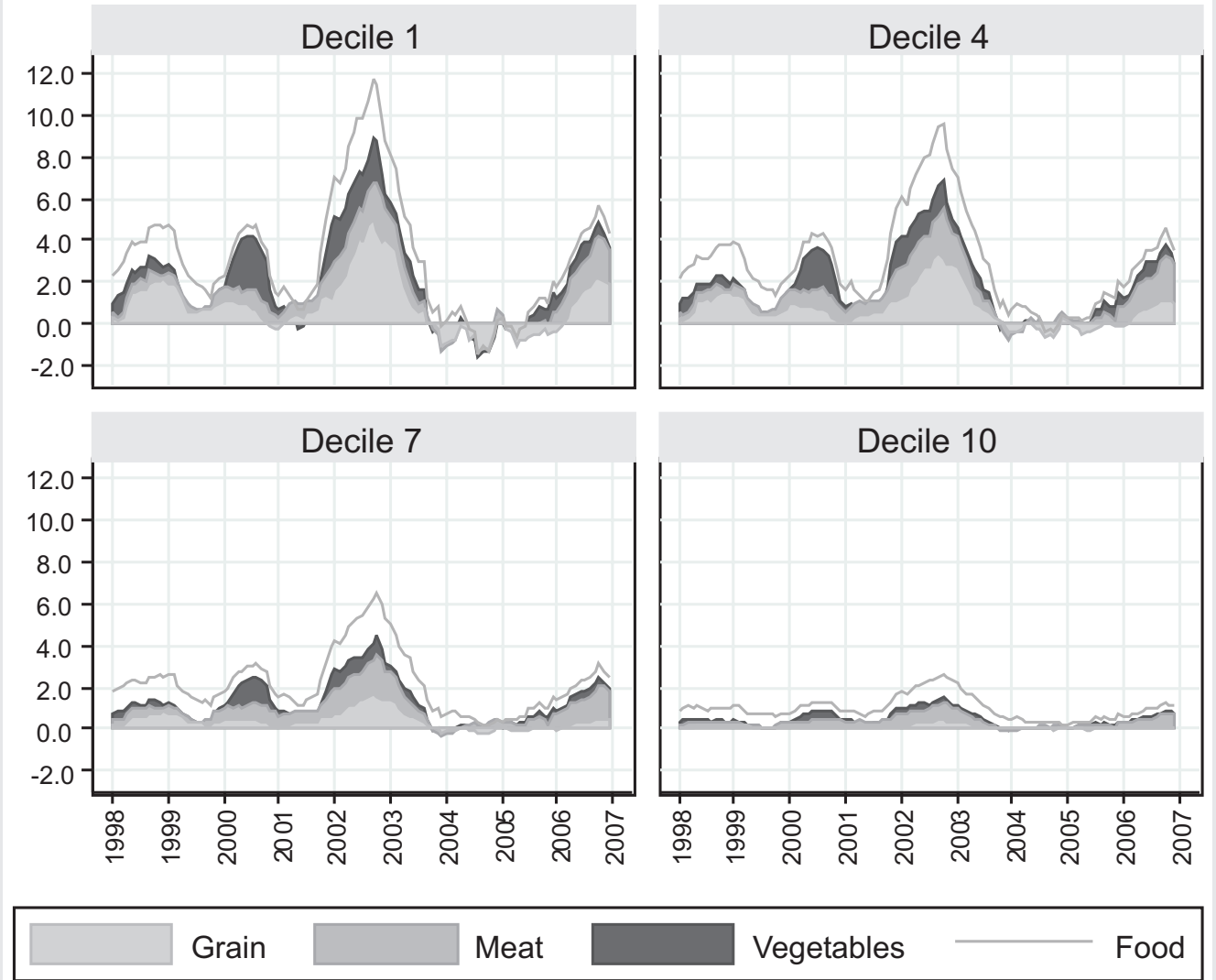

Source: $\quad$ Own calculations, IES 2000 (Statistics South Africa) 


\section{Appendix C}

Table C-1 - Decile-Specific Democratic Price Indices, 1997-2006

\begin{tabular}{|c|c|c|c|c|c|c|c|c|c|c|c|}
\hline & All & Dec 1 & Dec 2 & Dec 3 & $\operatorname{Dec} 4$ & Dec 5 & Dec 6 & Dec 7 & $\operatorname{Dec} 8$ & $\operatorname{Dec} 9$ & Dec 10 \\
\hline Jan-97 & 76.60 & 77.20 & 77.54 & 78.12 & 78.05 & 77.34 & 76.61 & 75.74 & 74.26 & 74.84 & 76.57 \\
\hline Feb-97 & 76.86 & 77.32 & 77.70 & 78.33 & 78.30 & 77.59 & 76.89 & 76.03 & 74.59 & 75.17 & 76.91 \\
\hline Mar-97 & 77.42 & 77.78 & 78.17 & 78.83 & 78.82 & 78.17 & 77.46 & 76.62 & 75.21 & 75.78 & 77.57 \\
\hline Apr-97 & 78.27 & 78.33 & 78.76 & 79.43 & 79.43 & 78.83 & 78.28 & 77.56 & 76.32 & 77.03 & 78.91 \\
\hline May-97 & 78.52 & 78.57 & 79.00 & 79.67 & 79.68 & 79.09 & 78.54 & 77.84 & 76.60 & 77.29 & 79.11 \\
\hline Jun-97 & 78.90 & 79.10 & 79.49 & 80.14 & 80.12 & 79.48 & 78.93 & 78.19 & 76.90 & 77.53 & 79.28 \\
\hline Jul-97 & 79.76 & 79.66 & 80.24 & 80.94 & 80.94 & 80.39 & 79.93 & 79.17 & 77.91 & 78.46 & 80.14 \\
\hline Aug-97 & 79.76 & 79.66 & 80.24 & 80.94 & 80.94 & 80.39 & 79.93 & 79.17 & 77.91 & 78.46 & 80.14 \\
\hline Sep-97 & 80.29 & 80.09 & 80.68 & 81.38 & 81.43 & 80.90 & 80.48 & 79.76 & 78.54 & 79.07 & 80.72 \\
\hline Oct-97 & 80.78 & 80.61 & 81.22 & 81.90 & 81.94 & 81.40 & 80.99 & 80.24 & 79.01 & 79.50 & 81.10 \\
\hline Nov-97 & 81.01 & 80.82 & 81.43 & 82.10 & 82.13 & 81.61 & 81.20 & 80.49 & 79.29 & 79.79 & 81.35 \\
\hline Dec-97 & 81.34 & 81.20 & 81.78 & 82.44 & 82.46 & 81.95 & 81.53 & 80.83 & 79.64 & 80.12 & 81.62 \\
\hline Jan-98 & 82.00 & 81.85 & 82.44 & 83.10 & 83.13 & 82.61 & 82.22 & 81.52 & 80.33 & 80.77 & 82.19 \\
\hline Feb-98 & 82.24 & 82.07 & 82.69 & 83.33 & 83.39 & 82.85 & 82.47 & 81.75 & 80.58 & 81.00 & 82.43 \\
\hline Mar-98 & 83.07 & 83.01 & 83.60 & 84.24 & 84.29 & 83.77 & 83.36 & 82.58 & 81.37 & 81.67 & 82.99 \\
\hline Apr-98 & 84.14 & 83.93 & 84.46 & 85.07 & 85.13 & 84.67 & 84.38 & 83.73 & 82.71 & 83.09 & 84.39 \\
\hline May-98 & 84.65 & 84.64 & 85.15 & 85.67 & 85.70 & 85.18 & 84.89 & 84.20 & 83.13 & 83.45 & 84.67 \\
\hline Jun-98 & 84.97 & 84.97 & 85.45 & 85.97 & 85.99 & 85.49 & 85.18 & 84.52 & 83.48 & 83.80 & 84.98 \\
\hline Jul-98 & 85.70 & 85.59 & 86.16 & 86.63 & 86.64 & 86.21 & 85.95 & 85.29 & 84.34 & 84.62 & 85.73 \\
\hline Aug-98 & 86.15 & 85.89 & 86.50 & 87.00 & 87.04 & 86.65 & 86.42 & 85.80 & 84.89 & 85.19 & 86.25 \\
\hline Sep-98 & 86.89 & 86.98 & 87.46 & 87.90 & 87.86 & 87.41 & 87.12 & 86.44 & 85.47 & 85.69 & 86.73 \\
\hline Oct-98 & 87.42 & 87.65 & 88.13 & 88.53 & 88.46 & 87.96 & 87.66 & 86.93 & 85.92 & 86.07 & 87.03 \\
\hline Nov-98 & 87.71 & 87.97 & 88.48 & 88.87 & 88.78 & 88.26 & 87.97 & 87.21 & 86.19 & 86.27 & 87.22 \\
\hline Dec-98 & 88.15 & 88.52 & 88.95 & 89.32 & 89.24 & 88.72 & 88.44 & 87.65 & 86.61 & 86.64 & 87.51 \\
\hline Jan-99 & 88.91 & 89.15 & 89.64 & 90.07 & 90.03 & 89.51 & 89.27 & 88.47 & 87.42 & 87.41 & 88.24 \\
\hline Feb-99 & 89.10 & 89.28 & 89.78 & 90.22 & 90.21 & 89.69 & 89.47 & 88.69 & 87.68 & 87.67 & 88.48 \\
\hline Mar-99 & 89.83 & 89.70 & 90.22 & 90.73 & 90.78 & 90.43 & 90.20 & 89.54 & 88.65 & 88.66 & 89.49 \\
\hline Apr-99 & 90.50 & 89.98 & 90.47 & 91.01 & 91.09 & 90.86 & 90.82 & 90.38 & 89.74 & 89.90 & 90.81 \\
\hline May-99 & 91.07 & 90.73 & 91.09 & 91.52 & 91.58 & 91.36 & 91.27 & 90.91 & 90.35 & 90.56 & 91.42 \\
\hline Jun-99 & 91.49 & 91.17 & 91.40 & 91.82 & 91.90 & 91.72 & 91.65 & 91.36 & 90.88 & 91.14 & 91.93 \\
\hline Jul-99 & 92.33 & 91.92 & 92.26 & 92.59 & 92.65 & 92.54 & 92.54 & 92.23 & 91.82 & 92.02 & 92.73 \\
\hline Aug-99 & 92.49 & 91.92 & 92.30 & 92.67 & 92.73 & 92.66 & 92.71 & 92.45 & 92.08 & 92.30 & 93.03 \\
\hline Sep-99 & 93.25 & 92.89 & 93.13 & 93.44 & 93.50 & 93.42 & 93.43 & 93.20 & 92.83 & 93.04 & 93.64 \\
\hline Oct-99 & 93.72 & 93.40 & 93.58 & 93.85 & 93.90 & 93.84 & 93.84 & 93.66 & 93.34 & 93.60 & 94.22 \\
\hline Nov-99 & 94.47 & 94.29 & 94.52 & 94.74 & 94.76 & 94.65 & 94.61 & 94.37 & 93.98 & 94.15 & 94.67 \\
\hline Dec-99 & 94.88 & 94.91 & 95.12 & 95.28 & 95.28 & 95.10 & 95.00 & 94.69 & 94.27 & 94.39 & 94.84 \\
\hline Jan-00 & 96.11 & 96.10 & 96.39 & 96.57 & 96.58 & 96.38 & 96.29 & 95.96 & 95.47 & 95.50 & 95.88 \\
\hline Feb-00 & 96.47 & 96.62 & 96.88 & 97.00 & 97.02 & 96.76 & 96.67 & 96.28 & 95.77 & 95.73 & 96.05 \\
\hline Mar-00 & 97.82 & 98.13 & 98.28 & 98.34 & 98.38 & 98.21 & 98.02 & 97.67 & 97.21 & 96.99 & 97.03 \\
\hline Apr-00 & 99.12 & 99.26 & 99.32 & 99.35 & 99.36 & 99.28 & 99.17 & 99.04 & 98.84 & 98.78 & 98.80 \\
\hline May-00 & 99.65 & 100.10 & 99.98 & 99.93 & 99.91 & 99.76 & 99.64 & 99.49 & 99.30 & 99.22 & 99.22 \\
\hline Jun-00 & 100.20 & 100.65 & 100.48 & 100.38 & 100.35 & 100.21 & 100.12 & 100.05 & 99.95 & 99.90 & 99.90 \\
\hline Jul-00 & 101.01 & 101.06 & 101.01 & 100.91 & 100.89 & 100.93 & 100.94 & 100.99 & 101.12 & 101.14 & 101.08 \\
\hline Aug-00 & 101.28 & 101.16 & 101.13 & 101.08 & 101.04 & 101.13 & 101.19 & 101.33 & 101.54 & 101.61 & 101.55 \\
\hline Sep-00 & 101.67 & 101.38 & 101.35 & 101.35 & 101.32 & 101.48 & 101.61 & 101.82 & 102.11 & 102.18 & 102.05 \\
\hline Oct-00 & 102.04 & 101.68 & 101.64 & 101.62 & 101.62 & 101.82 & 101.96 & 102.23 & 102.60 & 102.67 & 102.51 \\
\hline Nov-00 & 102.22 & 101.85 & 101.73 & 101.68 & 101.69 & 101.93 & 102.09 & 102.44 & 102.90 & 103.00 & 102.84 \\
\hline Dec-00 & 102.43 & 102.01 & 101.82 & 101.80 & 101.85 & 102.12 & 102.31 & 102.69 & 103.19 & 103.27 & 103.10 \\
\hline Jan-01 & 103.59 & 102.80 & 102.61 & 102.60 & 102.68 & 103.01 & 103.47 & 104.02 & 104.76 & 104.95 & 104.83 \\
\hline Feb-01 & 104.22 & 103.75 & 103.54 & 103.50 & 103.54 & 103.74 & 104.17 & 104.56 & 105.19 & 105.18 & 104.97 \\
\hline Mar-01 & 105.30 & 104.31 & 104.24 & 104.32 & 104.43 & 104.79 & 105.24 & 105.79 & 106.60 & 106.66 & 106.49 \\
\hline Apr-01 & 105.97 & 104.81 & 104.75 & 104.84 & 104.98 & 105.37 & 105.86 & 106.51 & 107.44 & 107.55 & 107.38 \\
\hline May-01 & 105.97 & 104.81 & 104.75 & 104.84 & 104.98 & 105.37 & 105.86 & 106.51 & 107.44 & 107.55 & 107.38 \\
\hline Jun-01 & 106.92 & 105.54 & 105.41 & 105.54 & 105.68 & 106.19 & 106.77 & 107.61 & 108.76 & 108.88 & 108.59 \\
\hline Jul-01 & 107.87 & 106.23 & 106.33 & 106.44 & 106.57 & 107.15 & 107.86 & 108.67 & 109.90 & 109.86 & 109.43 \\
\hline Aug-01 & 108.17 & 106.71 & 106.90 & 106.99 & 107.06 & 107.52 & 108.27 & 108.93 & 110.06 & 109.79 & 109.28 \\
\hline Sep-01 & 108.70 & 107.35 & 107.51 & 107.52 & 107.62 & 108.06 & 108.85 & 109.48 & 110.61 & 110.23 & 109.62 \\
\hline Oct-01 & 109.71 & 108.75 & 108.86 & 108.71 & 108.72 & 109.05 & 109.78 & 110.34 & 111.48 & 111.00 & 110.26 \\
\hline Nov-01 & 110.59 & 109.86 & 109.96 & 109.69 & 109.66 & 109.94 & 110.64 & 111.16 & 112.29 & 111.70 & 110.86 \\
\hline Dec-01 & 111.51 & 111.14 & 111.28 & 110.95 & 110.87 & 111.02 & 111.66 & 111.99 & 112.94 & 112.06 & 111.05 \\
\hline Jan-02 & 113.61 & 112.75 & 112.88 & 112.61 & 112.52 & 112.85 & 113.69 & 114.29 & 115.60 & 114.82 & 113.88 \\
\hline Feb-02 & 114.13 & 113.64 & 113.63 & 113.25 & 113.15 & 113.42 & 114.17 & 114.68 & 115.88 & 115.13 & 114.22 \\
\hline Mar-02 & 115.67 & 115.56 & 115.47 & 114.98 & 114.91 & 115.04 & 115.72 & 116.07 & 117.16 & 116.30 & 115.38 \\
\hline Apr-02 & 117.00 & 117.23 & 117.00 & 116.35 & 116.23 & 116.34 & 116.92 & 117.29 & 118.39 & 117.58 & 116.61 \\
\hline May-02 & 117.76 & 118.01 & 117.66 & 116.94 & 116.83 & 116.98 & 117.55 & 118.06 & 119.30 & 118.60 & 117.59 \\
\hline Jun-02 & 118.89 & 119.98 & 119.28 & 118.39 & 118.17 & 118.15 & 118.67 & 118.98 & 120.02 & 119.16 & 118.02 \\
\hline Jul-02 & 119.98 & 120.92 & 120.42 & 119.53 & 119.28 & 119.28 & 119.91 & 120.12 & 121.16 & 120.11 & 118.96 \\
\hline
\end{tabular}


Table C-1 - Decile-Specific Democratic Price Indices, 1997-2006 (Continued...)

\begin{tabular}{|c|c|c|c|c|c|c|c|c|c|c|c|}
\hline & AII & Dec 1 & Dec 2 & Dec 3 & Dec 4 & Dec 5 & Dec 6 & Dec 7 & Dec 8 & $\operatorname{Dec} 9$ & Dec 10 \\
\hline Jul-02 & 119.98 & 120.92 & 120.42 & 119.53 & 119.28 & 119.28 & 119.91 & 120.12 & 121.16 & 120.11 & 118.96 \\
\hline Aug-02 & 120.92 & 122.05 & 121.61 & 120.67 & 120.39 & 120.33 & 120.92 & 121.03 & 121.97 & 120.76 & 119.45 \\
\hline Sep-02 & 122.52 & 124.14 & 123.63 & 122.56 & 122.19 & 122.04 & 122.50 & 122.49 & 123.27 & 121.91 & 120.46 \\
\hline Oct-02 & 123.98 & 125.73 & 125.32 & 124.21 & 123.82 & 123.60 & 123.99 & 123.91 & 124.60 & 123.12 & 121.50 \\
\hline Nov-02 & 124.20 & 125.40 & 125.17 & 124.18 & 123.85 & 123.79 & 124.28 & 124.35 & 125.18 & 123.71 & 122.06 \\
\hline Dec-02 & 124.58 & 126.04 & 125.71 & 124.73 & 124.34 & 124.22 & 124.68 & 124.68 & 125.44 & 123.83 & 122.17 \\
\hline Jan-03 & 125.89 & 126.95 & 126.67 & 125.72 & 125.35 & 125.31 & 126.07 & 126.21 & 127.23 & 125.58 & 123.80 \\
\hline Feb-03 & 125.80 & 126.77 & 126.41 & 125.46 & 125.10 & 125.09 & 125.93 & 126.15 & 127.30 & 125.72 & 124.04 \\
\hline Mar-03 & 127.11 & 127.67 & 127.28 & 126.38 & 126.10 & 126.30 & 127.13 & 127.63 & 129.04 & 127.57 & 125.88 \\
\hline Apr-03 & 127.74 & 128.21 & 127.79 & 126.89 & 126.66 & 126.87 & 127.73 & 128.28 & 129.77 & 128.35 & 126.70 \\
\hline May-03 & 127.56 & 128.14 & 127.83 & 126.96 & 126.70 & 126.80 & 127.71 & 128.11 & 129.42 & 127.78 & 126.09 \\
\hline Jun-03 & 127.18 & 127.84 & 127.51 & 126.70 & 126.41 & 126.43 & 127.41 & 127.75 & 128.98 & 127.20 & 125.49 \\
\hline Jul-03 & 128.45 & 128.03 & 128.19 & 127.51 & 127.32 & 127.66 & 128.87 & 129.40 & 130.92 & 129.16 & 127.28 \\
\hline Aug-03 & 129.34 & 129.31 & 129.27 & 128.46 & 128.20 & 128.49 & 129.64 & 130.19 & 131.76 & 129.98 & 127.96 \\
\hline Sep-03 & 129.49 & 128.95 & 129.02 & 128.35 & 128.15 & 128.58 & 129.81 & 130.54 & 132.27 & 130.54 & 128.45 \\
\hline Oct-03 & 129.70 & 129.44 & 129.51 & 128.80 & 128.55 & 128.86 & 130.07 & 130.66 & 132.25 & 130.42 & 128.29 \\
\hline Nov-03 & 129.83 & 129.17 & 129.49 & 128.88 & 128.69 & 129.04 & 130.29 & 130.88 & 132.49 & 130.68 & 128.51 \\
\hline Dec-03 & 129.44 & 128.37 & 128.74 & 128.22 & 128.11 & 128.58 & 129.89 & 130.60 & 132.34 & 130.69 & 128.63 \\
\hline Jan-04 & 131.15 & 130.06 & 130.39 & 129.76 & 129.62 & 130.13 & 131.60 & 132.34 & 134.24 & 132.66 & 130.49 \\
\hline Feb-04 & 131.73 & 130.77 & 130.90 & 130.17 & 130.07 & 130.60 & 132.00 & 132.84 & 134.90 & 133.50 & 131.30 \\
\hline Mar-04 & 132.68 & 131.60 & 131.69 & 131.00 & 130.98 & 131.63 & 132.92 & 133.83 & 135.95 & 134.56 & 132.35 \\
\hline Apr-04 & 132.93 & 131.97 & 131.87 & 131.10 & 131.07 & 131.79 & 133.04 & 134.07 & 136.31 & 135.00 & 132.77 \\
\hline May-04 & 132.91 & 131.51 & 131.66 & 131.04 & 131.04 & 131.82 & 133.10 & 134.18 & 136.44 & 135.11 & 132.88 \\
\hline Jun-04 & 132.98 & 131.05 & 131.23 & 130.69 & 130.78 & 131.74 & 133.11 & 134.45 & 136.96 & 135.82 & 133.61 \\
\hline Jul-04 & 133.32 & 130.80 & 131.28 & 130.87 & 130.96 & 132.09 & 133.64 & 134.98 & 137.64 & 136.39 & 134.19 \\
\hline Aug-04 & 133.13 & 130.47 & 131.07 & 130.71 & 130.80 & 131.93 & 133.56 & 134.85 & 137.48 & 136.09 & 133.89 \\
\hline Sep-04 & 133.53 & 130.83 & 131.31 & 130.94 & 131.05 & 132.23 & 133.86 & 135.29 & 138.07 & 136.78 & 134.55 \\
\hline Oct-04 & 134.09 & 131.35 & 131.82 & 131.39 & 131.54 & 132.80 & 134.44 & 135.92 & 138.74 & 137.44 & 135.04 \\
\hline Nov-04 & 135.08 & 132.78 & 133.07 & 132.45 & 132.56 & 133.75 & 135.31 & 136.79 & 139.62 & 138.30 & 135.77 \\
\hline Dec-04 & 134.94 & 132.62 & 132.98 & 132.44 & 132.54 & 133.68 & 135.27 & 136.67 & 139.43 & 137.97 & 135.41 \\
\hline Jan-05 & 135.62 & 133.37 & 133.80 & 133.26 & 133.29 & 134.34 & 136.12 & 137.39 & 140.08 & 138.45 & 135.77 \\
\hline Feb-05 & 135.51 & 132.97 & 133.51 & 132.99 & 133.04 & 134.17 & 136.05 & 137.39 & 140.16 & 138.54 & 135.86 \\
\hline Mar-05 & 136.88 & 133.93 & 134.40 & 133.87 & 134.04 & 135.47 & 137.28 & 138.92 & 141.99 & 140.58 & 137.84 \\
\hline Apr-05 & 137.29 & 133.75 & 134.34 & 133.90 & 134.14 & 135.76 & 137.58 & 139.49 & 142.83 & 141.66 & 138.89 \\
\hline May-05 & 137.90 & 134.73 & 135.04 & 134.42 & 134.65 & 136.26 & 138.00 & 139.97 & 143.43 & 142.37 & 139.58 \\
\hline Jun-05 & 137.49 & 133.88 & 134.46 & 133.97 & 134.22 & 135.89 & 137.72 & 139.71 & 143.16 & 142.06 & 139.26 \\
\hline Jul-05 & 138.78 & 134.78 & 135.48 & 134.98 & 135.28 & 137.13 & 139.03 & 141.13 & 144.78 & 143.77 & 140.86 \\
\hline Aug-05 & 139.34 & 135.43 & 136.02 & 135.41 & 135.72 & 137.58 & 139.44 & 141.64 & 145.42 & 144.55 & 141.63 \\
\hline Sep-05 & 139.94 & 136.03 & 136.61 & 136.02 & 136.28 & 138.18 & 139.95 & 142.21 & 146.07 & 145.25 & 142.21 \\
\hline Oct-05 & 140.11 & 136.25 & 136.77 & 136.13 & 136.39 & 138.30 & 140.05 & 142.35 & 146.26 & 145.49 & 142.47 \\
\hline Nov-05 & 140.29 & 136.99 & 137.41 & 136.68 & 136.89 & 138.61 & 140.32 & 142.38 & 146.06 & 145.05 & 141.96 \\
\hline Dec-05 & 140.77 & 138.24 & 138.60 & 137.75 & 137.85 & 139.34 & 140.90 & 142.63 & 145.93 & 144.62 & 141.40 \\
\hline Jan-06 & 141.68 & 138.86 & 139.25 & 138.39 & 138.50 & 140.05 & 141.82 & 143.64 & 147.15 & 145.93 & 142.67 \\
\hline Feb-06 & 141.94 & 139.23 & 139.62 & 138.64 & 138.78 & 140.32 & 142.05 & 143.86 & 147.39 & 146.16 & 142.86 \\
\hline Mar-06 & 142.95 & 140.31 & 140.72 & 139.75 & 139.93 & 141.50 & 143.13 & 144.84 & 148.27 & 146.94 & 143.59 \\
\hline Apr-06 & 143.52 & 140.85 & 141.21 & 140.22 & 140.41 & 142.05 & 143.67 & 145.47 & 148.97 & 147.69 & 144.18 \\
\hline May-06 & 144.53 & 142.37 & 142.40 & 141.16 & 141.31 & 142.93 & 144.41 & 146.29 & 149.90 & 148.79 & 145.23 \\
\hline Jun-06 & 145.20 & 143.06 & 142.95 & 141.65 & 141.81 & 143.50 & 144.92 & 146.97 & 150.72 & 149.75 & 146.14 \\
\hline Jul-06 & 146.86 & 144.36 & 144.46 & 143.04 & 143.22 & 145.06 & 146.62 & 148.79 & 152.76 & 151.78 & 147.98 \\
\hline Aug-06 & 147.59 & 144.97 & 145.05 & 143.61 & 143.81 & 145.76 & 147.28 & 149.57 & 153.66 & 152.77 & 148.89 \\
\hline Sep-06 & 148.96 & 146.91 & 146.78 & 145.24 & 145.32 & 147.09 & 148.65 & 150.82 & 154.93 & 153.74 & 149.64 \\
\hline Oct-06 & 149.35 & 147.94 & 147.78 & 146.17 & 146.13 & 147.67 & 149.19 & 151.02 & 154.78 & 153.25 & 149.07 \\
\hline Nov-06 & 149.24 & 148.07 & 147.88 & 146.21 & 146.18 & 147.59 & 149.11 & 150.82 & 154.50 & 152.89 & 148.72 \\
\hline Dec-06 & 149.55 & 148.64 & 148.37 & 146.70 & 146.67 & 148.03 & 149.47 & 151.09 & 154.62 & 152.89 & 148.64 \\
\hline
\end{tabular}

Source: $\quad$ Own calculations, IES 2000 (Statistics South Africa) 